\title{
Untersuchungen über die Biochemie der Meeresalgen.
}

Von

\section{Harald Kylin.}

(Ans dem medizinisch-chemischen Institut der Universität Upsala.)

(Der Redaktion zugegangen am 8. Juni 1915.)

\section{Inhaltsverzeichnis.}

I. Anorganische Bestandteile.

II. Organische Säuren.

III. Mannit.

IV. Die Zuckerarten der Florideen.

V. Die Zuckerarten der Fucoideen.

VI. Laminarin.

VII. Die Zellwandbestandteile der Fucoideen.

VIII. Die Zellwandbestandteile der Florideen.

IX. Einige quantitative Bestimmungen.

Mit vollem Recht schreibt Kniep in einer jüngst erschienenen Arbeit, daß unsere Kenntnisse gerade von den fundamentalen Ernährungsprozessen der autotrophen Meerespflanzen noch äußerst mangelhaft sind, daß wir über die Assimilationsprodukte und Reservestoffe der meisten Meeresalgen noch sehr ungenügend unterrichtet sind und bei vielen noch nicht sicher wissen, ob Kohlenhydrate oder anders gebaute Körper vorliegen.

Seit mehreren Jahren habe ich eben den oben erwähnten Problemen eine Untersuchung gewidmet und in einem früheren Aufsatz «Zur Biochemie der Meeresalgen» auch einige Ergebnisse mitteilen können. Dieser Aufsatz ist aber nur als eine vorläufige Mitteilung zu betrachten, und wurde infolge einer Unterbrechung meiner damaligen Untersuchungen veröffentlicht. Später habe ich wieder Gelegenheit erhalten, die Forscbungen auf diesem Gebiete weiter zu treiben, und beabsichtigte anbei die gewonnenen Resultate zusammenzustellen. 
Unter den Meeresalgen habe ich in erster Linie meine Aufmerksamkeit den Fucoideen und den Florideen zugewendet und nur nebenbei die Chlorophyceen berücksichtigt. Die Planktonalgen, die einer besonderen Untersuchung wert wären, habe ich in meine gegenwärtigen Forschungen nicht einschließen können.

Bei den Untersuchungen habe ich immer Wert darauf gelegt, die Probleme, soweit es möglich war, sowohl von makrochemischer wie mikrochemischer Seite angreifen zu können.

Zum Zwecke mikrochemischer Untersuchungen der Meeresalgen brachte ich im Sommer 1914 etwa drei Monate an der zoologischen Station Kristineberg zu, wo mir von der schwedischen Akademie der Wissenschaften ein Arbeitsplatz zur Verfügung gestellt worden war, und gestatte ich mir, dieser Akademie, die meine Untersuchungen auch mehrmals finanziell unterstützt hat, meinen ergebensten Dank auszusprechen.

Die makrochemischen Untersuchungen sind im medizinischchemischen Institut der Universität Upsala ausgeführt worden, wo ich seit Jahren einen Arbeitsplatz gehabt habe, und schulde ich dafür dem Präfekten dieses Institutes, Herrn Professor Dr. S. G. Hedin, große Dankbarkeit. Auch Herrn Professor Dr. C. Th. Mörner bringe ich meinen herzlichsten Dank für all die Hilfe, die er mir hat zuteil werden lassen, sowie für das Interesse, mit dem er meine Untersuchungen stets verfolgt hat.

Das Material der makrochemischen Untersuchungen stammt von der schwedischen Westküste in der Nähe der zoologischen Station Kristineberg her. Teils habe ich es selbst eingesammelt, teils ist es mir von dem Assistenten dieser Station, Herrn Dr. Hj. Östergren, gesandt worden, und spreche ich ihm dafür meinen ergebensten Dank aus.

\section{Anorganische Bestandteile.}

1. Stickst off.

Das Meerwasser enthält, wie bekannt, nur außerordentlich geringe Mengen Salpeter und doch vermögen mehrere Algen ihn bis zu merklicher Konzentration aufzuspeichern. So enthält z. B. Codium tomentosum nach den Angaben von 
Nathansohn (1902, S. 280) gewöhnlich etwa $0,1 \% \mathrm{NaNO}_{3}$; der Salpetergehalt erreichte in einem Falle sogar den Wert von $0,3 \%$.

Die Fähigkeit der Nitratanhäufung ist von Nathansohn (a. a. 0.) mittelst der Diphenylaminreaktion bei einer Anzahl Meeresalgen konstatiert worden; er erwähnt folgende Arten: Chaetomorpha aerea, Taonia atomaria, Bryopsis penicillum, Ulva lactuca, Enteromorpha, Griffithsia opuntioides, Antithamnion cruciatum, Halyseris polypodioides, Cutleria multifida, Scytosiphon lomentarius und Ceramium sp. Er bemerkt aber, daß diese Algen keineswegs immer die Salpeterreaktion aufweisen. Das Vorhandensein von Salpeter war aber nicht ausschließlich durch die $\mathrm{Zu}$ sammensetzung des Wassers bestimmt, da mitunter neben salpeterbaltigen Algen an demselben Fundorte salpeterfreie Exemplare anderer Arten vorkamen, die sonst die Fähigkeit der Speicherung besaßen. Bei Cutleria multifida wiesen die Thallusspitzen, die in lebhaftem Wachstum begriffen waren, intensive Salpeterreaktion auf, die erwachsenen Partien zeigten sie dagegen nicht oder nur in ganz schwachem Maße. Dictyota dichotoma erwies sich als stets salpeterfrei.

Nittels der Diphenylaminprobe habe ich eine Anzahl Meeresalgen auf das Vorkommen von Salpeter geprüft. Die zu prüfenden Thallusteile oder Schnitte wurden immer mit destilliertem Wasser sorgfältig abgespült und dann in ein Tröpfchen des Reagens eingelegt. Die dabei eintretende Blaufärbung wurde in bezug auf ihre Stärke geschätzt und mit der Blaufärbung verglichen, die beim Zusammenfließen des Reagens mit einem Tropfen Meerwasser entsteht.

Unter den Chlorophyceen wurden Ulva lactuca und Enteromorpha intestinalis geprüft. Beide Arten erwiesen sich als salpeterhaltig, die Reaktion war aber nicht besonders kräftig.

Unter den Fucoiden wurde eine Reihe sowohl einjähriger wie mehrjähriger Arten untersucht. Ectocarpus siliculosus gab eine schwache, aber deutliche Reaktion. Asperococcus bullosus, Desmarestia viridus und Spermatochrus pa-

Hoppe-Seyler's Zeitschrift f. physiol. Chemie. XCIV. 
radoxus gaben dagegen keine Reaktion. Es wurden jüngere und ältere Thallusteile von verschiedenen Fundorten geprüft, aber immer mit negativem Erfolg. Bei den mehrjährigen Arten Ascophyllum nodosum und Fucus vesiculosus kann in den jüngeren Thallusteilen eine geringe Menge Salpeter vorhanden sein; die Reaktion ist immer sehr schwach, und nicht selten bleibt sie aus. Ältere Teile sind immer mit negativem Erfolg geprüft worden. Der Stamm von Laminaria saccharina gibt eine schwache aber deutliche Reaktion, das Blatt gibt im allgemeinen auch eine Nitratreaktion aber schwächer als der Stamm (die Prüfungen sind im August ausgeführt worden).

Die Florideen zeigen in bezug auf ihren Nitratgehalt sehr große Verschiedenheiten voneinander. Bei Delesseria sanguinea konnte kein Salpeter nachgewiesen werden, weder im Blatt, noch im Stamm, noch in älteren oder jüngeren Nerven. Mit negativem Erfolg wurden auch Iridaea edulis, Antithamnion plumula und Odonthalia dentata geprüft. Spermothamnion roseolum und Polysiphonia nigrescens gaben eine schwache aber deutliche Reaktion. Bei Chondrus crispus enthalten die älteren, abgerundeten Thallusteile mehr Nitrat als die jüngeren, die nur eine schwache Reaktion gaben. Ceramium rubrum und Lomentaria clavellosa wiesen eine sehr kräftige Nitratreaktion auf, die jüngeren Teile kräftiger als die älteren. Von diesen beiden Algen braucht man nur ein etwa millimeterlanges Thallusstück in das Reagenströpfchen einzulegen, um eine kräftige Blaufärbung zu bekommen. Kräftige Nitratspeicherung zeigen auch Polyides rotundus und Furcellaria fastigiata, bei der ersteren besonders in den oberen Gabelzweigen, bei der letzteren im ganzen Thallus. Callithamnion corymbosum enthält auch reichliche Mengen Nitrat.

Es gibt also unter den Florideen einige Arten, die eire große Fähigkeit besitzen, "Nitrat zu' speichern. 'Diese sind Ceramium rubrum, Lomentaria clavellosa, Polyides rotundus, Furcellaria fastigiata und Callithamnion corymbosum. Einige andere Arten besitzen diese Fähigkeit 
nur in geringem Maße, während andere sich als salpeterfrei erweisen. Die Fucoideen scheinen im allgemeinen salpeterfrei zu sein, oder, wenn Nitrate vorhanden sind, ist dies nur in sehr geringen Mengen der Fall. Dies deutet darauf hin, daß große stoffwechsel-physiologische Verschiedenheiten. zwischen den verschiedenen Algen vorkommen, die einer eingehenderen Untersuchung wert wären. Das Fehlen von Salpeter könnte auf eine erschwerte Aufnahme dieses Stoffes hindeuten, könnte aber auch davon bedingt sein, daß der Salpeter bei den salpeterfreien Algen rascher zu organischen Verbindungen verarbeitet wird als bei denen, die reichliche Mengen Nitrate enthalten.

Um das Vorkommen von Ammoniurnsalzen bei den Meeresalgen nachzuweisen, wurden Versuche in folgender Weise angestellt. In destilliertem Wasser gespülte Thallusteile wurden in ein Uhrgläschen gelegt und mit verdünnter Natronlauge ( $0 \%$ iger) übergossen. Das Uhrgläschen wurde dann mit einem anderen bedeckt, auf welchem ein angefeuchtetes rotes Lackmuspapier angeklebt war. Nach 5-10 Minuten wurden die Ränder des Papieres blaugefärbt und nach 30-40̄ Minuten war das Papier ganz blau. Beim Trocknen wurde es wieder rot. Bei allen geprüften Algen ließen sich auf diese Weise Ammoniumsalze nachweisen. Geprüft wurden folgende Arten: Ulva lactuca, Enteromorpha intestinalis, Ascophyllum nodosum, Fucus serratus, Laminaria saccharina, Spermatochnus paradoxus, Ectocarpus siliculosus, Bangia fuscopurpurea, Polysiphonia nigrescens, Chondrus crispus und Furcellaria fastigiata.

Da geringe Mengen von Ammoniumsalzen im Meerwasser vorbanden sind (vgl. Angaben von Wille, 1899, S. 335), ist die Möglichkeit gegeben, daß es sich hier um eine Aufnahme von Ammoniak von außen handelt. Es ist aber nicht ausgeschlossen, daß der Ammoniak von den Algen durch Reduktion von Nitraten gebildet wird.

\section{Phosphor.}

Meines Wissens liegt keine Untersuchung vor, die sich mit der Frage beschäftigt, ob die Meeresalgen in ihren Geweben Phosphate anzuhäufen vermögen. Das Meerwasser enthält nur 
sehr geringe Phosphatmengen, und es fragt sich nun, ob es Meeresalgen gibt, die Phosphate in solchen Mengen aufspeichern, daß diese sich mikrochemisch nachweisen lassen.

Die einschlägigen Versuche wurden in folgender Weise angestellt. Die zu prüfenden Thallusteile oder Schnitte wurden in destilliertem Wasser abgespült, in ein Tröpfchen einer Lösung von molybdänsaurem Ammon gelegt und dann einige Minuten, einige Stunden oder bis zum nächsten Tag bei Zimmertemperatur liegen gelassen. Sind Phosphate in nicht zu geringen Mengen vorhanden, bekommt man schon nach einigen Minuten einen gelben Niederschlag; sind nur geringe Menge vorhanden, erhält man erst nach einigen Stunden oder nach einem Tage einen Niederschlag. In mehreren Fällen wurde nach einem Tage noch kein Niederschlag erhalten.

Bei Ascophyllum nodosum, Fucus serratus und F. vesiculosus sind Phosphate in den jüngsten Thallusteilen leicht nachweisbar; man bekommt schon nach einigen Minuten einen reichlichen, gelben Niederschlag. Die Phosphate sind besonders in der Zone des Zuwachses, von der Spitze 5-10 mm nach unten, angehäuft; von dort an wird die Phosphatmenge immer geringer und in einer Entfernung von $15-20 \mathrm{~mm}$ von der Spitze ist sie schon so gering, daß man erst nach einigen Stunden oder nach einem Tage eine positive Reaktion bekommt. In noch älteren Thallusteilen lassen sich überhaupt keine Phosphate nachweisen; erst in den ältesten, stammähnlichen Teilen sind sie wieder vorhanden und in nicht unbedeutenden Mengen, hier aber in den Rindenpartien lokalisiert, indem sie in den zentralen Teilen des Querschnittes nur in sehr geringen Mengen vorkommen.

Im Stamme von den Laminaria-Arten, L. digitata und L. saccharina sind die Phosphate in der Rinde und im Mark angehäuft, in den zwischenliegenden Gewebepartien sind sie nur in geringen Mengen yorhanden. In den jüngeren Teilen der Rhizoide und im untersten Teile des Blattes (der Zuwachszone) sind sie wieder reichlich aufgespeichert. Die älteren Teile des Blattes enthalten nur geringe Phosphatmengen, hauptsächlich im Mark lokalisiert. 
Mit negativem Erfolg sind folgende Fucoideen geprüft worden: Asperococcus bullosus, Ectocarpus siliculosus, Spermatochnus paradoxus und Sphacelaria cirrhosa. Phosphate fehlen bei diesen wahrscheinlich nicht, sind aber in so geringen Mengen vorhanden, daß sie nicht mikrochemisch nachweisbar sind.

Eine Reihe Chlorophyceen und Florideen sind auch geprüft worden, alle aber mit negativem Erfolg. Folgende Arten wurden geprüf: Bryopsis plumosa, Enteromorpha intestinal is, Ulva lactuca, Ceramium rubrum, Chondrus crispus, Furcellaria fastigiata, Polysiphonia nigrescens und Porphyra laciniata.

Unter den Arten, bei denen sich Phosphate nicht mikrochemisch nachweisen ließen, wurden einige in folgender Weise makrochemisch geprüft. Die Algen wurden in destilliertem Wasser gespült, dann mit destilliertem Wasser unter Zusatz von etwas Toluol übergossen und bis zum nächsten Tag liegen gelassen. Nach dem Abfiltrieren wurde das Extrakt mit Ammoniak schwach alkalisiert und bis zum folgenden Tag stehen gelassen. Der Niederschlag wurde dann abfiltriert und mit molybdänsaurem Ammon auf Phosphate geprüft. Bei allen auf diese Weise geprüften Algen ließ sich das Vorhandensein von Phosphaten leicht nachweisen. Folgende Arten wurden geprüft: Spermatochnus paradoxus, Enteromorpha intestinalis, Ulva lactuca, Ceramium rubrum, Chondrus crispus und Porphyra laciniata.

Bei allen untersuchten Meeresalgen sind demnach Phosphate vorhanden. Im allgemeinen sind aber die Phosphatmengen sehr gering und mikrochemisch nicht nachweisbar. Nur bei den gröberen Algen Ascophyllum, Fucus und Laminaria kommt eine wirkliche Anhäufung von Phosphaten vor, und diese ist teils in den jüngsten im Wachsen begriffenen, teils in den ältesten stammähnlichen Teilen lokalisiert.

\section{Jod.}

Es ist bekannt, daß die Meeresalgen, besonders die Fucoideen, die Spuren von Jodverbindungen, welche in Meer- 
wasser enthalten sind, assimilieren und konzentrieren können. So können z. B. die Laminaria-Arten L. digitata und L. saccharina nach den Angaben von Wille (1899, S. 336) das Jod bis zu etwa $0,6 \%$ des Trockengewichtes aufspeichern. Unbekannt ist aber noch, in welcher Weise das Jod in den Algen gebunden ist, ob es als Alkalisalz oder in organischer Bindung vorkommt. Van Itallie (1889) behauptet, er habe bei Fucus Alkalijodide gefunden. Nach Hundeshagen (1895, S. 474) soll bei den Tangen das Jod an einen albuminoiden Körper (also in organischer Bindung) gebunden sein, der vielleicht mit dem bei den Tieren vorkommenden Jodospongin identisch oder nahe verwandt sei. Dies ist aber nur eine Behauptung; den Nachweis bleibt er schuldig. Fucus vesiculosus und Laminaria digitata sind in bezug auf die Bindungsweise des Jods von Eschle (1897) untersucht worden; er kam zu der Schlußfolgerung, daß das Jod fast ausschlieBlich in organischer Verbindung vorhanden ist.

Systematische Untersuchungen über die Bindungsweise des Jods bei den Meeresalgen habe ich nicht angestellt, nur einige nebenbei gemachte Beobachtungen mögen erwähnt werden, da diese mir sicher zu beweisen scheinen, daß3 das Jod in den Algen als Jodid vorkommen kann; ob daneben auch Jod in organischer Verbindung vorhanden ist, bleibt noch $\mathrm{zu}$ untersuchen.

Zum Zwecke einer Untersuchung der bei den Fucoideen vorkommenden Zuckerarten-wurde an der Luft getrocknetes, zerkleinertes Material mehrere Tage mittelst 50\% igem Alkohol extrahiert. Das Extrakt wurde nach dem Abfiltrieren auf dem Wasserbade eingeengt und mit $96 \%$ igem Alkohol gefällt; dies Verfahren wurde nach dem Abfiltrieren des Niederschlages noch zweimal wiederholt, wobei jedesmal zehn Volumen Alkohol zugesetzt wurden. Da die Alkalijodide in Alkohol ziemlich löslich sind, bleiben sie immerfort in Lösung. Nach der letzten Fällung wurde der Alkohol auf dem Wasserbade unter Zusatz von Wasser vertrieben. In der auf diese Weise erhaltenen Wasserlösung ließen sich Jodide leicht nachweisen, und diese Jodide müssen auch von vornherein in der Alge 
vorhanden gewesen sein, da es sich nicht leicht denken läßt, daß das Jod während der oben beschriebenen. Extraktionsund Reinigungsvorgänge von irgend einer organischen Verbindung in ein Jodsalz umgewandelt worden wäre. Das Vorkommen von Jod in anorganischer Verbindung (Jodide) ist auf diese Weise für Ascophyllum nodosum, Fucus serratus, F. vesiculosus, Laminaria Cloustoni, L. digitata und $L$. saccharina nachgewiesen worden.

In diesem Zusammenhang möchte ich auch auf ein eigentümliches Vorkommen von Jod bei zwei Florideen hinweisen.

Robertson (1894, S. 172) beobachtete, daß sich das Papier, worauf Bonnemaisonia asparagoides gelegt worden war, längs den Zweigen der Alge blau färbte. Diese Erscheinung erklärte er auf folgende Weise. Die Alge enthält Jod. Beim Absterben der Alge tritt dieses heraus und färbt dann die im Papier enthaltene Stärke blau. Dieselbe Beobachtung ist auch von Golenkin (1894, S. 257) gemacht worden. Von ihm wurde aber außerdem nachgewiesen, daß die Blaufärbung nicht von dem gesamten Thallus ausging, sondern von besonderen, stark lichtbrechenden Zellen, die besonders die jüngeren Teile und die Zystokarpien bedeckten. Diese Zellen führen nach Golenkin je eine Vakuole, die Jod oder eine stärkefärbende Jodverbindung enthält.

Die Angaben von Robertson und Golenkin habe ich in einem jüngst erschienenen Aufsatz insofern bestätigen können, als bei Bonnemaisonia asparagoides eine große Menge besonderer, stark lichtbrechender Zellen vorkommt, die ich Blasenzellen genannt habe, und die die Ausgangspunkte der Blaufärbung darstellen. Die Beobachtungen werden am besten in solcher Weise ausgeführt, daß ein kleines Stückchen von der Alge in einen Tropfen von einer Lösung löslicher Stärke gelegt und mit einem Deckgläschen bedeckt wird. Im Mikroskope kann man dann sehr gut verfolgen, wie die Blasenzellen zerplatzen, wie der Inhalt aus den Zellen heraustritt und wie sich die Stärkelösung dann blau färbt. Wahrscheinlich enthalten die Blasenzellen eine labile, leicht Jod abspaltende Verbindung (vgl. Molisch, 1913, S. 82). 
Bei Spermothamnion roseolum kommen auch besondere, stark lichtbrechende Zellen vor, die irgend eine Jodverbindung enthalten. Das Jod wird aber erst dann abgespalten, wenn die Reaktion sauer ist. Werden einige Fäden dieser Alge auf einem Objektträger in einen Tropfen Stärkelösung gelegt, die mit Essigsäure oder Salzsäure angesäuert worden ist, mit einem Deckgläschen bedeckt und dann im Nikroskope beobachtet, so findet man, daß die Blasenzellen von einer blauen Kappe umgeben sind. Nur die jüngeren Blasenzellen besitzen die Fähigkeit, Jod abzuspalten; von der Spitze des Fadens ab kann man 8-10, seltener 12-14 funktionsfähige Blasenzellen beobachten (vgl. näher Kylin, 1915).

Über die biologische Bedeutung dieser jodabspaltenden Blasenzellen ist nichts sicheres bekannt. In meinem oben angeführten Aufsatz habe ich indessen die Vermutung ausgesprochen, daß sie irgend eine Schutzeinrichtung gegen Tiere, besonders gegen kleine pflanzenfressende Mollusken darstellen.

\section{Calcium.}

Durch genaue Untersuchungen über die Anatomie der Laminariaceen ist Wille (1897, S. 47) zu der Ansicht gelangt, da $B$ die Interzellularsubstanz dieser Algen zum wesentlichen Teil aus Calciumpektinat besteht. Er weist darauf hin, daß der Kalk ein nicht unbedeutender Bestandteil der Asche verschiedener Tangarten ist, daß aber die Zellen nur geringe Mengen Kalksalze enthalten, und es schien ihm demnach, als ob der Kalk vorzugsweise an die Interzellularsubstanz gebunden wäre.

Über einen direkten Nachweis des Calciums in der Interzellularsubstanz der Meeresalgen liegen noch keine Literaturangaben vor. Ein solcher Nachweis ist aber sehr einfach. Man hat nur nötig, einige Thallusteile oder Schnitte in einen Tropfen einer Lösung von oxalsaurem Ammon zu legen. Bei mikroskopischer Beobachtung sieht man dann, wie die Zellwände mit einer reichlichen Menge kleiner Calciumoxalatkrystalle besetzt sind; in den Zellen findet man dagegen nur wenige oder sogar 
keine Krystalle. Es ist vorteilhaft, aber nicht notwendig, die Lösung des oxalsauren Ammons mit Essigsäure anzusäuern.

Will man sich überzeugen, daß der Kalk in den Zellwänden in einer wasserunlöslichen Verbindung vorliegt, so werden die Schnitte oder Thallusteile zum Abtöten in siedendes Wasser gelegt und dann bis zum nächsten Tag in destilliertem Wasser liegen gelassen. Die löslichen Calciumverbindungen werden dabei herausgelaugt, die unlöslichen Calciumpektinate der Zellwände bleiben aber zurück, und durch oxalsaures Ammon ist es leicht, das Vorhandensein von Calcium nachzuweisen.

Bei den gröberen Fucoideen Ascophyllum, Fucus, Halidrys und Laminaria kann man nicht selten sogar beobachten, daß die Calciumoxalatkrystalle sich nicht gleichmäßig in den Zellwänden verteilen, sondern am reichlichsten in den mittleren Partien vorhanden sind. Dies steht damit im Zusammenhang, daß die Zellwände aus zwei verschiedenen Schichten zusammengesetzt sind, einer mittleren, der Interzellularsubstanz, die aus Calciumpektinaten besteht, und dann einer inneren, welche die Zelle begrenzt, und die hauptsächlich aus Zellulose besteht. Unter den zarteren Fucoideen babe ich nur Dictyosiphon foeniculaceus und Ectocarpus siliculosus untersucht; bei beiden ließ sich Calcium in den Zellwänden leicht nachweisen.

Unter den Florideen wurden Chondrus crispus, Ceramium rubrum, Furcellaria fastigiata und Polysiphonia urceolata, und unter den Chlorophyceen Cladophora rupestris und Ulva lactuca untersucht. Bei allen konnte ich Calcium in den Zellwänden nachweisen.

$\mathrm{Da}$ das Calcium für den Aufbau der Zellwände notwendig wäre, ist von Böhm (1875) behauptet worden, und in jüngster Zeit hat sich Hansteen (1910) dieser Auffassung angeschlossen. Hansteen zeigte, da $B$ in kalkfreien Lösungen an solchen Stellen, wo das ausgiebigste Flächenwachstum der Zellwände stattfand, die Wände aufgelöst und daher zerstört werden. Durch Untersuchungen von Moliscb (1895) hat sich die überraschende Tatsache ergeben, daß einige Algen (Microtbamnion Kützingianum Naeg., Stichococcus 
bacillaris Naeg., Ulothrix subtilis (?) Kg. und Protococcus sp.) des Kalkes völlig entbehren können, während andere, wie Spirogyra und Vaucheria in einer sonst kompletten, aber kalkfreien Nährlösung alsbald zugrunde gehen. Molisch hat auch nachgewiesen, daß niedere Pilze bei vollständigem Ausschlusse von Kalk sich gleichfalls normal entwickeln können.

Dem Resultate Molischs zufolge muß man selbstverständlich den Schluß ziehen, daß der Kalk zum Aufbau der Zellwände nicht immer notwendig ist, wie es eben Molisch getan hat. Dies sind aber nur Ausnahmefälle und im großen und ganzen ist sicher die Auffassung Böhm's vollkommen richtig. Bei den Meeresalgen spielt das Calcium, an Pektinsäuren gebunden, eine hervorragende Rolle; diese Frage werde ich aber an einer anderen Stelle (S. 414) des näheren erörtern.

\section{Organische Säuren.}

Der Zellinhalt der Assimilationsorgane der höheren, in der Luft lebenden Pflanzen hat im allgemeinen eine saure Reaktion. Die Algen leben aber unter ganz anderen Außenbedingungen als die höheren Pflanzen, und es ist von vornherein wahrscheinlich, daß dieses die Reaktion des Zellinhalts beeinflußst. Was die Meeresalgen betrifft, so ist es bekannt, daß das Meerwasser eine schwach alkalisch reagierende Salzlösung darstellt, und zu erwarten wäre daher, daß der Zellinhalt, wenn er nicht gerade eine alkalische Reaktion zeigte, doch stärker saure Reaktionen vermiede. Einige Beobachtungen über dieses Thema will ich hier kurz mitteilen.

Wasserextrakte von den gröberen Fucoideen, Ascophyllum, Fucus und Laminaria, habe ich mehrmals in bezug auf ihre Reaktion geprüft und sie immer neutral oder höchstens kaum merkbar sauer gefunden (Prüfung mittels Lackmuspapier). Werden die Extrakte auf dem Wasserbade konzentriert, tritt eine schwach saure Reaktion ein, was darauf beruht, daß Ammoniak während des Konzentrierens aus den anwesenden Ammoniumsalzen entweicht. 
Schon bei einer früheren Gelegenheit (Ky lin, 1910, S. 178) habe ich darauf hingewiesen, daß Wasserextrakte von Ceramium rubrum eine schwach alkalische Reaktion haben. Hierfür spricht ohne weiteres die Tatsache, daß Trippelphosphat aus den Wasserextrakten krystallisiert.

Die oben besprochene Beobachtung in bezug auf $\mathrm{Ce}$ ramium rubrum habe ich bei späteren Untersuchungen über diese Alge bestätigen können. Die schwach alkalische Reaktion des Zellinhalts bei Ceramium rubrum ist aber eine Erscheinung, die unter den Florideen nicht vereinzelt dasteht, sondern es scheint, als ob der Zellinhalt der Rotalgen im allgemeinen diese Reaktion besitze.

Eine Untersuchung über die Reaktion des Zellinhalts der Florideen ist sehr leicht, da sie in sich selbst einen Indikator einschließen, Der Indikator ist der rote Farbstoff, das Phykoerythrin. Beim Erhitzen verfärbt sich dieses in alkalischer Flüssigkeit leicht ins Grüne, in saurer dagegen zuerst ins Rotviolette und bei längerem Kochen ins Blaue. Es ist nun eine bekannte Tatsache, daß sich die Farbe der lebenden Florideen in siedendem Wasser ins Grüne verändert, daß sie aber bein Ansäuern ins Violette umschlägt. Diese Erscheinung erklärt sich sehr leicht, wenn man die Farbenveränderungen des Phykoerythrins berücksichtigt, durch die Annahme einer alkalischen Reaktion des Zellinhalts. Hinsichtlich der Farbenveränderungen des Phykoerythrin in alkalischen und sauren Flüssigkeiten verweise ich des näheren auf meine Arbeit, «Über Phykoerythrin und Phykocyan bei Ceramium rubrum (Huds.) Ag.s S. 204 bis 207.

Aus dem oben Angeführten geht also hervor, daß freie organische Säuren im Zellinhalt der Fucoideen und Florideen nicht vorhanden sind. Dagegen können sie selbstverständlich als Salze vorkommen, und ich habe meine Aufmerksamkeil auf die Frage gerichtet, ob Oxalate in den Meeresalgen vorhanden sind oder nicht. Die Oxalsäure gibt, wie bekannt, ein in Wasser unlösliches Calciumsalz, und da verschiedene Calciumsalze im Zellinhalt der Meeresalgen wohl nie vollkommen fehlen, ist demnach der eventuell anwesenden Oxalsäure die Möglichkeit 
gegeben, Calciumoxalat zu bilden. Eine große Anzahl Meeresalgen habe ich auch in bezug auf das Vorkommen von Calciumoxalatkrystallen untersucht, aber immer mit negativem Erfolg. Schnitte oder Thallusteile wurden deshalb in einen Tropfen Calciumnitratlösung gelegt; niemals konnte ich aber 0xalatkrystalle beobachten. Mehrmals wurden die Präparate nach dem Zusatz der Calciumnitratlösung über die Nacht in Ammoniakdämpfen liegen gelassen, positiver Erfolg wurde aber nicht erhalten. Mikrochemisch ist demnach das Vorkommen von Oxalaten bei diesen beiden Gruppen von Meeresalgen nicht nachweisbar.

Oxalate kommen aber bei einigen von mir untersuchten Meeresalgen vor, sie lassen sich aber erst makrochemisch nachweisen. Meine Aufmerksamkeit vurde auf diese Tatsache zuerst bei Rhodymenia palmata gelenkt. Diese Alge wurde zum Zweck einer Untersuchung ihrer Zuckerarten mehrere Tage im Wasser unter Zusatz von Toluol extrahiert. Das Extrakt wurde auf dem Wasserbade eingeengt und dann mit Alkohol gefällt. Der Niederschlag wurde nach dem Abfiltrieren mit Wasser versetzt, es blieb aber ein Bodensatz übrig, der sich nicht wieder löste. Dieser wurde mikroskopisch untersucht, und es zeigte sich, daß er unter anderem auch Calciumoxalatkrystalle enthielt, die durch die Form eines Briefkouvertes sehr leicht zu erkennen sind. Sie waren, wie bei Calciumoxalatkrystallen zu erwarten, in Essigsäure unlöslich, in Salzsäure dagegen leicht löslich. - Die Untersuchung wurde noch einmal mit demselben Resultate wiederholt. Außer Rhodymenia palmata habe ich auf dieselbe Weise noch folgende Florideen untersucht: Bangia fuscopurpurea; Ceramium rubrum, Chondrus crispus und Porphyra laciniata, und bei allen habe ich das Vorkommen von Oxalaten nachweisen können.

Einige Fucoideen habe ich nach einer etwas anderen Methode untersucht. Eine Menge getrocknetes, zerkleinertes Material wurde mit $0,5 \%$ iger Salzsäure übergossen und bis zum nächsten Tag stehen gelassen. Nach dem Abfiltrieren wurde das Extrakt mit Ammoniak schwach alkalisiert, der. 
Niederschlag nach einem Tage mit Essigsãure angesäuert und mikroskopisch untersucht. Das Vorkommen von Calciumoxalatkrystallen war leicht zu konstatieren. In dieser Weise habe ich Ascophyllum nodosum, Fucus serratus, F. vesiculosus, Laminaria digitata und L. saccharina untersucht, und bei allen die Anwesenheit ron Oxalaten nachweisen können. - Sicher handelt es sich um sehr geringe Oxalatmengen, die in den Mleeresalgen vorhanden sind.

\section{Mannit.}

Im Jahre 1844 wurde von Stenhouse nachgewiesen, daB die Fucoideen Nlannit enthalten. Er unțersuchte folgende Arten: Ascophyllum nodosum, Alaria esculenta, Fucus serratus, F. vesiculosus, Halidrys siliquosa, Laminaria digitata und L. saccharina, alle mit positivem Erfolg. Die Angabe Stenhous es habe ich schon bei einer früheren Gelegenheit (K Ỵlin, 1913, S. 174) bestätigen können; ich teilte damals auch mit, daB bei Laminaria Cloustoni und Pylaiella lit oralis ebenfalls Mannit vorkommt. Gegenwärtig kann ich noch drei mannithaltige Fucoideen hinzufügen, nämlich Chorda filum, Spermatochnus paradoxus und Sphacelaria bipinnata. Alle bisher untersuchten Fucoideen. baben sich als mannithaltig erwiesen.

Es ist bekannt, daß Mannit bei den Pilzen auftritt, daB er aber oft erst beim Trocknen gebildet wird, und zwar durch eine Umwandlung der Trehalose (vgl. die Angaben in Czapek, Biochemie der Pflanzen, zweite Auflage, Bd. 1, S. 299). Und da bei meinen Untersuchungen über das Vorkommen von Mannit bei den Fucoiden getrocknetes Material benutzt wurde, erhebt sich die Frage, ob nicht auch bei den Braunalgen der Mannit erst beim. Trocknen entsteht. Um diese Frage $z u$ beantworten, wurden frische, eben aus dem Meere geholte Thallusteile ron Laminaria digitata in siedenden Alkohol gelegt, eine Stunde unter Rückfluß gekocht und dann bis zum nächsten Tag stehen gelassen. Nach dem Abfiltrieren wurde das Extrakt auf dem Wasserbade stark eingeengt, mit siedendem Alkohol 
versetzt und unmittelbar filtriert. Beim Erkalten entstanden Mannitkrystalle. Mannit muß demnach bei Laminaria digitata schon in den frischen Thallusteilen vorhanden gewesen sein. Auf dieselbe Weise und mit demselben Erfolg sind auch Ascophyllum nodosum und Fucus vesiculosus untersucht worden.

Stenhouse berichtet auch über das Vorkommen von Mannit bei einer Floridee, Rhodymenia palmata. Diese Angabe kann ich aber nur insofern bestätigen, als es gelingt, aus dieser Alge mannitähnliche, süßschmeckende Krystalle herzustellen. Es handelt sich aber hier nicht um Mannit, sondern um Trehalose (vgl. näher S. 360). Mannit fehlt dagegen bei Rhodymenia pąlmata sowohl vor wie nach dem Trocknen. Unter den übrigen Florideen habe ich in bezug auf das Vorkommen von Mannit folgende Arten untersucht: Ceramium rubrum, Ghondrus crispus, Furcellaria fastigiata und Porphyra laciniata. Bei keiner dieser Arten ließ sich Mannit nachweisen.

In Ulva latissima (U. lactuca) konnte St e nh ouse keinen Mannit auffinden. Diese Chlorophycee habe ich auch geprüft, Mannit war aber nicht vorhanden; in Enteromorpha intestinalis fehlt Mannit ebenfalls.

Aus $1000 \mathrm{~g}$ trockner Laminaria saccharina erhielt Stenhouse 121,5 g Mannit. Diese Alge soll demnach 12,15\% Mannit enthalten. Es ist aber zu bemerken, daß die Ausbeute sicher nicht reinen Mannit darstellte, sondern ohne Zweifel mit einer nicht unbedeutenden Menge Salze veruneinigt war. Die Angabe $12,15 \%$ ist also zu hoch. Die Mannitmenge der Laminaria digitata schätzt Stenhouse als kaum halb so groß wie die der L. saccharina; die Nenge bei :Halidrys siliquosa belaufe sich auf $5-6 \%$ und die bei Fucus vesiculosus auf $1-2 \%$. F. serratus soll etwas weniger Mannit als Laminaria digitata enthalten.

Die Angaben der Mannitmengen der. Fucoideen sind demnach sehr unsicher, und um diesen Mangel einigermaßen $: a b-$ zuhelien, habe ich Versuche gemacht, den Mannit bei drei Fucoideen quantitativ zu bestimmen. Die Untersuchung ist in 
folgender Weise bewerkstelligt worden. $25 \mathrm{~g}$ an der Luft getrocknetes, zerkleinertes Material wurden mit $750 \mathrm{ccm}$ Wasser übergossen, eine Stunde in siedendem Wasserbade gekocht und bis zum nächsten Tag stehen gelassen. Das Extrakt wurde dann durch ein Seidentuch abfiltriert, das Material wieder mit $500 \mathrm{ccm}$ Wasser versetzt, eine Stunde gekocht, bis zum nächsten Tag stehen gelassen, dann abfiltriert und gut ausgewaschen. Die vereinigten Wasserextrakte wurden bis auf etwa $100 \mathrm{ccm}$ konzentriert, mit $4.00 \mathrm{ccm}$ Alkohol gefällt, heiß abfiltriert und mit warmem Alkohol ausgewaschen. Dies Verfahren wurde noch einmal wiederholt, nur mit dem Unterschied, daß die Konzentration bis auf etwa $25 \mathrm{ccm}$ getrieben, und diese Lösung dann mit zehn Volumen warmen Alkohols gefällt wurde. Alle amorphen Kohlenhydrate lassen sich aber nicht auf diese Weise entfernen, geringe Mengen Laminarin bleiben immer übrig. Un diese zu entfernen, wurde das Filtrat von der lelzlen Alkoholfällung stark konzentriert (bis auf etwa $30 \mathrm{ccm}$ ) mit Schwefelsäure bis $5 \%$ versetzt und 4 Stunden in siedendem Wasserbade gekocht, um das Laminarin vollstündig zu hydrolysieren. Die Schwefelsäure wurde dann mit $\mathrm{NaOH}$ neutralisiert, die Lösung stark konzentriert, mit dem zehnfachen Yolumen warmen Alkohols versetzt, heiß abfiltriert und mit warmem Alkohol gut nachgewaschen. Das Filtrat wurde dann zum Zwcck des Auskrystallisierens des Mannits mehrere Tage in Eisschrank stehen gelassen. Der Mannit wurde abfiltriert und getrocknet, das Filtrat aber, um die noch vorhandenen Mannitmengen zum Auskrystallisieren zu bringen, noch einmal auf die oben beschriebene Weise behandelt. Die vereinigten Mannilmengen wurden bei $+110^{\circ}$ getrocknet und gewogen. Um die Verunreinigung von Salzen $z u$ bestimmen, wurde dic Mannilmenge vorsichtig zum Verkohlen gebracht, mit Wasser ausgelaugt, abfiltriert und gut gewaschen. Das Filtrat wurde dann zur Trockenheit verdampit, und nach dem Vertreiben alles Wassers gewogen. Der Unterschied dieser beiden Bestimmungen wird von dem reinen Mannit reprïsentiert. Die Resultate der quantitativen Mannitbestimmung sind in der Tabelle 1 wicdergegeben. 
Tabelle 1.

Quantitative Mannitbestimmung.

\begin{tabular}{l|c|c|c|c|c}
\hline \hline & $\begin{array}{c}\text { Trocken- } \\
\text { gewicht } \\
\text { des } \\
\text { Materials } \\
\mathrm{g}\end{array}$ & $\begin{array}{c}\text { Menge } \\
\text { Mannit } \\
\text { und Salz }\end{array}$ & $\begin{array}{c}\text { Menge } \\
\text { Salz }\end{array}$ & $\begin{array}{c}\text { Menge } \\
\text { Mannit }\end{array}$ & $\begin{array}{c}\text { Mannit in } \\
\text { \% des } \\
\text { Trocken- } \\
\text { gewichts }\end{array}$ \\
\hline Ascophyllum nodosum & 21,85 & 1,233 & 0,113 & 1,120 & 5,2 \\
Fucus serratus . . . & 22,05 & 1,725 & 0,301 & 1,424 & 6,5 \\
Laminaria digitata . . . & 22,10 & 1,793 & 0,299 & 1,494 & 6,8
\end{tabular}

Es ist indessen nicht möglich, allen Mannit aus den Alkohollösungen zum Auskrystallisieren zu bringen und die obigen Angaben wären demnach etwas zu klein. Dies wird aber andererseits dadurch kompensiert, daß sich wohl kaum alle fremden organischen Stoffe entfernen lassen. Ich halte den ersteren Fehler für größer àls den letzteren und die Angaben wären demnach immer als etwas zu klein zu betrachten. Die Angaben gelten übrigens für die im August eingesammelten Algen. Wahrscheinlich variieren die Mannitmengen mit den Jahreszeiten; vgl. das Laminarin S. 399.

Die Angabe Stenhouse, daß Laminaria saccharina doppelt so viel Mannit enthält als L. digitata, ist meiner Erfahrung gemäß nicht richtig. Ich halte es für wahrscheinlicher, daß diese beiden Laminaria-Arten approximativ gleiche Mengen Mannit enthalten. Halidrys siliquosa und Chorda filum enthalten große Mengen Mannit, etwa wie die LaminariaArten, Halidrys wahrscheinlich sogar mehr. Fucus vesiculosus steht in bezug auf die Mannitmenge Ascophyllum am nächsten.

IV. Die Zuckerarten der Florideen.

Tihomirow (1910) gibt an, daß die Florideen Chondrus crispus und Gigartina mamillosa einfache Zuckerarten enthalten. Zum Zweck des Nachweises behandelte er Thallusteile dieser Algen mit essigsaurem Phenylhydrazin in genauem Anschluß an eine Methode von Senft. Die Präparate wurden bei Zimmertemperatur liegen gelassen und nach etwa einem 
Monate erschienen die gelben Sphärokrystalle des Phenylosazons, die die Anwesenheit einfacher Zuckerarten beweisen würden. Dies ist in der Literatur die einzige Angabe über einfache Zuckerarten bei den Florideen, aus Gründen, die ich unten anführen werde, scheint mir aber der Beweis nicht vollkommen einwandfrei $z u$ sein.

Nach Kolkwitz (1900, S. 54) bekommt man beim Kochen der Thallusteile der Florideen in Fehlings Flüssigkeit keinen Niederschlag von Kupferoxydul, und dies würde die Abwesenheit reduzierender Zuckerarten beweisen. Die Richtigkeit dieser Angabe von Kolkwitz kann ich bestätigen. Mehrmals habe ich verschiedene Florideen mit $\mathrm{Fehlings}$ Flüssigkeit geprüft, aber keine reduzierenden Stoffe finden können. Nur eine stellt eine Ausnahme dar, nämlich Furcellaria fastigiata, bei welcher eine Art Gerbsäure vorhanden ist (vgl. näher Kylin, 1912, S. 409).

Durch die von Senft ausgedachte Phenylhydrazinmethode habe ich mikrochemisch eine Reihe verschiedener Florideen auf das Vorkommen von Zuckerarten geprüft. Von jeder Art wurden drei Präparate angesetzt, das eine wurde drei Tage bei Zimmertemperatur auf bewahrt, das zweite wurde eine halbe Stunde und das dritte zwei Stunden im Wärmeschrank auf $100^{\circ} \mathrm{er}-$ hitzt. In keinem Falle wurden aber Phenylosazonkrystalle erhalten. Dieser Erfolg schließt das Vorkommen von Monosacchariden oder leichter hydrolysierbaren Disacchariden (besonders Rohrzucker) aus. Die ersteren hätten schon in der Kälte Osazonkrỵstalle bilden müssen, die letzteren wären wenigstens nach zweistündigem Erhitzen hydrolysiert worden und hätten dann Osazonkrystalle ergeben. Die in der Kälte aufbewahrten Präparate habe ich, wie oben gesagt worden ist, drei Tage liegen lassen. Die Zeit bis zu einem Monat auszudehnen, wie Thihomirow getan hat, scheint mir unzweckmäßig, da es nicht ausgeschlossen ist, daß während einer so langen Zeit Monosaccharide aus Polysacchariden irgend einer Art entstehen können, und da es mir scheint, als ob man nicht von mikrochemisch nachweisbaren Mengen ron Monosacchariden sprechen kann, wenn nach drei Tagen in der Kälte keine Osazonkrystalle entstanden sind.

Hoppe-Seyler's Zeitechrift \&. physiol. Chemie. XCIY. 
Aus dem oben angeführten geht demnach hervor, daß Monosaccharide und unter den Disacchariden wenigstens Rohrzucker sich mikrochemisch bei den Florideen nicht nachweisen lassen. Dies schließt immerhin nicht aus, daß diese Zuckerarten in so geringen Mengen vorhanden sind, daß man sie erst makrochemisch nachweisen kann.

Die makrochemische Untersuchung über die Zuckerarten der Florideen habe ich auf folgende Weise bewerkstelligt. Die frischen, eben aus dem Meere geholten Algen wurden mit destilliertem Wasser übergossen und dann zehn Tage bei Zimmertemperatur stehen gelassen, als Antiseptikum wurde Toluol zugesetzt. Die Algenmenge wurde in keinem Falle näher bestimmt, überstieg aber nicht etwa $70 \mathrm{~g}$ Trockengewicht. Nach dem Abfiltrieren wurde das Extrakt auf dem Wasserbade konzentriert und mit etwa vier Volumen Alkohol gefällt, die Alkohollösung wurde noch einmal konzentriert und nun mit acht Volumen Alkohol gefällt. Nachdem die amorphen, aus Zellwandschleim bestehenden Polysaccharide auf diese Weise entfernt worden waren, wurde das Filtrat unter Zusatz von Wasser konzentriert, bis der Alkohol vollkommen vertrieben worden war. Die etwas gelbbraun gefärbte Lösung wurde schließlich mit Tierkohle gereinigt.

Die auf die oben beschriebene Weise erhaltene Lösung enthält diejenigen Mono- und Disaccharide, die in den Algenzellen vorhanden sind. Um die Natur dieser Zuckerarten zu bestimmen, wurde die Lösung folgendermaßen untersucht. Die optische Drehung wurde bèstimmt und auf ihre Eigenschaft, die Fehlingsche Flüssigkeit primär zu reduzieren, geprüft, da aber das Reduktionsvermögen sich als sehr gering erwies, konnte es nicht quantitativ bestimmt werden. Eine Portion der Lösung wurde mit essigsaurem Phenylhydrazin versetzt und dann im siedenden Wasserbade gekocht. Nach $3 / 4$ Stunden wurde nachgesehen, ob sich ein Niederschlag von Osazon gebildet hatte, da aber dies nie der Fall war, wurde die Lösung noch $5 / 4$ Stunden gekocht und dann zum Abkühlen bei Zimmertemperatur hingestellt. Erst nach dem Erkalten wurde eine geringe Menge Osazonkrystalle erhalten. Die Lösung wurde 
auch mit Resorcinsalzsäure gekocht (Seliwanoffs Probe), in keinem Falle wurde aber eine so beträchtliche Rotfärbung erhalten, daß sie auf die Gegenwart von Lävulose hindeuten könnte. Um die Lösung zu invertieren, wurde ein genau abgemessenes Volumen mit Schwefelsäure bis zu 5\% versetzt und zwei Stunden im siedenden Wasserbade gekocht. Nach der Invertierung wurde soviel Wasser zugesetzt, daß das Volumen genau dasjenige wurde, welches zur Invertierung abgemessen worden war. Die invertierte Lösung wurde dann in bezug auf ihr Drehungsvermögen und inre Reduktionsfähigkeit untersucht. Da sich die Lösung während der Invertierung braun verfärbte, war es nicht möglich, das Drehungsvermögen mit größerer Genauigkeit zu bestimmen. Für die Bestimmung wurde eine $1 \mathrm{dm}$-Röhre benutzt. Die abgelesenen Rotationswinkel sind in der Tabelle 2 verdoppelt worden, um sie leichter mit denen der nicht invertierten Lösung vergleichbar zu machen, die mittelst einer $2 \mathrm{dm}$-Röhre bestimmt wurden. Die Reduktionsfähigkeit wurde durch Titrierung nach Fehling bestimmt. Die Resultate sind in der Tabelle 2 zusammengestellt worden.

Tabelle 2.

Die Zuckerarten der Florideen.

\begin{tabular}{|c|c|c|c|c|c|}
\hline & $\begin{array}{c}\text { Menge } \\
\text { der } \\
\text { Lö- } \\
\text { sung } \\
\text { ccm }\end{array}$ & \begin{tabular}{|c} 
V \\
der Inve \\
Drehungs- \\
vermögen \\
in 2 dm- \\
Röhre
\end{tabular} & $\begin{array}{l}\text { or } \\
\text { ertierung } \\
\text { Reduktions- } \\
\text { aahigkigeit } \\
\text { als Dextrose } \\
\text { berechnet } \\
\%\end{array}$ & $\mid \begin{array}{c}\text { Na } \\
\text { der Inve } \\
\text { Drehungs- } \\
\text { vermögen } \\
\text { in } 2 \mathrm{dm}- \\
\text { Röhre }\end{array}$ & $\begin{array}{l}\text { ach } \\
\text { ertierung } \\
\text { Reduktions- } \\
\text { rähigkeit } \\
\text { als Dextrose } \\
\text { berechnet } \\
\%\end{array}$ \\
\hline Bangia fuscopurpurea & 35 & $+1,25^{\circ}$ & Spuren & $+0,5^{\circ}$ & 0,30 \\
\hline Ceramium rabrum . . & 100 & $-0,85^{\circ}$ & Spuren & $-0,3^{0}$ & 0,1 \\
\hline Chondrus crispus .. & 34 & $+4,20^{\circ}$ & Spuren & $+1,4^{\circ}$ & 0,98 \\
\hline Porphyra laciniata . . & 35 & $+3,95^{\circ}$ & Spuren & $+1,3^{\circ}$ & 0,94 \\
\hline Rhodỵmenia palmata. & 100 & $1+17,90^{\circ}$ & 0,1 & $+6,3^{\circ}$ & 3,87 \\
\hline
\end{tabular}


krystalle immer erhalten wurden, wenn auch erst nach dem Erkalten der Lösungen und in sehr geringen Mengen, so wird durch diese beiden Fakta der Beweis erbracht, daB die untersuchten Florideen einfache Zuckerarten enthalten, daß diese aber nur in äußerst geringen Mengen vorhanden sind. Nun erhebt sich aber die Frage, ob ein Gemisch von Dextrose und Lävulose, oder ob nur eine dieser Zuckerarten vorliegt. Dextrose und Lävulose von einander zu unterscheiden, wenn sie gleichzeitig in einer Lösung vorkommen, ist indessen eine schwierige Aufgabe, und besonders, wenn sie, wie im hier vorliegenden Falle, nur in sehr geringen Mengen vorhanden sein können. Ich will aber darauf hinweisen, da $B$ die Gegenwart von Lävulose sich durch die Seliwanoffsche Probe nicht hat bestätigen lassen, und es liegt daher am nächsten, zu behaupten, daß diese Zuckerart bei den Florideen fehlt, und also nur die Gegenwart von Dextrose anzuerkennen. Der negative Erfolg der Seliwanoffschen Probe gestattet auch die Behauptung, daß Rohrzucker bei den Florideen fehlt. Diese Zuckerart ist, wie bekannt, aus Dextrose und Lävulose aufgebaut und gibt bei der Prüfung mit der Seliwan offschen Probe ihrem Gehalt an Lävulose zufolge eine kräftige Rotfärbung.

Nun gibt es aber eine reduzierende Zuckerart, die nach zweistündigem Kochen und darauf folgendem Erkalten Osazonkrystalle gibt. Dies ist Maltose, und die oben als Beweise für die Gegenwart von Dextrose angeführten Tatsachen könnten also auch mit dem Vorkommen von Maltose im Einklang stehen. Die geringe Ausbeute an Osazon zeigt indessen, daß diese Zuckerart, wenn sie wirklich vorhanden ist, nur in sehr geringen Mengen vorliegen kann. Es gilt demnach, noch einen Beweis zu liefern, welcher die Gegenwart von Dextrose unzweideutig beweisen kann, und diesen erbringe ich unter Hinweis auf folgende Versuchsanordnung. Die mit essigsaurem Phenylhydrazin versetzte Lösung wurde drei Viertelstunden in siedendem Wasserbade gekocht und dann bei Zimmertemperatur zum Erkalten stehen gelassen. Vor dem Erkalten gab es in der Lösung keine Osazonkrystalle, solche bildeten sich aber in geringen Mengen während des Erkaltens. In 
diesen Fällen können keine Maltoseosazonkrystalle mitspielen, da sie nach einem Kochen von so kurzer Dauer nicht gebildet werden. Es ist demnach erwiesen, daß die untersuchten Florideen Spuren von Dextrose enthalten; $o b$ daneben auch Spuren von Maltose vorhanden sind, muB dahingestellt werden; so viel geht aber aus dem oben Angeführten hervor, daß Mallose in nachweisbaren Mengen nicht vorkommt.

Man könnte nun den Einwurf machen, daß die untersuchten Lösungen freilich Spuren von Dextrose enthalten, daß sich aber diese Spuren während der Reinigung der Extrakte gebildet haben und demnach nicht in den lebenden Florideen vorhanden wären. Die Wasserextrakte haben eine sehr schwach alkalische Reaktion (vgl. S. 349), während des Konzentrierens wird aber die Reaktion schwach sauer, was darauf berubt, daß Ammoniak aus den vorhandenen Ammoniumsalzen entweicht. Die saure Reaktion ist aber so unbedeutend, daß man bei vorsichtigem Konzentrieren auf dem Wasserbade nur an eine unbedeutende Spaltung von Rohrzucker zu denken hat. Nun ist aber diese 'Zuckerart nicht vorhanden, und es scheint mir deshalb vollkommen sicher, daß die in den Lösungen nachgewiesenen Spuren von Dextrose auch in den Algen präformiert sind.

Werden die Angaben über das Drehungsvermögen und die Reduktionsfähigkeil vor und nach der Hydrolyse miteinander verglichen, so finden wir, daß die untersuchten Arten sich in zwei Gruppen verteilen. In der einen steht Ceramium rubrum vereinzelt da, die andere schließt die übrigen vier Arten ein. Über Ceramium kann ich nichts weiteres mitteilen, als was aus den Ziffern der Tabelle hervorgeht. In bezug auf die anderen Arten will ich darauf hinweisen, daß das Drehungsvermögen der Lösungen sich während der Hydrolyse- stark verminderte, während die Reduktionsfähigkeil bedeutend zunahm und außerdem darauf, daß vor der Hydrolyse nur eine sehr unbedeutende Menge Osazonkrystalle zu erhalten waren. Diese Tatsachen stehen am besten mit der Annahme im Einklang, daß die vier Rotulgen Bangia fuscopurpurea, Chon- 
drus crispus, Porphyra laciniata und Rhodymenia palmata Trehalose enthalten. Trehalose ist ein stark rechtdrehendes, primär nicht reduzierendes Disaccharid, welches kein Osazon gibt.

Um aber die Annahme, daß Trehalose bei einigen Florideen vorkommt, besser sicherzustellen, wurden noch einige Versuche gemacht. Etwa $\mathbf{7 0} \mathrm{g}$ an der Luft getrocknetes Material von Rhodymenia palmata wurde mit Wasser extrahiert und das Extrakt in der schon oben beschriebenen Weise gereinigt. Die schließlich mit Tierkohle abgefärbte Lösung betrug $105 \mathrm{ccm}$ und zeigte in $2 \mathrm{dm}$-Röhre eine Rechtdrehung von 30,10. Diese Lösung, die stark süß schmeckte, wurde zum Sirup konzentriert und dann in den Exsikkator über Schwefelsäure hineingestellt. Nach einer Woche war der Sirup zu einem Krystallbrei erstarrt, der aus langen, prismatischen Krystallen bestand. Der Krystallbrei wurde mit Alkohol ausgerührt, abfiltriert, mit Alkohol nachgewaschen, auf der Nutsche gut abgezogen und dann im Exsikkator getrocknet. Auf diese Weise wurde etwa 6,2 g Substanz erhalten. Die Versuche; diese Substanz durch Umkrystallisieren aus Alkohol weiter zu reinigen, scheiterten; sie wurde deshalb wieder in Wasser gelöst, die Lösung konzentriert und in den Exsikkator zum Krystallisieren hineingesetzt. Der Krystallbrei wurde in der oben beschriebenen Weise behandelt und getrocknet. Es wurden jetzt nur 2,9 g Substanz wieder erhalten, die 5,7\% Asche enthielt; $0,2637 \mathrm{~g}$ gaben $0,0151 \mathrm{~g}$ Asche. Um die spezifische Drehung $\mathrm{zu}$ bestimmen, wurden $1,153 \mathrm{~g}$ (aschenfrei berechnet) in Wasser gelöst; Lösung $50 \mathrm{ccm}$; Drehung nach einem Tage $+7,39^{\circ}$ in $2 \mathrm{dm}$-Röhre. Die aus diesen Angaben berechnete spezifische Drehung beträgt $+160^{\circ}$, und dieser Wert stimmt ja ziemlich gut mit den Angaben der spezifischen Drehung der Trehalose überein, die zwischen +167 und 178,3 schwanken. Die Lösung reduzierte die Fehlingsche Flüssigkeit kaum merkbar; sie gab keine Osazonkrystalle. Nach dem Hydrolysieren (5\% ige Schwefelsäure, 4 Stunden) war die optische Drehung $+2,50$ in $2 \mathrm{dm}$-Röhre gemessen, was einer 2,37\% igen Dextroselösung entspricht. Die primäre Lösung enthielt 2,31\% Substanz 
(Trehalose) und war diese also beim Hydrolysieren in Dextrose umgewandelt worden.

Durch die oben angeführten Tatsachen ist vollkommen sicher bewiesen, daB Trehalose bei Rhodymenia palmata vorkommt. Die Trehalosemenge scheint auch nicht unbedeutend $z$ sein, wahrscheinlich etwa $10 \%$ des Trockengewichtes. Ich verweise auf die Angabe, daB ich aus etwa $70 \mathrm{~g}$ an der Luft getrockneten Materials $105 \mathrm{ccm}$ Zuckerlösung erhielt, die in $2 \mathrm{dm}$-Röhre eine Drehung von $+30,1^{\circ}$ zeigte, was einer etwa 8,5\% igen Trehaloselösung entspricht und auf die Angabe, daß das erste Auskrystallisieren eine Ausbeute von etwa $6,2 \mathrm{~g}$ gab, welche Angaben freilich keine sichere quantitative Berechnung, wohl aber eine approximative Schätzung gestatten.

Auch mit Chondrus crispus sind die Versuche, Trehalose nachzuweisen, wiederholt worden. $70 \mathrm{~g}$ an der Luft getrocknetes Material wurde mit Wasser extrahiert und das Extrakt in ähnlicher Weise wie bei Rhodymenia palmata gereinigt. Die gereinigte Lösung betrug $60 \mathrm{ccm}$; optische Drehung in $2 \mathrm{dm}$-Röhre vor der Hydrolyse $+6,2^{\circ}$, nach der Hydrolyse (5\% ige Schwefelsäure, 4 Stunden) + 2,1; Lösung primär sehr schwach, sekundär stark reduzierend. Diese Angaben slimmen mit denen in der Tabelle 2 überein und unter Hinweis darauf, daß das Vorkommen von Trehalose bei Rhodymenia sicher bewiesen ist, bestätigen sie die Annahme, daß diese Zuckerart auch bei Chondrus crispus vorhanden ist. Die Menge ist aber bei Chondrus crispus bedeutend geringer als bei Rhodymenia palmata.

Eine geringe Menge getrocknetes Material von Porphyra laciniata wurde in derselben Weise wie Chondrus crispus untersucht und die dabei erhaltenen Ergebnisse bestätigten die Angaben, die schon in der Tabelle 2 gemacht sind. Die Versuche mit Bangia fuscopurpurea zu wiederholen, habe ich keine Gelegenheit gehabt, diejenigen aber mit Ceramium rubrum sind wiederholt worden, wodurch die Angaben in der Tabelle 2 sich bestätigen ließen und also sicher bewiesen wurde, daß Trehalose bei dieser Alge fehlt. 
Die oben gegebene Auseinandersetzung über die Zuckerarten der Florideen läßt sich folgenderweise zusammenfassen. Unter den Monosacchariden sind Spuren von Dextrose vorhanden, Lävulose fehlt dagegen. Unter den Disacchariden fehlt Rohrzucker; Maltose fehlt ebenfalls oder es sind nur nicht sicher nachweisbare Mengen vorhanden; bei vier unter fünf untersuchten Arten kommt Trehalose vor, als trehalosehaltig haben sich Bangia fuscopurpurea, Chondrus crispus, Porphyra laciniata und Rhodymenia palmata erwiesen; bei der letzten ist die Trehalosemenge etwa 10\% des Trockengewichtes; Trehalose fehlt bei Ceramium rubrum.

Der Beobachtung, daß einfache Zuckerarten (Dextrose), wenn auch in sehr geringen Mengen, in den Florideen vorhanden sind, muß man meiner Meinung nach eine große theoretische Bedeutung zuerkennen, wenn es gilt, die Assimilationsvorgänge dieser Algen näher zu erörtern, oder die Frage zu beantworten, welche Stoffe bei der Assimilation der Rotalgen in erster Linie gebildet werden. Bei den höheren (grünen) Pflanzen wird nach den grundlegenden Untersuchungen von Schimper (1885) durch die Assimilation immer Glykose (= einfache Zuckerarten) gehildet. Er faßt das Hauptresultat seiner Untersuchungen in folgender Weise zusammen (a. a. O., S. 787): "Wir dürfen aus diesen Erscheinungen mit größter Wahrscheinlichkeit schließen, daß überall im Assimilationsprozeß Glykose gebildet wird-und daß die Stärke aus diesér Glykose entsteht, wenn die Menge derselben in der Zelle ein bestimmtes, je nach der Art ungleiches Maximum überschreitet».

Wie bekannt, spricht man in der Pflanzenphysiologie von solchen Pflanzen, die «Stärkeblätter», und von solchen, die «Zuckerblätter» besitzen, und versteht unter diesen Ausdrücken, daß sich die durch den Assimilationsprozeß primär gebildete Glykose bei einigen Pflanzen sehr rasch in Stärke umsetzt, sich dagegen bei anderen nur in geringen Mengen oder überhaupt garnicht zu Stärke kondensiert. Im ersteren Falle spricht man von "Stärkeblättern», im letzteren von «Zuckerblättern». In den «Stärkeblättern» sind Zuckerarten nur in geringen 
Mengen vorhanden, in den «Zuckerblättern» werden sie dagegen nicht unbeträchtlich angehäuft. Hinsichtlich der Detailangaben verweise ich auf die pflanzenphysiologischen Handbücher.

Bei den Florideen ist Stärke vorhanden und zwar eine besondere Modifikation, die Florideenstärke genannt worden ist, ich beabsichtige aber hier nicht, dieses Thema näher zu erörtern, sondern verweise auf meinen früheren Aufsatz :Zur Biochemie der Meeresalgen»; die bloße Tatsache, daß Stärke vorhanden ist, ist in diesem Zusammenhang hinreichend.

Haben wir also die beiden Talsachen vor Augen, daß Stärke bei den Florideen vorkommt, einfache Zuckerarten aber nur in kaum nachweisbaren Mengen, so liegt es sehr nahe, die Assimilationsvorgänge dieser Algen mit denen der «Stärkeblätter zu vergleichen, d. h. in beiden Fällen sind einfache Zuckerarten als das Assimilationsprodukt zu bezeichnen, diese werden aber nie angehäuft, sondern schnell zu Stärke kondensiert, die einen Reservestoff darstellt. Primär werden also bei den Florideen in ähnlicher Weise wie bei den höheren Pflanzen durch den A'ssimilationsprozeB einfache Zuckerarten gebildet, im Verlauf der weiteren Bearbeitung dieser Zuckerarten sind aber die Florideen am nächsten den sStärkeblättèrn, vergleichbar. Es bestehen immerhin Unterschiede, indem von den Florideen und von den «Stärkeblättern, verschiedene Stärkemodifikationen gebildet werden. Hierzu kommt noch, daß bei den Florideen die primär gebildete Dextrose sich nicht nur zu Stärke, sondern in einigen Fällen auch $\mathrm{zu}$ Trehalose kondensiert. Die Trehalose entspricht dann den Disacchariden Rohrzucker und Maltose, die in den sStärkeblättern , auftreten können.

\section{Die Zuckerarten der Fucoideen.}

Werden Schnitte oder Thallusteile von Fucoideen in Fehlings Flüssigkeit gekocht, erhält man immer einen reichlichen Niederschlag von Kupferoxydul. Reduzierende Stoffe sind demnach vorhanden und es könnle ja sein, daß unter diesen Stoffen auch Zuckerarten wären. Ein reduzierender 
Stoff, der in den Fucoideen immer vorzukommen scheint, ist aber das Fukosan, welches einen mit den Gerbstoffen verwandten Stoff darstellt (vgl. näher Kylin, 1912 und 1914), und man kann also aus der Tatsache, daß Schnitte, Thallusteile oder Extrakte aus Fucoideen die Fehlingsche Flüssigkeit reduzieren, keine Schlüsse in bezug auf das Vorkommen reduzierender Zuckerarten bei diesen Algen ziehen.

Tihomirow (1910) behauptet, die Gegenwart von einfachen Zuckerarten bei mehreren Fucoideen nachgewiesen zu haben. Er behandelte Schnitte mit essigsaurem Phenylhỵdrazin nach der Methode von Senft und erhielt in den Zellen einen gelbbraunen Niederschlag, der aus Sphärokrystallen von Phenylosazon bestehen sollte und das Vorkommen von einfachen Zuckerarten beweisen würde. Die Präparate wurden bei Zimmertemperatur liegen gelassen und der Niederschlag trat erst nach einer bis zwei Wochen auf. In diesem Zusammenhang will ich aber die Bemerkung wiederholen, die ich schon hinsichtlich des mikrochemischen Nachweises des Zuckers bei den Florideen gemacht habe, nâmlich $\mathrm{daB}$ es mir unzweckmäßig scheint, die Versuchszeit so lange auszudehnen, da es nicht ausgeschlossen ist, daß während derselben Monosaccharide aus Polysacchariden irgend einer Art entstehen können (vgl. S. 355).

In ähnlicher Weise wie bei den Florideen habe ich durch die Phenylhydrazinmethode von Senft eine Reihe verschiedener Fucoideen auf das Vorkommen von Zuckerarten geprüft. Von jeder Art wurden also drei Präparate angesetzt, das eine wurde drei Tage bei Zimmertemperatur auf bewahrt, das zweite wurde eine halbe Stunde und das dritte zwei Stunden im Wärmeschrank auf $100^{\circ}$ erhitzt. In keinem Falle wurden aber die gelben Krystallnadeln des Phenylglykosazons erhalten, wohl aber bisweilen gelbbraune sphärokrystallähnliche Gebilde, die möglicherweise als Sphärokrystalle aus Glykosazon zu deuten sind (vgl. Ky lin, 1914, S. 175): Diese Gebilde treten aber nur spärlich auf und fehlen im allgemeinen vollkommen.

Als Schlußfolgerung der oben angeführten Versuche ergibt sich, daß Monosaccharide und unter den Di- 
sacchariden der Rohrzucker in erwähnenswerten Mengen bei den Fucoideen nicht vorhanden sind; in geringen Mengen sind sie möglicherweise vorhanden, mikrochemisch läßt sich dies aber kaum sicher nachweisen (vgl. die Auseinandersetzung, die hinsichtlich des mikrochemischen Nachweises der Zuckerarten bei den Florideen auf S. 356 gegeben wurde).

Die Untersuchung über das Vorkommen von Zuckerarten muß man also auf makrochemische Weise weiter treiben, und schon in meinem früheren Aufsatz «Zur Biochenie der Meeresalgen, habe ich durch makrochemische Untersuchungsmethoden feststellen können, daß geringe Mengen einfacher Zuckerarten bei den Fucoideen wirklich rorhanden sind. Später habe ich die Untersuchung wiederholt und auch einigermaßen ergänzt, und ich möchte hier darüber etwas mitteilen.

An der Luft getrocknetes, zerkleinertes Material wurde drei Tage in 50\% $100 \mathrm{~g}$ Naterial), dann abfiltriert und wieder drei Tage in Alkohol von derselben Stïrke extrahiert. Die vereinigten Extrakte wurden auf dem Wasserbade konzentriert und mit vier Volumen Alkohol gefiilt. Das Filtrat wurde nach dem Abfiltrieren des Niederschlages wieder stark konzentriert und mil zelın Volumen Alkohol gefällt. Dies Verfahren wurde noch einmal wiederholt, um die amorphen Polysaccharide (das Laminarin) so gut wie möglich zu entfernen. Die alkoholische Lösung wurde dann unter Zusatz von Wasser auf dem Wasserbade vcrdampft, bis der Alkohol vollkommen vertrieben worden war. Die auf diese Weise erhaltene Wasserlösung, die von Phykophäin (oxydierendes Fukosan) mehr oder weniger tief braun gefürbl war, wurde, um das Fukosan zu entfernen, mit Blciessig gefüllt, mit Schwefelwasserstoff entbleit, nach dem Abfiltrieren des Schwefelbleis mit Natronlauge neutralisiert und im Vakuum konzentriert. Die so erhaltene Lösung war farblos oder schwach gelblich gefärbt; im letzteren Falle wurde sie mit ciner geringen Menge Tierkolle abgefärbt.

Die Lösung ist jetzt in bezug auf die Natur der in ihr rorkommenden Zuckerarten zu untersuchen. Die Untersuchung 
ist in derselben Weise bewerkstelligt worden, wie die Untersuchung der Lösungen, die aus den Florideen dargestellt worden sind. Ich verweise deshalb auf die schon früher gegebene Schilderung und beabsichtige hier nur die wichtigsten Momente hervorzuheben.

Die Lösung wurde in bezug auf das Drehungsvermögen und die Reduktionsfähigkeit vor und nach der Invertierung geprüft. Um die Lösung zu invertieren, wurde Schwefelsäure bis zu 5\% zugesetzt und dann eine Stunde im siedenden Wasserbade gekocht. Eine Portion der Lösung wurde vor der Hydrolyse mit essigsaurem Phenylhydrazin versetzt und drei Viertelstunden im siedenden Wasserbade gekocht. Nach dieser Zeit war ein nicht unbedeutender Niederschlag von Osazonkrystallen gebildet worden; das Kochen wurde noch fünf Viertelstunden fortgesetzt; dann heiß abfiltriert und bei Zimmertemperatur zum Erkalten stehen gelassen. Es bildete sich dabei noch eine geringe Menge Osazonkrystalle. Die Lösung wurde auch mittels der Seliw an off schen Probe (Resorcin-Salzsäure) geprüft, die dabei auftretende Rotfärbung war aber nicht hinreichend stark, um die Gegenwart von Lävulose oder Rohrzucker zu beweisen. Diese Zuckerarten fehlen, wie meine Untersuchungen zeigen werden, bei den Fucoideen. In meinem früheren Aufsatz $*$ Zur Biochemie der Meeresalgen» habe ich nachzuweisen versucht, daß Lävulose wahrscheinlich bei den Fucoideen vorkommt, wobei ich aber die bei der Seliwanoffschen Probe auftretende Rotfärbung nicht richtig beurteilte und mich deshalb geirrt habe.

Die Resultate der Untersuchungen über die Zuckerarten der Fucoideen habe ich in der nebenstehenden Tabelle 3 zusammengestellt.

Hinsichtlich der Natur der bei den Fucoideen vorkommenden Zuckerarten verweise ich zuerst auf die beiden Tatsachen, daß die gereinigten Lösungen vor der Hydrolyse reduzierend wirken und nach dreiviertelstündigem Kochen Osazonkrystalle geben. Durch diese beiden Tatsachen ist der Beweis erbracht, daß die untersuchten Lösungen einfache Zuckerarten enthielten. Von den beiden einfachen Zuckerarten, 
Tabelle 3.

Die Zuckerarlen der Fucoideen.

\begin{tabular}{|c|c|c|c|c|c|c|}
\hline & $\begin{array}{c}\text { An der } \\
\text { Luft } \\
\text { gotrock- } \\
\text { netes } \\
\text { Mla- } \\
\text { terial } \\
\text { g }\end{array}$ & $\begin{array}{c}\text { Menge } \\
\text { der } \\
\text { Lö- } \\
\text { sung } \\
\mathrm{ccm}\end{array}$ & $\begin{array}{l}\text { Vo } \\
\text { der Inve } \\
\text { Drehungs- } \\
\text { vermögen } \\
\text { in 2 dm- } \\
\text { Röhre }\end{array}$ & $\begin{array}{l}\text { or } \\
\text { ertierung } \\
\text { Reduktions- } \\
\text { Fhigkeit } \\
\text { als Dextrosc } \\
\text { berochnet } \\
\%\end{array}$ & $\begin{array}{l}\text { Na } \\
\text { der Inv } \\
\text { Drehungs- } \\
\text { vermögen } \\
\text { in 2 dm- } \\
\text { Rühre }\end{array}$ & $\begin{array}{l}\text { ach } \\
\text { rertierung } \\
\mid \begin{array}{|l}\text { Reduktions- } \\
\text { fihigkeit } \\
\text { als Dextroso } \\
\text { bereclinet } \\
\%\end{array}\end{array}$ \\
\hline Ascophyllum nodosum & 460 & 110 & $-0,75^{\circ}$ & $0,4+1$ & $+1,50^{\circ}$ & 1,6 \\
\hline Fucus serratus . . & 380 & 60 & $\pm 0,00^{\circ}$ & 0,80 & $+0,35^{\circ}$ & 1,00 \\
\hline ; resiculosus & 460 & 110 & $-0,45^{\circ}$ & 0,54 & $+0,1^{\circ}$ & 0,87 \\
\hline Laminaria Cloustoni & $3: 30$ & 50 & $-0,57^{\circ}$ & 0,68 & $+0,65^{\circ}$ & 0,93 \\
\hline , digitata. & 500 & 90 & $+0,17^{\circ}$ & 0,83 & $+0,45^{\circ}$ & 1,28 \\
\hline saccharina . & 700 & 60 & $-0,75^{\circ}$ & 1,28 & $1+0,55^{\circ}$ & 1,70 \\
\hline
\end{tabular}

Dextrose und Lävulose, die hier in Frage kommen können, fehlt Lävulose, wie die Versuche zeigen, die ich auf S. 398 näher besprechen werde.

Die bei den Fucoideen vorkommenden Dextrosemengen sind aber sehr unbedeutend. Eine approximative Berechnung läBt sich aus den Angaben in der Tabelle 3 machen. Die extrahierten Algenmengen sind dort angegeben, weiter die Menge der schließlich erhaltenen Zuckerlösungen, und die Reduktionsfähigkeit dieser Lösungen. Aus diesen Angaben läBt sich die in der Alge vorkommende Dextrosemenge berechnen, jedoch unter den Voraussetzungen, daß die Dextrose den einzigen reduzierenden Stoff der Lösung darstellt, und da $B$ keine Dextrosemengen während der Reinigung verloren gegangen sind. Diese Voraussetzungen treffen freilich nicht völlig $\mathrm{zu}$, eine approximative Berechnung scheint mir jedoch gestattet zu sein, und sie wïrde ergeben, daß bei den untersuchten Fucoideen die Dextrosemenge nur etwa 0,1 bis $0,2 \%$ des Trockengewichtes ist. Zielit man nun in Betracht, da $B$ das Trockenmaterial nur etwa $20-25 \%$ des Frischgewichtes darstellt, so kommt man zu dem Resultate, daß die frischen Algen höchstens 0,05\% Dextrose entbalten, und bei einem so geringen Dextrosegehalt kann es nicht Wunder nehmen, wenn man in den frisch geschnittenen 
Fucoideen mikrochemisch die Gegenwart der Dextrose nicht sicher nachweisen kann.

Sind nun aber diese geringen Dextrosemengen nicht während der Reinigung der Extrakte gebildet? Ich habe schon darauf hingewiesen (vgl. S. 348), daß die Extrakte während des Konzentrierens der Entweichung von Ammoniak wegen schwach sauer werden, und dies könnte ja die Entstehung der Monosaccharide verursachen. Die Versuche wurden deshalb mit Material von Laminaria digitata und L. saccharina wiederholt, bei allen Konzentrierungen wurde aber eine geringe Menge Calciumcarbonat zugesetzt, um das Auftreten einer sauren Reaktion möglichst zu verhindern. Auch bei diesen Versuchsserien ließ sich aber Dextrose nachweisen, und es scheint deshalb sicher, daß die Dextrose in den Algen präformiert vorhanden ist. Vgl. die Auseinandersetzung, die über diese Frage in bezug auf die Florideen gegeben ist.

Es erübrigt jetzt, die Frage zu erörtern, welche Disaccharide bei den Fucoideen vorkommen. Hinsichtlich des Rohrzuckers verweise ich darauf, daß seine Gegenwart sich durch die Seliwanoffsche Probe nicht hat bestätigen lassen, und auf Seite 398 werde ich noch einen Versuch besprechen, der mir sicher zu beweisen scheint, daß diese Zuckerart nicht vorhanden sein kann. Maltose scheint mir ebenfalls zu fehlen. Die zu untersuchenden Lösungen wurden, wie oben erwähnt, vor der Hydrolyse mit essigsaurem Phenylhydrazin versetzt und dann zwei Stunden im siedenden Wasserbade gekocht. Der Niederschlag von. Osazon wurde heiß abfiltriert, und das Filtrat bei Zimmertemperatur zum Erkalten stehen gelassen. Dabei bildete sich eine geringe Menge eines Osazonniederschlages, der aber sicher aus Glykosazon bestand. Das Osazon der Maltose, das erst nach zweistündigem Kochen gebildet wird, ist in warmem Wasser löslich, in kaltem Wasser aber unlöslich und fällt deshalb beim Erkalten aus. Der oben erwähnte Osazonniederschlag, der sich beim Erkalten bildete, könnte demnach zum Teil aus dem Osazone der Maltose bestehen. Da aber die Menge dieses Osazonniederschlages sehr gering war, muß die Maltose, wenn diese Zuckerart wirk- 
lich vorhanden wäre, nur in den geringsten Spuren vorkommen, in bedeutend geringeren Mengen als die Dextrose, von welcher Zuckerart die frische Alge, wie aus dem oben Angeführten hervorgeht, doch nur höchstens $0,05 \%$ enthält. Nit diesen Versuchsresultaten vor Augen, scheint es mir sehr wahrscheinlich, daß Maltose bei den untersuchten Fucoideen nicht vorkommt, und unter Hinweis auf die Erörterung, die ich hinsichtlich der verschiedenen Laminarinmodifikationen geben werde, scheint es mir sogar sicher, daB Naltose bei diesen Algen überhaupt nicht gebildet wird.

Werfen wir aber einen Blick auf die Tabelle 3, so finden wir, daß das Drehungsvermögen der untersuchten Lösungen während der Hydrolyse vergrößert wurde, in den meisten Fällen sogar von negativem zu positivem überschlug, und $d a B$ die Reduktionsfähigkeit nicht unbedeutend zunahm. Diese beiden Tatsachen zeigen, daß ein hydrolysierbares Polysaccharid irgend einer Art vorhanden ist. Bei der Reinigung der Extrakte wurde aber besondere Fürsorge darauf verwendet, die amorphen Polysaccharide so gut wie möglich zu entfernen. Die Extrakte wurden ja nach starkem Konzentrieren zweimal mit je zehn Volumen Alkohol gefällt, und das letztemal größerer Gewißheit halber mehrere Tage im Eisschrank stehen gelassen. Da bei diesen Fällungen reichliche Mengen Neutralsalze vorhanden waren, scheint es mir, als ob die amorphen Polysaccharide vollkommen weggeschafft worden wären, und die alkoholische Lösung nur noch Disaccharide (eventuell Trisaccharide) enthalten könnte. Sind die Voraussetzungen zutreffend, muß man also unter Hinweis auf die Tabelle 3 behaupten, daB die untersuchten Fucoideen wirklich Disaccharide enthalten. Oben wurde aber erwiesen, da $B$ Rohrzucker und Maltose nicht vorkommen, und an eine Gegenwart von Trehalose ist, mit den Angaben in der Tabelle 3 vor Augen, gar nicht zu denken.

Aus dem oben angeführten geht demnach hervor, daß es wahrscheinlich ist, daß ein Disaccharid irgend einer Art, wenn auch nur in geringen Mengen, in den unter- 
suchten Fucoideen vorkommt. Dieser Disaccharid muß aber eine negative spezifische Drehung besitzen und während der Hydrolyse eine rechtsdrehende Zuckermischung geben. Ein solches Disaccharid ist aber nicht bekannt, und es ergibt sich also die Schlußfolgerung, daß die in Rede stehenden Fucoideen, wenn überhaupt ein Disaccharid, ein noch unbekanntes enthalten müssen.

Nun enthalten aber die Fucoideen ein linksdrehendes Polysaccharid, das Laminarin, welches während der Hydrolyse eine rechtsdrehende Zuckermischung gibt, und es könnte deshalb scheinen, als ob die Angaben in der Tabelle 3 sich daraus erklären ließen, daß dieses Polysaccharid nicht vollkommen entfernt worden wäre. Das Laminarin ist aber kein gut definierbares Polysaccharid mit konstanter Zusammensetzung, sondern stellt nur einen Sammelbegriff für eine Reihe mit einander verwandter Polysaccharide dar, die sich unter anderem dadurch unterscheiden, daß sie mit Alkohol mehr oder weniger fällbar sind. Das Laminarin ist durch Kondensierung. von Dextrosemolekülen zusammengesetzt, und diejenigen Modifikationen, die von mehreren Dextrosemolekülen aufgebaut worden sind, und demnach ein größeres Molekulargewicht besitzen, sind von Alkohol leichter fällbar, als diejenigen, die in ihren Molekülen nur wenige Dextrosemoleküle enthalten. Von diesen letzteren Modifikationen kann man sich eine denken, die nur aus zwei Dextrosemolekülen aufgebaut ist, und demnach die Zusammensetzung eines Disaccharids besitzt.

Aus theoretischen Gründen, die ich später näher erörtern werde, muß man das Vorkommen eines solchen Disaccharides annehmen, das den Ausgangspunkt der ganzen Laminarinreihe darstellt. Als Name dieses Disaccharides schlage ich Laminariose vor, und dieses neue Disaccharid muB sich von den bisher bekannten dadurch unterscheiden, daß es eine negative spezifische Drehung besitzt; die bisher bekannten sind alle rechtsdrehend. Die Herstellung der Laminariose aus den $\mathrm{Fu}-$ coideen ist mir nicht gelungen, und ich kann deshalb das Vor- 
kommen dieser neuen Zuckerart nicht experimentell beweisen, ich glaube aber, daß diese Zuckerart eben daran schuld ist, $\mathrm{da} ß$ die in der Tabelle 3 untersuchten Lösungen sowohl ihr Drehungsrermögen als ihre Reduktionsfähigkeit während der H⿰̣drolyse vergrößerten.

Die Bedeutung der Beobachtung, da $B$ die Fucoideen geringe Mengen einfacher Zuckerarten (Dextrose) enthalten, für unsere Auffassung des Verlaufs der Assimilationsvorgänge bei diesen Algen werde ich später (S. 401) näher erörtern.

\section{Laminarin.}

In einem früheren Aufsatze :Zur Biochemie der Meeresalgen $>$ habe ich nachgewiesen, da $\beta$ man aus einigen Fucoideen ein Polysaccharid extrahieren kann. Als Name dieses Polysaccharides wurde ein von Schmiedeberg (1S8ð, S. 427) gegebener aufgenommen, nämlich Laminarin, welcher Name sich sehr wahrscheinlich eben auf den von mir extrahierten Stoff bezieht. Dieser Forscher behauptet nämlich, daß es in Laminaria aeine Art Dextrin, Laminarin, Dextrin von der Formel $10\left(\mathrm{C}_{6} \mathrm{H}_{19} \mathrm{O}_{6}\right)-9 \mathrm{H}_{2} \mathrm{O}=\mathrm{C}_{60} \mathrm{H}_{102} \mathrm{O}_{56}$ " gibt; und der von mir aus Laminaria digitata und L. saccharina extrahierte Stoff war auch in mehreren Hinsichten dextrinähnlich. Außer bei den Laminaria-Arten konnte ich auch bei Ascophyllum nodosum und Fucus vesiculosus das Vorkommen eines Polysaccharides nachweisen.

Die wichtigsten Eigenschaften des Laminarins wurden in meinem früheren Aufsatz folgenderweise zusammengestellt. Das Laminarin ist ein weißes, geschmackloses, in Wasser leicht lösliches Pulver. Es ist in absolutem Alkohol unlöslich, in 50\% igem Alkohol ziemlich löslich; löst sich in siedendem $75 \%$ igem Alkohol und fält bei Abkühlen wieder aus, bei langsamer Abkühlung in Form von Kügelchen, die of mit einander zusarnmengeballt sind. Es wird von Jod nicht gefärbt. Die Wasserlösung reduziert schwach Fehlings Flüssigkeit, wird nicht von Bleiessig gefällt, wird aber von ammoniakalischem Bleiessig niedergeschlagen; linksdrehend; $\alpha_{1}$ etwa - 13,00; gibt bei der Hydrolyse nur Dextrose.

Hoppe-Seyler's Zeiluchrift t. phrsiol. Chemie. XCIV. 
Die fortgesetzten Untersuchungen haben aber gezeigt, daß das Laminarin nicht ein bestimmtes Polysaccharid mit konstanter Zusammensetzung darstellt, sondern eine ganze Reihe verschiedener, aber mit einander nahe verwandter Stoffe repräsentiert.

\section{A. Extraktionsmethoden.}

Bei meinen Untersuchungen habe ich drei verschiedene Extraktionsmethoden gebraucht und ich werde zunächst diese mit einigen Worten beleuchten.

Methode 1. Das an der Luft getrocknete, zerkleinerte Material wurde drei Tage in 50\% igem Alkohol extrahiert (etwa $400 \mathrm{ccm}$ Alkohol auf $100 \mathrm{~g}$ Material), dann abfiltriert und noch drei Tage in Alkohol von derselben Stärke extrahiert. Die vereinigten Extrakte wurden auf dem Wasserbade konzentriert und mit vier Volumen Alkohol gefällt. Der Niederschlag wurde abfiltriert (das Filtrat zur Untersuchung von Zuckerarten verwendet, vgl. S. 365) und in einer größeren Menge Wasser gelöst. Die wässerige Lösung wurde mit Bleiessig gefällt und nach dem Abfiltrieren des Niederschlages erhält man eine farblose, wasserklare Lösung, aus welcher das Laminarin durch Zusatz von Ammoniak gefällt wird. Der Niederschlag wird abfiltriert, gut ausgewaschen und mit Schwefelwasserstoff zersetzt. Nach dem Abfiltrieren des Schwefelbleis wurde das Filtrat mit Natronlauge neutralisiert, dann auf dem Wasserbade konzentriert und mit vier bis sechs Volumen Alkohol gefällt, wobei das Laminarin als eine flockige Fällung niedergeschlagen wird. Auch in konzentrierten Lösungen entsteht ein bleibender Niederschlag erst nach Zusatz von mehr als einem Volumen Alkohol. Wird der Alkohol langsam zugesetzt, ballt sich der Niederschlag zu einer zähen Masse zusammen. Das Laminarin reinigt man weiter durch wiederholtes Auflösen in Wasser und Ausfällung mit vier bis sechs Volumen Alkohol.

Bei dem Konzentrieren nach dem Abfiltrieren des Schwefelbleis wird die vorher farblose Lösung gelbbraun verfärbt. Dies beruht darauf, daß das Fukosan sich nicht mit Bleiessig voll- 
kommen niederschlagen läßt. Diese Fukosanreste oxydieren sich bei dem Konzentrieren zu Phykophäin, welches die Lösung gelbbraun verfärbt. Es ist nicht möglich, diese gefärbten Beimischungen vollkommen zu entfernen, wenn das Laminarin bei neutraler Reaktion mit Alkohol ausgefällt wird; bei salzsäuresaurer Reaktion lassen sie sich aber entfernen. Am besten reinigt man deshalb das Laminarin auf solche Weise, daß man die nach dem Abfiltrieren des Schwefelbleis konzentrierte Lösung einmal mit Alkohol fällt, das Laminarin wieder in Wasser löst, diese wässerige Lösung mit Salzsäure schwach ansäuert und dann wieder mit Alkohol fällt.

Die schließlich erhaltene farblose Laminárinlösung fällt man zum letztenmal mit Alkohol, filtriert den Niederschlag $a b$, wäscht ibn mit Alkohol aus und saugt ihn dann auf der Nutsche gut $a b$. Nach dieser Behandlung wird das Laminarin im Exsikkator über Schwefelsäure zum Trocknen gelegt.

Methode 2. Bei einigen Gelegenheiten wurde das nach der Methode 1 extrahierte Material mit einer größeren Menge $20 \%$ igem Alkohol versetzt. Es quillt bei dieser Behandlung sehr stark auf (besọnders bei den Laminaria-Arten) und die Extrakte werden sehr stark schleimig, was auf der Gegenwart von Fukoidin (vgl. S. 404) beruht. Durch Zusatz von Baryumacetat läßt sich das Fukoidin ausfällen. Übrigens kann man die Verunreinigungen mit Bleiessig ausfällen, ohne daß das Laminarin trotz des Gehalts an Alkohol mitgerissen wird. Die Bleiessigfällung wird abfiltriert und aus dem Filtrate wird das Laminarin mit Ammoniak ausgefällt. Der Laminarinniederschlag wird dann weiter nach der Methode 1 behandelt und gereinigt.

Methode 3. An der Luft getrocknetes, zerkleinertes Material wurde mit einer größeren Menge Wasser übergossen (etwa $1000 \mathrm{ccm}$ auf $100 \mathrm{~g}$ Material), eine Stunde in siedendem Wasser gekocht und dann bis zum nächsten Tag stehen gelassen. Das Extraki wurde abgegossen, das Material mit Wasser versetzt und dann noch einmal auf die oben erwähnte Weise behandelt. Die vereinigten Extrakte werden mit Bleiessig gefallt und aus dem Filtrate nach dem Abfiltrieren der Bleiessigfällung wird das Laminarin mit Ammoniak ausgefällt. 
Der Laminarinniederschlag wird dann weiter nach der Methode 1 behandelt und gereinigt.

Es kann aber bei dieser Methode passieren, daß die Verunreinigungen von Fukosan trotz einem reichlichen Zusatz von Bleiessig nicht gut zu entfernen sind. Dies kündigt sich beim Konzentrieren nach dem Abfiltrieren des Schwefelbleis dadurch an, daß die Lösung tief braun verfärbt wird. Bei der weiteren Reinigung des Laminarins sind die gefärbten Beimischungen sehr schwierig zu entfernen, und es gelingt bisweilen nicht, eine farblose Laminarinlösung zu bekommen. Es ist deshalb ratsam, wenn die Lösung nach dem Konzentrieren stärker braun gefärbt ist, sie noch einmal mit Bleiessig zu reinigen. Um einen Niederschlag $z u$ erhalten muß man in diesem Falle auch etwas Kochsalz hinzusetzen. Der Niederschlag wird abfiltriert, das Filtrat entbleit, dann mit Natronlauge neutralisiert, konzentriert und mit Alkohol gefällt. Die gefärbten Verunreinigungen, die noch vorhanden sind, lassen sich gut durch Fällen mit Alkohol in saurer Lösung entfernen.

Von diesen drei Methoden ist die letzte ohne weiteres als die bequemste zu empfehlen, wenn man nur beabsichtigt, das Material zur Laminarindarstellung zu verwenden. Ebensogut wie getrocknetes kann man dabei frisches Material brauchen, das man nur etwas zu zerschneiden hat. In siedendem Wasser läßt sich das Laminarin auch gut aus größeren Thallusstücken extrahieren.

Das durch diese Methoden dargestellte Laminarin enthält etwas Asche, im allgemeinen ungefähr $0,2-0,3 \%$; in einigen Fällen ist der Aschengehalt bis etwas mehr als $1 \%$ gestiegen, in anderen dagegen auf weniger als $0,1 \%$ hinuntergebracht worden.

Die Asche besteht zum größten Teil aus Sulfaten, die wahrscheinlich beim Konzentrieren der schwefelwasserstoffhaltigen Lösungen entstanden sind. Chloride waren nur in geringen Mengen vorhanden. Calcium ließ sich im allgemeinen nachweisen.

-Bei mehreren Bestimmungen gilt es, das Laminarin vollkommen wasserfrei zu erhalten. Dies erreicht man entweder 
dadurch, daß man das Laminarin eine längere Zeit im Exsikkator über Schwefelsäure stehen läßt, oder dadurch, daß man es im Trockenschrank bei $+110^{\circ}$ trocknet. Vergleichende Versuche haben gezeigt, daß sich das Laminarin bei dieser Temperatur nicht verändert. Vgl. die Versuche $1 \mathrm{a}, 6 \mathrm{~b}$ und $6 \mathrm{c}$.

\section{B. Laminarin aus verschiedenen Fucoideen.}

1. Ascophyllum nodosum.

1a. Aus $460 \mathrm{~g}$ im August eingesammelten Materials wurde das Laminarin durch die Methode 1 extrahiert und gereinigt. Der Laminarinniederschlag zeigte eine große Neigung, sich zu einer zähen Masse zusammenzuballen, und erst bei Zusatz von zehn bis zwölf Volumen Alkohol wurde ein Niederschlag erhalten, der sich abfiltrieren und trocknen ließ. 5,0 g Laminarin; $0,93 \%$ Asche; 0,4711 g gaben 0,0044 g Asche.

$0,933 \mathrm{~g}$, Asche abgerechnet, im Exsikkator getrocknet, wurden in Wasser gelöst ${ }^{1}$ ) Lösung $50 \mathrm{ccm}$; Drehung in $4 \mathrm{dm}-$ Röhre $-2,42^{\circ}$; spezifische Drehung demnach $-32,4^{0}$

$$
a_{\mathrm{D}}=-\frac{2,42 \cdot 50}{0,933 \cdot 4}=-32,4^{0}\left(1 \mathrm{a}_{1}\right) \text {. }
$$

$0,964 \mathrm{~g}$, Asche abgerechnet, bei $+110^{\circ}$ getrocknet, wurden in Wasser gelöst; Lösung $50 \mathrm{ccm}$; Drehung in $4 \mathrm{dm}$ Röhre $-2,46^{\circ}$; spezifische Drehung demnach $-31,9^{\circ}$.

$$
\alpha_{\mathrm{D}}=-\frac{2,46 \cdot 50}{0,964 \cdot 4}=-31,9^{\circ} \text { (1 az). }
$$

Das Molekulargewicht (siehe S. 376) ist etwas zu hoch, um der Zusammensetzung $5\left(\mathrm{C}_{6} \mathrm{H}_{10} \mathrm{O}_{5}\right) \cdot \mathrm{H}_{2} \mathrm{O}$ zu entsprechen, aber bedeutend $\mathrm{zu}$ niedrig für $6\left(\mathrm{C}_{6} \mathrm{H}_{10} \mathrm{O}_{5}\right) \cdot \mathrm{H}_{2} \mathrm{O}$. Nun muB man aber in Betracht ziehen, da $B$ das Material nicht aschenfrei war, sondern 0,93\% Asche enthielt. In den Angaben der Kon-

1) Die abgewogene Substanzmenge wurde in Wasser gelösl, und die Lösung über die Nacht stehen gelassen, um eine eventuell auftretende Maltirotation verschwinden zu lassen. Die Lösung wurde dann in ein Meßkölbchen von $50 \mathrm{~cm}$ gegossen und Wasser bis zur Marke zugesetzl. Im allgemeinen wrurde so viel Substanz abgewogen, da $B$ die zu untersuchende Lösung etwa 2-3\% Laminarin enthielt. 
Molekulargewichtsbestimmung. ${ }^{1}$ )

\begin{tabular}{c|c|c|c|c}
\hline \hline $\begin{array}{c}\text { Konzen- } \\
\text { tration }\end{array}$ & $\begin{array}{c}\text { Gefrier- } \\
\text { punkts- } \\
\text { erniedrigung }\end{array}$ & $\begin{array}{c}\text { Molekular- } \\
\text { gewicht }\end{array}$ & \multicolumn{2}{|c}{$\begin{array}{c}\text { Molekulargewicht berechnet } \\
\text { für }\end{array}$} \\
\hline 4,593 & 0,100 & 854 & 828 & 900 \\
6,680 & 0,137 & 907 & - & - \\
8,945 & 0,196 & 849 & - & -
\end{tabular}

zentrationen ist die Asche abgerechnet. Die Gegenwart der Mineralsalze verursacht aber, daß die Gefrierpunktserniedrigungen zu groß sind und die berechneten Molekulargewichte demnach zu klein. Hauptsächlich ist Natriumsulfat vorhanden, daneben aber auch etwas Kochsalz und Calciumsulfat (vgl. S. 374). Die von den Mineralbestandteilen verursachte Gefrierpunktserniedrigung läßt sich nicht exakt, wohl aber approximativ bestimmen, und man kann daraus berechnen, daß die gefundenen Molekulargewichte um etwa $50 \overline{0}-75$ zu erhöhen sind, um die wahrscheinlichst richtigsten $\mathrm{zu}$ bekommen. Macht man also diese Korrektion, so erhält man ein Molekulargewicht; welches am nächsten der Zusammensetzung $6\left(\mathrm{C}_{6} \mathrm{H}_{10} \mathrm{O}_{5}\right) \cdot \mathrm{H}_{2} \mathrm{O}$ entspricht.

Im Kapillarrohre erhitzt, beginnt die Substanz bei $190^{\circ}$ $\mathrm{zu}$ sintern, und wird bei $250-255^{\circ}$ unter Blasenbildung zersetzt. Das Laminarin schmilzt nicht.

1b. Aus $240 \mathrm{~g}$ im August eingesammelten Materials wurde das Laminarin nach der Methode 3 extrahiert und gereinigt. In ähnlicher Weise wie in dem Versuche 1a zeigte auch hier der Laminarinniederschlag eine große Neigung, sich zu einer zähen Masse zusammenzuballen, und erst bei Zusatz von zehn bis zwölf Volumen Alkohol wurde ein Niederschlag erhalten, der sich abfiltrieren und trocknen ließ. 3,1 g Laminarin; $1,30 \%$ Asche; 0,4312 g gaben 0,0056 g Asche.

1) Die Molekulargewichtsbestimmungen sind mitlels eines Beckmannschen Apparats gemacht worden. In bezug auf die Methode und die Berechnung der Molekulargewichte verweise ich auf die von Hanslian in Abderhalden "Handbuch der biochemischen Arbeitsmethoden», Bd. 6, 'S. 355, gegebene Darstellung. 
$0.987 \mathrm{~g}$, Asche abgerechnet, $\left.{ }^{1}\right)$ wurden in Wasser gelöst; Lösung $50 \mathrm{ccm}$; Drehung - 2,61 in $4 \mathrm{dm}$-Röhre; spezifische Drehung demnach $-33,10$.

$$
\alpha_{D}=-\frac{2,61 \cdot 50}{0,987 \cdot 4}=-33,1^{0}(1 \mathrm{~b}) .
$$

Molekulargewichtsbestimmung.

\begin{tabular}{c|c|c|c|c}
\hline \hline $\begin{array}{c}\text { Konzen- } \\
\text { tration }\end{array}$ & $\begin{array}{c}\text { Gefrier- } \\
\text { punkts- } \\
\text { erniedrigung }\end{array}$ & $\begin{array}{c}\text { Molekular- } \\
\text { getwicht }\end{array}$ & $\begin{array}{c}\text { Molekulargewicht berechnet } \\
\text { für } \\
\mathbf{5}\left(\mathrm{C}_{6} \mathrm{H}_{10} \mathrm{O}_{6}\right) \cdot \mathrm{H}_{2} \mathrm{O}\end{array} \mathbf{6}\left(\mathrm{C}_{6} \mathrm{H}_{10} \mathrm{O}_{6}\right) \cdot \mathrm{H}_{2} \mathrm{O}$ \\
\hline 3,456 & 0,075 & 857 & 828 & 990 \\
5,570 & 0,116 & 893 & - & - \\
7,437 & 0,157 & 881 & - & -
\end{tabular}

Dieselben Bemerkungen, die ich in bezug auf die Molekulargewichtsbestimmung in der Versuchsserie 1a gemacht habe, sind auch hier zu machen, und wenn man diese berücksichtigt, muß man behaupten, daß das Molekulargewicht der wahrscheinlichsten Zusammensetzung $6\left(\mathrm{C}_{6} \mathrm{H}_{10} \mathrm{O}_{5}\right) \cdot \mathrm{H}_{2} \mathrm{O}$ entspricht.

Die aus Ascophylium nodosum dargestellte Laminarinmodifikation besitzt demnach eine spezifische Drehung, die - 32, ๖ beträgt, und entspricht am besten der molekularen Zusammensetzung $6\left(\mathrm{C}_{6} \mathrm{H}_{10} \mathrm{O}_{5}\right) \cdot \mathrm{H}_{2} \mathrm{O}$. Damit will ich aber garnicht gesagt haben, daß hier ein bestimmtes Kohlenhydrat mit der konstanten Zusammensetzung $6\left(\mathrm{C}_{6} \mathrm{H}_{10} \mathrm{O}_{5}\right) \cdot \mathrm{H}_{2} \mathrm{O}$ vorliegt, sondern es könnte auch sein, daß wir eine Mischung mehrerer mit einander verwandter Kohlenhydrate vor uns haben, welche Mischung hinsichtlich ihres Molekulargewichts der oben erwähnten Zusammensetzung entspricht. Aus Gründen, die ich hier nicht näher erörtern werde, die aber aus der folgenden Darstellung deutlich hervorgehen, finde ich, daß die letztere Annahme die wahrscheinlichste ist, und ich glaube also, daß die hier in Rede stehende Laminarinmodifikation ein Gemenge, z. B. von den Kohlenhydraten $5\left(\mathrm{C}_{6} \mathrm{H}_{10} \mathrm{O}_{5}\right) \cdot \mathrm{H}_{8} \mathrm{O}, 6\left(\mathrm{C}_{6} \mathrm{H}_{10} \mathrm{O}_{5}\right) \cdot$ $\mathrm{H}_{2} \mathrm{O}$ und $7\left(\mathrm{C}_{6} \mathrm{H}_{10} \mathrm{O}_{5}\right) \cdot \mathrm{H}_{2} \mathrm{O}$ oder von noch mehreren darstellt.

7) Wenn nichts anderes gesagt ist; ist das Material bọi $+110^{\circ}$ getrocknet worden. 


\section{Fucus serratus.}

2a. Aus $380 \mathrm{~g}$ im August eingesammelten Materials wurde das Laminarin nach der Methode 1 extrahiert und gereinigt. Bei der Reinigung wurde das Laminarin jedesmal mit je sechs Volumen Alkohol ausgefällt, und schließlich wurden $8,5 \mathrm{~g}$ Substanz bekommen. $0,16 \%$ Asche; $0,5577 \mathrm{~g}$ gaben $0,0009 \mathrm{~g}$ Asche.

$1,347 \mathrm{~g}$, Asche abgerechnet, wurden in Wasser gelöst; Lösung $50 \mathrm{ccm}$; Drehung in $4 \mathrm{dm}$-Röhre $-2,39^{\circ}$; die spezifische Drehung ist demnach $-22,2^{\circ}$.

$$
\alpha_{\mathrm{D}}=-\frac{2,39 \cdot 50}{1,347 \cdot 4}=-22,2^{\circ}(2 \mathrm{a}) .
$$

Molekulargewichtshestimmung.

\begin{tabular}{c|c|c|c}
\hline $\begin{array}{c}\text { Konzen- } \\
\text { tration }\end{array}$ & $\begin{array}{c}\text { Gefrier- } \\
\text { punkts- } \\
\text { erniedrigung }\end{array}$ & $\begin{array}{c}\text { Molekular- } \\
\text { gewicht }\end{array}$ & $\begin{array}{c}\text { Molekulargewicht berechnet } \\
\text { für } \\
12\left(\mathrm{C}_{6} \mathrm{H}_{10} \mathrm{O}_{5}\right) \cdot \mathrm{H}_{2} \mathrm{O}\end{array}$ \\
\hline 4,408 & 0,040 & 2049 & 1962 \\
7,249 & 0,055 & 2452 & - \\
9,833 & 0,070 & 2613 & -
\end{tabular}

Die Bestimmungen bei größerer Konzentration zeigen ein höheres Molekulargewicht als diejenigen bei geringerer, was darauf hindeutet, daß in irgend einer Weise eine molekulare Veränderung bei Vergrößerung der Konzentration stattfindet, und man muß dann den kleineren Wert des Molekulargewichts als den richtigsten betrachten. Wahrscheinlich ist aber auch der Wert 2049 etwas zu hoch, der bei einer Konzentration von 4,408 gefunden worden ist. Der absolute Wert interessiert aber in diesem Zusammenhang nicht so sehr, als die Tatsache, daß das Molekulargewicht der hier in Rede stehenden Laminarinmodifikation bedeutend größer ist, als dasjenige der Modifikation aus Ascophyllum. Die spezifischen Drehungen dieser beiden Modifikationen sind auch sehr verschieden, für die Ascophyllum-Modifikation - $32,5^{\circ}$, für die Fucus serratusModifikation $-22,2^{\circ}$. Es wurde schon oben angedeutet, daß die erstere Modifikation ein Gemenge verschiedener Kohlenhydrate darstellt, und die folgenden Angaben $2 \mathrm{~b}$ und $2 \mathrm{e}$ werden zeigen, daß die letztere wirklich ein Gemenge ist. 
2 b. Das Material aus 2 a wurde weiter nach der Methode 2 extrahiert, und das Extrakt nach dieser Methode gereinigt. Nach dem Abfiltrieren des Schwefelbleis wurde das Filtrat auf j0 ccm konzentriert und dann mit zwei Volumen Alkohol gefällt. Der zähe Niederschlag wurde abdekantiert, und die abdekantierte Flüssigkeit nach $2 \mathrm{c}$ behandelt. Der Laminarinniederschlag wurde in Wasser gelöst und mit vier Volumen Alkohol gefällt. Dies Verfahren wurde noch einigemal wiederholt. Schließlich wurden $6,0 \mathrm{~g}$ reines Laminarin erhalten. Asche $0,08 \% ; 0,4764 \mathrm{~g}$ gaben $0,0004 \mathrm{~g}$ Asche.

$1,087 \mathrm{~g}$, Asche abgerechnet, wurden in Wasser gelöst; Lösung $50 \mathrm{ccm}$; Drehung in $4 \mathrm{dm}$-Röhre $-1,13^{\circ}$; die spezifische Drehung ist demnach $-13,0^{\circ}$.

$$
\alpha_{\mathrm{D}}=-\frac{1,13 \cdot 50}{1,087 \cdot 4}=-13,0^{\circ}(2 \mathrm{~b})
$$

$2 \mathrm{c}$. Die in der Versuchserie $2 \mathrm{~b}$ abdekantierte Flüssigkeit wurde mit $200 \mathrm{ccm}$ versetzt, der dabei entstandene Laminarinniederschlag in etwas Wasser gelöst und dann einigemal durch Fällung mit je sechs Volumen Alkohol weiter gereinigt. 2,0 g Laminarin; Asche 0,21\%;0,4790 g gaben 0,0010 g Asche.

$1,328 \mathrm{~g}$, Asche abgerechnet, wurden in Wasser gelöst; Lösung $50 \mathrm{ccm}$; Drehung in $4 \mathrm{dm}$-Röhre $-2,43^{\circ}$; die spezifische Drehung ist demnach $-22,9^{\circ}$.

$$
\alpha_{\mathrm{D}}=-\frac{2,43 \cdot 50}{1,328 \cdot 4}=-22,9^{\circ}(2 \mathrm{c}) \text {. }
$$

Aus Fucus serratus sind demnach zwei verschiedene Laminarinmodifikationen dargestellt worden; die eine besitzt eine spezifische Drehung von $-13,0^{\circ}$, die andere eine Drehung von $-22,9^{\circ}$. Jede von diesen Modifikationen repräsentiert aber sicher Gemenge von verschiedenen Kohlenhydraten. Die stärker negativ drehende Modifikation bat ein geringeres Molekulargewicht, als die weniger stark negativ drehende. Die erstere entspricht etwa der molekularen Zusammensetzung $12\left(\mathrm{C}_{6} \mathrm{H}_{10} \mathrm{O}_{5}\right) \cdot \mathrm{H}_{2} \mathrm{O}$, die letztere dagegen etwa $17\left(\mathrm{C}_{6} \mathrm{H}_{10} \mathrm{O}_{3}\right) \cdot \mathrm{H}_{2} \mathrm{O}$ (vgl. die Molekulargewichtsberechnungen für Laminarinmodifkationen aus Laminaria digitata und L. saccharina). 
3. Fucus vesiculosus.

3 a. Aus $460 \mathrm{~g}$ im August eingesammelten Materials wurde das Laminarin nach der Methode 1 extrahiert und gereinigt. $2,8 \mathrm{~g}$ Substanz; Asche $0,60 \% ; 0,4680 \mathrm{~g}$ gaben $0,0028 \mathrm{~g}$ Asche.

$1,014 \mathrm{~g}$, Asche abgerechnet, wurden in Wasser gelöst; Lösung $50 \mathrm{ccm}$; Drehung $-1,76^{\circ}$ in $4 \mathrm{dm}$-Röhre; die spezifische Drehung ist demnach $-21,7^{\circ}$.

$$
\alpha_{\mathrm{D}}=-\frac{1,76 \cdot 50}{1,014 \cdot 4}=-21,7^{\circ}(3 \mathrm{a}) \text {. }
$$

$3 \mathrm{~b}$. Aus dem in 3 a behandelten Material wurde eine geringe Menge Laminarin nach der Methode 2 extrahiert und gereinigt; $0,8 \mathrm{~g}$ Substanz; Asche $0,20 \% ; 0,2459 \mathrm{~g}$ gaben $0,0005 \mathrm{~g}$ Asche.

$0,421 \mathrm{~g}$, Asche abgerechnet, wurden in.Wasser gelöst; Lösung $50 \mathrm{ccm}$; Drehung $-0,67^{\circ}$ in $4 \mathrm{dm}$-Röhre; die spezifische Drehung ist demnach $-19,9^{\circ}$.

$$
\alpha_{D}=-\frac{0,67 \cdot 50}{0,421 \cdot 4}=-19,9^{\circ}(3 \mathrm{~b}) \text {. }
$$

4. Laminaria Cloustoni.

4 a. Aus $330 \mathrm{~g}$ im August eingesammelten Materials wurde das Laminarin nach der Methode 1 extrahiert und gereinigt. 1,5 g Substanz; Asche $0,33 \% ; 0,4193 \mathrm{~g}$ gaben $0,0014 \mathrm{~g}$ Asche.

$0,793 \mathrm{~g}$, Asche abgerechnet, wurden in Wasser gelöst; Lösung $50 \mathrm{ccm}$; Drehung $\because 0,65$ in $4 \mathrm{dm}$-Röhre; die spezifische Drehung ist demnach $-10,2^{\circ}$.

$$
\alpha_{\mathrm{D}}=-\frac{0,65 \cdot 50}{0,793 \cdot 4}=-10,2^{\circ}(4 \mathrm{a}) \text {. }
$$

Von der Lösung nach der Bestimmung der spezifischen Drehung wurden $20 \mathrm{ccm}$ abgemessen, mit Schwefelsäure bis $5 \%$ versetzt und dann vier Stunden in siedendem Wasserbade gekocht. Nach der Hydrolyse wurde Wasser bis genau $20 \mathrm{ccm}$ zugesetzt. Die hydrolysierte Lösung zeigte in $2 \mathrm{dm}$ Röhre' eine Drehung von $+1,66^{\circ}$, was einem Dextrosegehalt von 1,58\% entspricht; die Reduktionsfähigkeit, nach F ehling 
bestimmt, entsprach 1,57\% Dextrose. Die ursprüngliche Lösung enthielt 1,586\% Laminarin. Das Laminarin war demnach durch die Hydrolyse quantitativ in Dextrose umgewandelt worden.

Derjenige Teil der Lösung, der nicht zur Hydrolyse verwendel worden war, wurde in Eisschrank gesetzt; nach einem Tage war ein aus kleinen Kügelchen bestehender Niederschlag gebildet, der sich bei Erwärmen leicht wieder löste.

$4 \mathrm{~b}$. Das Material aus $4 \mathrm{a}$ wurde dann weiter nach der Methode 2 extrahiert, und das Laminarin nach dieser Methode gereinigt. 3,8 g Substanz; Asche 0,26\%; 0,4592 g gaben $0,0012 \mathrm{~g}$ Asche.

$1,088 \mathrm{~g}$, Asche abgerechnet, wurden in Wasser gelöst; Lüsung $50 \mathrm{ccm}$; Drehung in $4 \mathrm{dm}$-Röhre $-0,85^{\circ}$; die spezifische Drehung ist demnach $-9,8^{\circ}$,

$$
\alpha_{D}=-\frac{0,85 \cdot 50}{1,088 \cdot 4}=-9,8^{\circ}(4 \mathrm{~b}) \text {. }
$$

Die Lösung wurde in Eisschrank gestellt, und es bildete sich dabei, wie im vorigen Falle ( $4 \mathrm{a})$, ein Niederschlag, der sich bei Erwärmen leicht wieder löste.

Man beobachte, daß das Laminarin aus Laminaria Cloustoni bei niedrigerer Temperatur auch aus ziemlich verdünnten Lösungen $(1,6-2,1 \%)$ ausfällt und bei Erwärmen wieder leicht gelöst wird. Diese Eigenschaft fehlt bei den aus den vorhergehenden Arten dargestellten Laminarinmodifikationen.

Um diese bei Laminaria Cloustoni vorkommenden Laminarinmodifikationen näher studieren zu können, sind folgende Versuchsserien angestellt worden.

4c. $75 \mathrm{~g}$ Material wurden nach der Methode 3 extrahiert. Eine größere Menge Wasser wurde zum Extrahieren verwendet und die vereinigten Extrakte betrugen $2000 \mathrm{ccm}$. Aus dem Filtrate nach der Reinigung mittelst Bleiessig wurde das Laminarin durch Zusatz von Ammoniak ausgefällt, und der Niederschlag in gewöhnlicher Weise mil Schwefelwasserstoff zcrlegt. Um alles Laminarin sicher in Lösung zu bringen, wurde vor dern Abfiltrieren des Schwefelbleis bis $60^{\circ}$ erwärmt. - Das Filtrat wurde mit Natronlauge neutralisiert, dann auf $40 \mathrm{~cm}$ kon- 
zentriert und im Eisschrank bis zum nächsten Tag stehen gelassen. Der Niederschlag wurde abfiltriert (die abfiltrierte Lösung nach $4 \mathrm{c}$ behandelt) und unter Erwärmen in etwas Wasser gelöst. Beim Erkalten dieser Lösung wurde das Laminarin wieder ausgefällt. Nachdem das Laminarin noch einmal durch Lösen in warmem Wasser und Ausfällen in der Kälte gereinigt worden war, wurde der Niederschlag mit Alkohol versetzt, abfiltriert, mit Alkohol gewaschen, auf der Nutsche abgesaugt und im Exsikkator getrocknet. 0,4 g Substanz; aschenfrei; $0,1442 \mathrm{~g}$ gaben keinen wiegbaren Rückstand.

$0,187 \mathrm{~g}$ wurden unter Erwärmen bis auf $75^{\circ}$ in $50 \mathrm{ccm}$ Wasser gelöst. Bei der Abkühlung der Lösung begann sie schon bei $50^{\circ}$ opaleszent $z u$ werden und bei $48^{\circ}$ war ein körniger Niederschlag gebildet worden. Da das Auftreten der Opaleszenz eben bezeichnet, daß die Löslichkeitsgrenze der Substanz erreicht ist, kann man also aus den obigen Angaben entnehmen, daß sich bei einer Temperatur von $50^{\circ} 0,187 \mathrm{~g}$ dieser Laminarinmodifikation in $50 \mathrm{ccm}$ Wasser lösen läßt. Die Löslichkeit ist demnach bei $+50^{\circ} 1$ Teil Substanz auf etwa 270 Teile Wasser. Zum Zwecke der Bestimmung der spezifischen Drehung wurde das Drehungsvermögen dieser Lösung bei $+55^{\circ}$ beobachtet. Dieses betrug $-0,06^{\circ}$ in $2 \mathrm{dm}$-Röhre. Die spezifische Drehung bei $+55^{\circ}$ ist demnach $-8,0^{\circ}$.

$$
\alpha_{\mathrm{D}}^{55^{\circ}}=-\frac{0,06 \cdot 50}{0,187 \cdot 2}=-8,0^{\circ}(4 \mathrm{c}) .
$$

Um die Löslichkeit dieser Laminarinmodifikation bei Zimmertemperatur kennen zu lernen, wurde die oben erwähnte Lösung nach der Bestimmung ihres Drehungsvermögens mehrere Tage bei Zimmertemperatur $\left(+18^{\circ}\right)$ stehen gelassen. Von dem Filtrate wurde dann 23,63 $\mathrm{g}$ abgewogen und bis zur Trockenheit auf dem Wasserbade verdampft. Rückstand 0,0254 g; Asche $0,0007 \mathrm{~g}$; der Laminarrückstand war demnach $0,0247 \mathrm{~g}$. Aus diesen Angaben läßt sich berechnen, daß von dieser Laminarinmodifikation bei $+18^{\circ} 1$ Teil auf 957 Teile $\mathrm{W}^{\top}$ asser löslich ist. Die Löslichkeit beträgt also (etwas abgerundet) bei $+18^{\circ} 1$ Teil Substanz auf 950 Teile Wasser. 
Das Laminarin, welches bei der vorhergehenden Bestimmung abfiltriert worden war, wurde unter Erwärmen in $75 \mathrm{ccm}$ Wasser gelöst und die Lösung mehrere Tage bei einer Temperatur von $+10^{\circ}$ stehen gelassen. Von dem Filtrate wurde dann 51,40 g abgewogen und bis zur Trockenheit auf dem Wasserbade verdampft. Rückstand $0,0175 \mathrm{~g}$; Asche $0,0005 \mathrm{~g}$; der Laminarinrückstand war demnach $0,0170 \mathrm{~g}$. Aus diesen Angaben läßt sich berechnen, daß von dieser Laminarinmodifikation bei $+10^{\circ} 1$ Teil auf 3023 Teile Wasser löslich ist. Die Löslichkeit beträgt also (etwas abgerundet) bei $+10^{\circ} 1$ Teil Substanz auf 3000 Teile Wasser.

4d. Das Filtrat von $4 \mathrm{c}$ (etwa $40 \mathrm{ccm}$ ) wurde mit $100 \mathrm{ccm}$ Alkohol gefällt, der Niederschlag abfiltriert (Filtrat dann weiter nach $4 \mathrm{e}$ behandelt) und in etwas Wasser gelöst. Aus dieser Lösung wurde das Laminarin durch Zusatz von vier Volumen Alkohol gefällt, und dann noch zweimal durch Lösen in Wasser und Fällen mit je vier Volumen Alkohol gereinigt. Es wurden $1,8 \mathrm{~g}$ getrocknetes Laminarin erhalten. Asche $0,22 \% ; 0,2774 \mathrm{~g}$ gaben 0,0006 mg Asche.

$0,658 \mathrm{~g}$, Asche abgerechnet, wurden in Wasser gelöst; Lösung $50 \mathrm{ccm}$; Drehung - 0,37 in $4 \mathrm{dm}$-Röhre; die spezifische Drehung ist demnach $-7,0^{\circ}$.

$$
a_{D}=-\frac{0,37 \cdot 50}{0,658 \cdot 4}=-7,0^{\circ}\left(4 d_{1}\right) .
$$

Die Lösung wurde bis auf $40^{\circ}$ erhitzt und das Drehungsvermögen dann bei einer Temperatur von $+35^{\circ}$ beobachtet. Dieses betrug $-0,50$ in $4 \mathrm{dm}$-Röhre. Bei $+35^{\circ}$ ist demnach die spezifische Drehung $-9,5^{\circ}$, also nicht unbedeutend höher als bei Zimmerlemperatur.

$$
a_{D}^{350}=-\frac{0,50 \cdot 50}{0,658 \cdot 4}=-9,5^{\circ}(4 \mathrm{~d} 2) .
$$

Aus dieser Lösung wurden im Eisschrank etwas Laminarin ausgefällt.

4 e. Das Filtrat aus $4 \mathrm{~d}$ (etwa $120 \mathrm{ccm}$ ) wurde mit $220 \mathrm{ccm}$ Alkohol versetzt, der Laminarinniederschlag abfiltriert, in Wasser gelöst und mit zehn Volumen Alkohol gefällt. Die Auflösung in Wasser und Ausfällung mit zehn Volumen Alkohol wurde 
noch einmal wiederholt. $0,4 \mathrm{~g}$ Substanz; Asche 1,25\%; $0,1120 \mathrm{~g}$ gaben $0,0014 \mathrm{~g}$ Asche.

$0,286 \mathrm{~g}$ Asche, abgerechnet, wurden in Wasser gelöst; Lösung $50 \mathrm{ccm}$; Drehung in $4 \mathrm{dm}$-Röhre $-0,32$; die spezifische Drehung ist demnach $-14,0^{\circ}$.

$$
a_{\mathrm{D}}=-\frac{0,32 \cdot 50}{0,286 \cdot 4}=-14,0^{\circ}(4 \mathrm{e})
$$

Aus dem oben angeführten geht demnach hervor, daß es bei Laminaria Cloustoni verschiedene Laminarinmodifikationen gibt, die sich durch ihre spezifische Drehung, ihre Löslichkeit in Wasser und ihre Fällbarkeit mit Alkohol von einander unterscheiden. Von besonderem Interesse ist das Vorkommen einer in kaltem Wasser sehr schwerlöslichen Modifikation. Die Löslichkeit dieser Modifikation beträgt bei $+10^{\circ}$ 1 auf 3000 Wasser, bei $+18^{\circ} 1$ auf 950 Wasser und bei $+50^{\circ} 1$ auf 270 Wasser. Die spezifische Drehung ist sehr gering; sie beträgt bei $+55^{\circ}$ nur $-8,0^{\circ}$, bei Zimmertemperatur ist sie sicher noch geringer, eine exakte Bestimmung läßt sich aber der geringen Löslichkeit wegen kaum bewerkstelligen.

Bei Abkühlung einer Lösung fällt diese Laminarinmodifikation in kleinen, winzigen Körnchen aus, die sich sehr schwer abfiltrieren lassen. Bei langsamerer Abkühlung werden die Körnchen etwas größer. Die größten Körnchen erhält man aber, wenn man eine stark verdünnte Lösung mehrere Tage in der Kälte stehen läßt. Auf diese Weise habe ich Körnchen erhalten, die $20 \mu \mathrm{im}$ Durchmesser waren. Die Körnchen stellen eine Art Sphärokrystalle dar. Eine innere Struktur, wie z. B. bei den Inulinsphäriten, läßt sich bei einer Vergrößerung von 450 mal noch nicht beobachten. Die Laminarinsphärite zeigen in polarisiertem Lichte ein dunkles Kreuz in ähnlicher Weise wie die Stärkekörner.

5. Laminaria digitata.

5 a. Aus $1000 \mathrm{~g}$ im August eingesammeltem Materiale wurde das Laminarin nach der Methode 1 extrahiert und gereinigt. Bei der Reinigung durch Zusatz von Alkohol wurden 
jedesmnl find Volumon zugesolat. 8,8 \& Lmminarin; Ascho $0,11 \% ; 0,6250$ genbon 0,0001 ig Ascho.

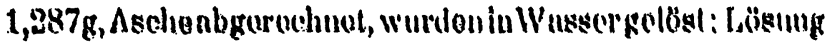

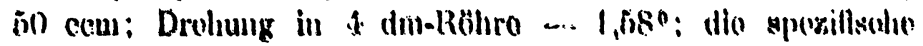
Dreliung ist demuach $-16,3^{\circ}$.

$$
a_{v}=-\frac{1,68 \cdot 60}{1,287 \cdot 1}=-16,80 \text { (6) } n \text { ). }
$$

bb. Das Mntorial aus ba wurde weiter nach dop Methode 2 oxtrahiort, und das Laminarin dureh dieso Molbode gercinigh, jodoch so, daB das Biltral nach dom Abfillrieren dise Schwofelbleis bis 160 aem kenzentriort mat mit gho ecm $\mathrm{Ml}$ kohol vorsolat wurde. Dor zäho Nedersohlag wurdo nbdokantiort (dio aludekantiorlo Flisssigkeit unch bo bohandoll), in 100 cem Wusser golöst und bnoh Angthorn mit Snlyalinre mil vier Volumen Alkohol nusgefillt. Dio Aullösung in W'assor und

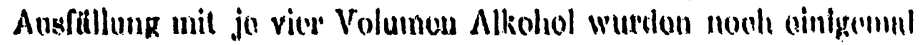

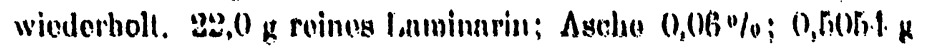
galien 0,(0)0!3 if Asche.

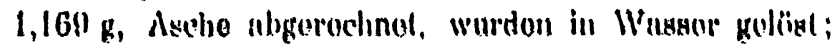

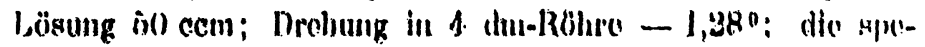
rilische Drohung ist demmols - 13,7".

$$
a_{11}=-\frac{1,28 \cdot n 0}{1,160 ! \cdot 1}=\ldots 18,7^{\circ}(6 !) \text {. }
$$

\begin{tabular}{|c|c|c|c|}
\hline $\begin{array}{l}\text { liunacn- } \\
\text { tration }\end{array}$ & $\begin{array}{l}\text { Ciefrior- } \\
\text { punkls- } \\
\text { michiodrigung }\end{array}$ & $\begin{array}{l}\text { Mlolokulnr- } \\
\text { gewirhlit }\end{array}$ & 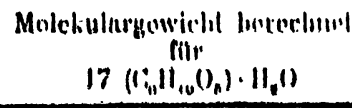 \\
\hline 1.1141 & 10,01277 & 4861 & 2774 \\
\hline$|1|,\{\mid\}$ & $0,014 \%$ & 182111 & $\cdots$ \\
\hline $\mathrm{N}, \mid \mathrm{NI}$ & 0,010 & $3 \mathrm{ROS}$ & $\ldots$ \\
\hline
\end{tabular}

Molokulnrgawichilshonlimnmuıg.

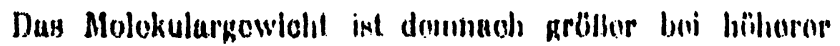
Konzentration als bel niodrigorer, und ich slaube, dies doutcl

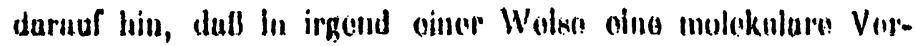
linderung boi Vorkriborung der Konzentrullon alntllindlyl. (Vkl. Fucus aorralus.) Von hesondorom Intorones isl ulur, dab die hior in Hede alehondo lamimurinmodilikation, allo oine: 
spezifische Drehung von $-13,7^{\circ}$ besitzt, ein bedeutend größeres Molekulargewicht hat als die schon früher besprochene, aus Fucus serratus dargestellte, die eine spezifische Drehung von $-22,2^{\circ}$ besitzt. Das Molekulargewicht dieser Modifikation war bei einer Konzentration von 4,408\% 2049, etwa der Zusammensetzung $12\left(\mathrm{C}_{6} \mathrm{H}_{10} \mathrm{O}_{5}\right) \cdot \mathrm{H}_{2} \mathrm{O}$ entsprechend. Es zeigt sich demnach, daß eine Abnahme der spezifischen Drehung mit einer Zunahme des Molekulargewichtes Hand in Hand geht.

5 c. Die von dem zähen Laminarinniederschlag in $5 \mathrm{~b}$ abdekantierte Flüssigkeit (etwa $390 \mathrm{ccm}$ ) wurde mit $390 \mathrm{ccm}$ Alkohol versetzt. Der Laminarinniederschlag wurde in $100 \mathrm{ccm}$ Wasser gelöst und dann durch mehrmaliges Umfällen mit je vier Volumen Alkohol gereinigt. 12,0 g Substanz; Asche 0,15\%; $0,4617 \mathrm{~g}$ gaben $0,0007 \mathrm{~g}$ Asche.

$1,274 \mathrm{~g}$, Asche abgerechnet, wurden in Wasser gelöst; Lösung $50 \mathrm{ccm}$; Drehung in $4 \mathrm{dm}$-Röhre $-1,73^{\circ}$; die spezifische Drehung ist demnach $-17,0^{\circ}$.

$$
\alpha_{D}=-\frac{1,73 \cdot 50}{1,274 \cdot 4}=-17,0^{\circ}(5 \mathrm{c}) .
$$

$5 \mathrm{~d}$. Aus $500 \mathrm{~g}$ im November eingesammeltem Materiale wurde das Laminarin nach der Methode 1 extrahiert und gereinigt. Nach dem Abfiltrieren des Schwefelbleis wurde das Filtrat bis auf $80 \mathrm{ccm}$ konzentriert und dann mit $140 \mathrm{ccm}$ Alkohol versetzt. Der zähe Laminarinniederschlag wurde abdekantiert (die abdekantierte Flüssigkeit nach 5 e behandelt), in $50 \mathrm{ccm}$ Wasser gelöst -und dann durch mehrmaliges Umfällen mit je drei Volumen Alkohol gereinigt. 6,0 g Substanz; Asche $0,31 \%$; 0,5501 g gaben 0,0017 $\mathrm{g}$ Asche.

$1,280 \mathrm{~g}$, Asche abgerechnet, wurden in Wasser gelöst; Lösung $50 \mathrm{ccm}$; Drehung in $4 \mathrm{dm}$-Röhre $-1,18^{\circ}$; die spezifische Drehung ist demnach $-11,5^{\circ}$.

$$
\alpha_{D}=-\frac{1,18 \cdot 50}{1,280 \cdot 4}=-11,5^{\circ}(5 \mathrm{~d}) \text {. }
$$

5 e. Die von dem Laminarinniederschlag in $5 \mathrm{~d}$ abdekantierte Flüssigkeit (etwa $200 \mathrm{ccm}$ ) wurde mit $40 \mathrm{ccm}$ Alkohol versetzt, wobei noch ein zäher Laminarinniederschlag entstand. 
Dieser wurde abdekantiert (die abdekantierte Flüssigkeit nach $5 \mathrm{f}$ behandelt), in $40 \mathrm{ccm}$ Wasser gelöst und dann durch mehrmaliges Umfällen mit je vier Volumen Alkohol gereinigt. $3,2 \mathrm{~g}$ Substanz; Asche 0,42\%; 0,4751 g gaben 0,0020 g Asche.

$1,097 \mathrm{~g}$, Asche abgerechnet, wurden in Wasser gelöst; Lösung $50 \mathrm{ccm}$; Drehung in $4 \mathrm{dm}$-Röhre $-1,38^{\circ}$; die spezifische Drehung ist demnach $-15,7^{\circ}$.

$$
\alpha_{D}=-\frac{1,38 \cdot 50}{1,097 \cdot 4}=-15,7^{\circ}(5 \mathrm{e}) \text {. }
$$

$5 \mathrm{f}$. Die in 5 e abdekantierte Flüssigkeit (etwa $220 \mathrm{ccm}$ ) wurde mit $220 \mathrm{ccm}$ Alkohol versetzt, der Laminarinniederschlag in $20 \mathrm{ccm}$ Wasser gelöst und dann durch mehrmaliges Umfällen mit je zehn Volumen Alkohol gereinigt. 1,4 g Substanz; Asche 1,05\%; 0,3732 g gaben 0,0039 g Asche.

$0,927 \mathrm{~g}$, Asche abgerechnet, wurden in Wasser gelöst; Lösung $50 \mathrm{ccm}$; Drehung in $4 \mathrm{dm}$-Röhre $-2,03^{\circ}$; die spezifische Drehung ist demnach $-27,40$.

$$
\alpha_{D}=-\frac{2,03 \cdot 50}{0,927 \cdot 4}=-27,4^{0}(5 \mathrm{f}) \text {. }
$$

5 g. Das schon früher in $5 \mathrm{~d}$ extrahierte Material wurde weiter nach der Methode 2 extrahiert. Bei der Reinigung durch Umfallen mit Alkohol wurde darauf geachtet, daß jedesmal nur eine solche Menge Alkokol zugesetzt wurde, die hinreichend war, um einen zähen Niederschlag hervorzurufen. Auf diese $\mathrm{W}^{\top}$ eise erhält man die Laminarinmodifikation, die am leichtesten mit Allsohol fallbar ist. Nach mehrmaligen Umfällungen wurde der Niederschlag wieder in etwas Wasser gelöst und mit einer größeren Menge Alkohol ausgefällt, um das Laminarin in einem solchen Zustande zu bekommen, da $\beta$ es sich abfiltrieren und trocknen ließ. 3,6 g Substanz; Asche 0,25\%; 0,4830 g gaben 0,0012 g Substanz.

$1,382 \mathrm{~g}$, Asche abgerechnet, wurden in Wasser gelöst; Lösung $50 \mathrm{ccm}$; Drehung in $4 \mathrm{dm}$-Röhre $-0,95^{\circ}$; die spezifische Drehung ist demnach $-8,6^{\circ}$.

$$
\alpha_{D}=-\frac{0,95 \cdot 50}{1,382 \cdot 4}=-8,6^{\circ}(5 \mathrm{~g}) \text {. }
$$

Hoppe-Seyler' Zeilschrift t. physiol. Chemie. XCIV. 
Die Lösung wurde in Eisschrank gestellt, es bildete sich aber dabei kein Laminarinniederschlag; vgl. Laminaria Cloustoni.

$5 \mathrm{~h}$. Aus $200 \mathrm{~g}$ im November eingesammelten Naterials wurde das Laminarin nach der Methode 3 extrahiert und gereinigt. Nach dem Abfiltrieren des Schwefelbleis wurde das Filtrat bis auf $100 \mathrm{ccm}$ konzentriert und dann mehrere Tage in Eisschrank stehen gelassen. Kein Laminarinniederschlag wurde aber gebildet, und doch enthielt die Lösung sicher mehr als 13\% Laminarin. Die Lösung wurde deshalb durch Zusatz von $160 \mathrm{ccm}$ Alkohol gefällt, der Laminarinniederschlag abdekantiert (die abdekantierte Flüssigkeit nach $5 \mathrm{i}$ behandelt), in $50 \mathrm{ccm}$ Wasser gelöst und dann durch mehrmaliges Fällen mit je drei Volumen Alkohol gereinigt. 3,5 g Substanz; Asche $0,32 \% ; 0,4798 \mathrm{~g}$ gaben $0,0016 \mathrm{~g}$ Asche.

$1,390 \mathrm{~g}$, Asche abgerechnet, wurden in Wasser gelöst; Lösung $50 \mathrm{ccm}$; Drehung in $4 \mathrm{dm}$-Röhre $-1,23^{\circ}$; die spezifische Drehung ist demnach $-11,1^{0}$.

$$
\alpha_{\mathrm{D}}=-\frac{1,23 \cdot 50}{1,390 \cdot 4}=-11,1^{\circ}(5 \mathrm{~h}) \text {. }
$$

$5 \mathrm{i}$. Die in $5 \mathrm{~h}$ abdekantierte Flüssigkeit (etwa $240 \mathrm{ccm}$ ) wurde durch Zusatz von $225 \mathrm{ccm}$ Alkohol gefällt, der Niederschlag in Wasser gelöst und dann durch mehrmaliges Umfällen mit je vier Volumen Alkohol gereinigt. 9,5 g Substanz; Asche $0,12 \% ; 0,4867 \mathrm{~g}$ gaben 0,0006 $\mathrm{g}$ Asche.

$1,430 \mathrm{~g}$, Asche abgerechnet, wurden in Wasser gelöst; Lösung $50 \mathrm{ccm}$; Drehung in $4 \mathrm{dm}$-Röhre $-1,60^{\circ}$; die spezifische Drehung ist demnach $-14,0^{\circ}$.

$$
\alpha_{D}=-\frac{1,60 \cdot 50}{1,430 \cdot 4}=-14,0^{\circ}(5 \mathrm{i}) \text {. }
$$

6. Laminaria saccharina.

6a. $700 \mathrm{~g}$ im August eingesammeltes Material wurde mit $1500 \mathrm{ccm} 70 \%$ igem Alkohol versetzt und drei Tage lang extrahiert. Das Material wurde dann abfiltriert, mit $1000 \mathrm{ccm}$ 70\% igem Alkohol versetzt und noch drei Tage extrahiert. 
Die vereinigten Extrakte wurden konzentriert und mit drei Volumen Alkohol gefällt. Der Niederschlag wurde in $100 \mathrm{ccm}$ Wasser gelöst; die Lösung mit Salzsäure angesäuert und dann durch mehrmaliges Umfällen mit je drei Volumen Alkohol gereinigt. $8,1 \mathrm{~g}$ Substanz; Asche $0,12 \% ; 0,4183 \mathrm{~g}$ gaben $0,0005 \mathrm{~g}$ Asche.

$1,035 \mathrm{~g}$, Asche abgerechnet, wurden in Wasser gelöst; Lösung $50 \mathrm{ccm}$; Drehung in $4 \mathrm{dm}$-Röhre $-1,00^{\circ}$; die spezifische Drehung ist demnach $-12,1^{\circ}$.

$$
\alpha_{D}=-\frac{1,00 \cdot 50}{1,035 \cdot 4}=-12,1^{\circ}(6 \mathrm{a}) \text {. }
$$

6 b. Das. nach 6 a behandelte Material wurde nach der Methode 1 extrahiert und das Laminarin nach dieser Methode gereinigt. Bei der Reinigung durch Umfällen mit Alkohol wurde jedesmal vier Volumen Alkohol zugesetzt. 17,5 g Substanz; Asche $0,27{ }^{\circ} \% ; 0,5066 \mathrm{~g}$ gaben $0,0015 \mathrm{~g}$ Asche.

$1,134 \mathrm{~g}$, Asche abgerechnet, in Exsikkator getrocknet, wurden in Wasser gelöst; Lösung $50 \mathrm{ccm}$; Drehung in $4 \mathrm{dm}$ Röhre $-1,60^{\circ}$; die spezifische Drehung ist demnach $-17,7^{\circ}$.

$$
\alpha_{D}=-\frac{1,60 \cdot 50}{1,134 \cdot 4}=-17,7^{\circ}\left(6 b_{1}\right) \text {. }
$$

$1,103 \mathrm{~g}$, Asche abgerechnet, bei $+110^{\circ}$ getrocknet, wurden in Wasser gelöst; Lösung $50 \mathrm{ccm}$; Drehung in $4 \mathrm{dm}$ Röhre $-1,58^{\circ}$; die spezifische Drehung ist demnach $-17,9^{\circ}$.

$$
\alpha_{\mathrm{D}}=-\frac{1,58 \cdot 50}{1,103 \cdot 4}=-17,9^{\circ}(6 \mathrm{~b} 2) \text {. }
$$

$6 \mathrm{c}$. Das Material aus $6 \mathrm{~b}$ wurde weiter nach der Methode 2 extrahiert und das Laminarin nach dieser Methode gereinigt. Bei der Reinigung durch Umfällen mit Alkohol wurde jedesmal vier Volumen Alkohol zugesetzt. 22,0 g Substanz; Asche $0,09 \% ; 0,4724 \mathrm{~g}$ gaben $0,0004 \mathrm{~g}$ Asche.

$1,221 \mathrm{~g}$, Asche abgerechnet, im Exsikkator getrocknet, wurden in Wasser gelöst; Lösung $50 \mathrm{ccm}$; Drehung in $4 \mathrm{dm}$ Röhre - 1,290; die spezifische Drehung ist demnach $-13,2^{\circ}$.

$$
a_{\mathrm{D}}=-\frac{1,29 \cdot 50}{1,221 \cdot 4}=-13,2^{\circ}\left(6 \mathrm{c}_{1}\right) \text {. }
$$


$1,200 \mathrm{~g}$, Asche abgerechnet, bei $+110^{\circ}$ getrocknet, wurden im Wasser gelöst; Lösung $50 \mathrm{ccm}$; Drehung in $4 \mathrm{dm}-$ Röhre $-1,28^{\circ}$; die spezifische Drehung ist demnach $-13,3^{\circ}$.

$$
a_{D}=-\frac{1,28 \cdot 50}{1,200 \cdot 4}=-13,3^{\circ}\left(6 c_{2}\right) \text {. }
$$

Molekulargewichtsbestimmung.

\begin{tabular}{c|c|c|c}
\hline $\begin{array}{c}\text { Konzen- } \\
\text { tration }\end{array}$ & $\begin{array}{c}\text { Gefrier- } \\
\text { punkts- } \\
\text { erniedrigung }\end{array}$ & $\begin{array}{c}\text { Molekular- } \\
\text { gewicht }\end{array}$ & $\begin{array}{c}\text { Molekulargewicht berechnet } \\
\text { für } \\
17\left(\mathrm{C}_{6} \mathrm{H}_{10} \mathrm{O}_{5}\right) \cdot \mathrm{H}_{2} \mathrm{O}\end{array}$ \\
\hline 4,532 & 0,030 & 2810 & 2772 \\
6,756 & 0,037 & 3396 & - \\
8,937 & 0,043 & 3866 & -
\end{tabular}

Das Molekulargewicht dieser Laminarinmodifikation stimmt gut mit demjenigen der aus Laminaria digitata dargestellten Modifikation überein, deren spezifische Drehung - 13,7 betrug; vgl. weiter die Erörterung S. 385.

$6 \mathrm{~d}$. Aus $100 \mathrm{~g}$ im November eingesammelten Materials wurde das Laminarin nach der Methode 3 extrahiert und gereinigt. Nach dem Abfiltrieren des Schwefelbleis wurde das Filtrat bis auf $60 \mathrm{ccm}$ konzentriert und mit $120 \mathrm{ccm}$ Alkohol versetzt. Der zähe Laminarinniederschlag wurde abdekantiert (die abdekantierte Flüssigkeit nach $6 \mathrm{e}$ behandelt), in etwas Wasser gelöst und durch mehrmaliges Umfällen mit je vier Volumen Alkohol gereinigt. 3,1 g Substanz; Asche 0,38\%; $0,3995 \mathrm{~g}$ gaben $0,0025 \mathrm{~g}$ Asche.

$0,951 \mathrm{~g}$, Asche abgerechnet, wurden in Wasser gelöst; Lösung $50 \mathrm{ccm}$; Drehung in $4 \mathrm{dm}$-Röhre $-1,10^{\circ}$; die spezifische Drehung ist demnach $-14,5^{\circ}$.

$$
\alpha_{\mathrm{D}}=-\frac{1,10 \cdot 50}{0,951 \cdot 4}=-14,5^{\circ}(6 \mathrm{~d}) \text {. }
$$

6 e. Die in $6 \mathrm{~d}$ abdekantierte Flüssigkeit (etwa $160 \mathrm{ccm}$ ) wurde mit $160 \mathrm{ccm}$ Alkohol versetzt, der Laminarinniederschlag in Wasser gelöst und durch mehrmaliges Umfällen mit je sechs Volumen Alkohol gereinigt. 1,0 g Substanz; Asche 1,41\%; $0,2411 \mathrm{~g}$ gaben $0,0034 \mathrm{~g}$ Asche. 
$0,731 \mathrm{~g}$, Asche abgerechnet, wurden in Wasser gelöst. Lösung $50 \mathrm{ccm}$; Drehung in $4 \mathrm{dm}$-Röhre $-1,30^{\circ}$; die spezifische Drehung ist demnach $-22,3^{\circ}$.

$$
\alpha_{\mathrm{D}}=-\frac{1,30 \cdot 50}{0,731 \cdot 4}=-22,3^{\circ}(6 \mathrm{e}) .
$$

\section{Verschiedene Laminarinmodifikationen.}

Es ist schon mehrmals hervorgehoben worden, daß es verschiedene Laminarinmodifikationen gibt, die sich von einander durch ihr Drehungsvermögen, ihr Molekulargewicht, ihre Löslichkeit in Wasser und ihre Fällbarkeit mit Alkohol unterscheiden. Hand in Hand mit einer Abnahme des numerischen Wertes der spezifischen Drehung geht eine Zunahme des Molekulargewichtes, eine $\mathrm{Ab}$ nahme der Löslichkeit in Wasser und eine Zunahme der Fällbarkeit mit Alkohol.

Diejenige Laminarinmodifikation, die eine spezifische Drehung von - 32,5 besitzt, entspricht etwa der molekularen Zusammensetzung $6\left(\mathrm{C}_{6} \mathrm{H}_{10} \mathrm{O}_{5}\right) \cdot \mathrm{H}_{2} \mathrm{O}$; bei einer spezifischen Drehung von $-22,2^{\circ}$ ist die Zusammensetzung am ehesten $12\left(\mathrm{C}_{6} \mathrm{H}_{10} \mathrm{O}_{5}\right) \cdot \mathrm{H}_{2} \mathrm{O}$, und bei einer spezifischen Drehung von etwa $-13,5$ am ehesten $17\left(\mathrm{C}_{6} \mathrm{H}_{10} \mathrm{O}_{5}\right) \cdot \mathrm{H}_{2} \mathrm{O}$. Doch ist $\mathrm{zu}$ bemerken, $\mathrm{da} B$ die beiden letzteren Bestimmungen ziemlich unsicher sind.

Die Modifikation, die einer molekularen Zusammensetzung von $17\left(\mathrm{C}_{6} \mathrm{H}_{10} \mathrm{O}_{5}\right) \cdot \mathrm{H}_{2} \mathrm{O}$ entspricht und deren spezifische Drehung etwa $-13,5$ beträgt, ist in kaltem Wasser leicht löslich. Die schwerlöslichen Modifikationen müssen demnach ein noch größeres Molekulargewicht und eine noch geringere spezifische Drehung besitzen. Wie groB das Molekulargewicht der schwerlöslichsten Laminarinmodifikation ist, weiß ich nicht, es ist aber sicher sehr hoch; auch die spezifische Drehung (bei Zimmertemperatur) ist nicht genau bestimmt worden, der numerische Wert ist aber geringer als $-7^{\circ}$.

Die hier besprochenen Modifikationen sind aber keine reinen, chemischen Individuen, sondern stellen Gemenge von verschiedenen, aber mit einander sehr nahe verwandten Kohlenhydraten dar. 
Die Modifikation, welche das geringste Molekulargewicht besitzt, ist in den untersuchten Fucoideen in verhältnismäßig geringen Mengen vorhanden. Nur bei Ascophyllum nodosum ist sie in etwas größeren Mengen angehäuft, und doch ist die Gesamtmenge des Laminarins bei dieser Alge ziemlich gering. Bei Fucus serratus, F. vesiculosus und Laminaria saccharina sind diejenigen Laminarinmodifikationen am reichlichsten vertreten, die eine spezifische Drehung von durchschnittlich $-15^{\circ}$ bis $-20^{\circ}$ besitzen; bei Laminaria digitata dagegen diejenigen, deren spezifische Drehung etwas $-12^{\circ}$ beträgt. Die in kaltem Wasser schwerlösliche Modifikation habe ich nur bei Laminaria Cloustoni gefunden.

Diejenige Modifikation, die der molekularen Zusammensetzung von $6\left(\mathrm{C}_{6} \mathrm{H}_{10} \mathrm{O}_{5}\right) \cdot \mathrm{H}_{2} \mathrm{O}$ entspricht, läßt sich noch ziemlich gut durch Zusatz von Alkohol niederschlagen. Es gibt aber solche Modifikationen, die sich aus einer Lösung nicht ausfällen lassen, wenn diese auch zehn Volumen Alkohol (bei reichlicher Gegenwart von Kochsalz) enthält: vgl. die Untersuchung über die Zuckerarten der Fucoideen S. 369.

Diese Modifikationen müssen ein niedrigeres Molekulargewicht, als der Formel $6\left(\mathrm{C}_{6} \mathrm{H}_{10} \mathrm{O}_{5}\right) \cdot \mathrm{H}_{2} \mathrm{O}$ entspricht, besitzen, und ich glaube, daß unter diesen auch eine vorliegt, welche die Zusammensetzung $2\left(\mathrm{C}_{6} \mathrm{H}_{10} \mathrm{O}_{5}\right) \cdot \mathrm{H}_{2} \mathrm{O}$ hat. Dies ist ein Disaccharid, welcher meiner Meinung nach den Ausgangspunkt der ganzen Laminarinreihe darstellt. Für diesen Disaccharid habe ich schon vorher (S. 3.70) den Namen Laminariose vorgeschlagen. Es ist mir aber nicht gelungen, diese Zuckerart herzustellen, die vorhergehende Auseinandersetzung scheint mir indessen erwiesen zu haben, daß die Annahme des Vorkommens eines solchen Disaccharides eine theoretische Notwendigkeit ist; vgl. S. 370 .

In diesem Zusammenhang möchte ich mit einigen Worten eine Untersuchung von Krefting und Torup (1909, S. 151) über ein neues Kohlenhydrat bei den Laminaria-Arten besprechen. Dieses Kohlenhydrat, welches sich besonders dadurch kennzeichnet, daß es in warmem Wasser leicht löslich war, bei Abkühlen aber wieder ausgefällt wurde, wurde von 
Krefting in folgender Weise aus einer Laminaria-Art, die er als L. digitata bestimmte, extrahiert. Das getrocknete Material wurde mit einer kalten Auflösung von Barythydrat behandelt, welche $\mathrm{Ba}(\mathrm{OH})_{2}$ im Überschuß enthielt. Nach einem Tage wurde das Extrakt abfiltriert, mit Essigsäure angesäuert und dann mehrere Tage bei einer niedrigen Temperatur stehen gelassen, wobei das Kohlenhydrat ausgefällt wurde. Zum Zwecke der weiteren Reinigung wurde es mehrmals aus warmem Wasser gefällt.

Die weitere Untersuchung dieser Substanz wurde von Torup bewerkstelligt. In bezug auf ihre Löslichkeit fand dieser Forscher, daß sie bei $0^{\circ}$ unauflöslich ist; bei +10 beträgt die Löslichkeit 1 auf 5000 Wasser, bei $+20^{\circ}$ etwa 1 auf $2000 \mathrm{Wasser}$; bei einer Temperatur von $50^{\circ}-55^{\circ}$ ist die reine Substanz in Wasser leicht löslich; in unreinem $\mathrm{Zu}$ stande ist sie schon bei einer Temperatur von $+40^{\circ}$ sehr leicht löslich. Das neue Kohlenhydrat gab keine Jodreaktion. Seine Lösung in Wasser ist linksdrehend. Die Substanz wird beim Kochen mit 2\%iger Salzsäure nach 2-2 $2 / 2$ Stunden quantitativ in Dextrose umgewandelt. Als Name dieses Kohlenhydrates wurde Kreftin vorgeschlagen (a. a. 0., S. 151, Fußnote).

Es leuchtet ein, daß das von Krefting und Torup dargestellte neue Kohlenhydrat mit derjenigen Laminarinmodifikation identisch ist, die ich bei Laminaria Cloustoni gefunden habe. Bei Laminaria digitata fehlt aber diese Modifikation. Krefting hat diese beiden Arten verwechselt; er hat L. Cloustoni, nicht, wie er behauplet, L. digitata untersucht. Dieser Forscher behauptet auch, daß das neue Kohlenhydrat bei der untersuchten Laminaria-Art nur im November, nicht aber im August vorkommt. Diese Behauptung steht wahrscheinlich damit in Zusammenhang, daß die Menge dieses Kohlenhydrats im November größer ist als im August, und daß es deshalb leichter ist, das Kohlenhydrat aus im November eingesammeltem Materiale herzustellen, als aus im August eingesammeltem. - Bei meinen Untersuchungen über Laminaria Cloustoni habe ich nur im August eingesammeltes Material zur Verfügung gehabt; es ist mir aber gelungen nach- 
zuweisen, daß die schwerlösliche Laminarinmodifikation bei der in Rede stehenden Alge auch während dieser Jahreszeit vorkommt.

Hinsichtlich der von Krefting benutzten Extraktionsmethode ist nur zu sagen, daß sie zum Zwecke der Darstellung des Kohlenhydrates nicht besonders geeignet ist, und zwar eben deshalb, weil es nicht gelingt, alle schleimigen Membranbestandteile durch Zusatz von Barythydrat $\mathrm{zu}$ binden. Diese schleimigen Bestandteile werden erst von Bleiessig völlig entfernt.

Auch eine Untersuchung von Hansteen (1892, S. 344) ist in diesem Zusammenhang mit einigen Worten zu berühren. Nach diesem Forscher sollen die Fukosanblasen oder, wie er sie nennt, Fukosankörner aus einem Kohlenhydrat bestehen, das der Gruppe $\left(\mathrm{C}_{6} \mathrm{H}_{10} \mathrm{O}_{5}\right)$ n angehört. Diesen Stoff nennt er Fukosan. Er extrahierte das Fukosan aus Fucus serratus, indem er die zerhackten Thallusteile in destilliertem Wasser 72 Stunden lang bei einer Temperatur von $75^{\circ}$ extrahierte. Das Extrakt wurde mit Bleizucker gefällt, mit Schwefelwasserstoff entbleit, und nach dem Abfiltrieren des Schwefelbleis bis auf etwa $1 / 10$ seines ursprünglichen Volumens eingeengt. Die auf diese Weise erhaltene Lösung wurde entweder mit Alkohol nach Ansäuerung mit Salzsäure, oder mit Alkoholäther nach Ansäuerung mit Essigsäure gefällt. Der Niederschlag soll aus dem genannten Kohlenhydrat Fukosan bestehen. Schon bei einer früheren Gelegenheit habe ich aber darauf aufmerksam gemacht (Kylin, 1913, S. 179), daß der Niederschlag ein Gemenge von zwei verschiedenen Kohlenhydraten darstellt. Er besteht nämlich einerseits aus Laminarin, andererseits aus einem Membranstoff, das Fukoidin, welches durch Zusatz von Bleizucker aus dem wässerigen Extrakte nicht zu entfernen ist. Belege für die Richtigkeit dieser Behauptung können wir aus Hansteens oben erwähnter Arbeit entnehmen. Er hat nämlich die spezifische'Drehung seines Fukosans auf $-43,40$ bestimmt. Nun beträgt aber die spezifische Drehung des bei Fucus serratus vorkommenden Laminarins durchschnittlich $-15^{\circ}$ bis $-20^{\circ}$, das Fukoidin ist aber sehr stark 
linksdrehend ( $\alpha_{\mathrm{D}}$ etwa $-220^{\circ}$ ), und sicher bestand demnach das Hansteensche Fukosan aus einer Mischung von Laminarin und Fukoidin. - In meinem Sinne des Wortes ist das Fukosan ein mit den Gerbstoffen verwandter Stoff; vgl. Kylin 1912 und 1913.

D. Die Einwirkung der Diastase auf Laminarin.

Die Diastaselösung wurde durch Extrahieren von Malz in Wasser dargestellt. Sie verzuckerte schnell eine Stärkelösung. Von der Diastaselösung wurden $10 \mathrm{ccm}$ abgemessen und mit $20 \mathrm{ccm}$ einer Laminarinlösung aus Laminaria saccharina $\left(-0,55^{\circ}\right.$ in $2 \mathrm{dm}$-Röhre) versetzt. Einzelheiten sind aus der Tabelle zu entnehmen. Die Versuche wurden im Wärmeschrank bei $+35^{\circ}$ stehen gelassen.

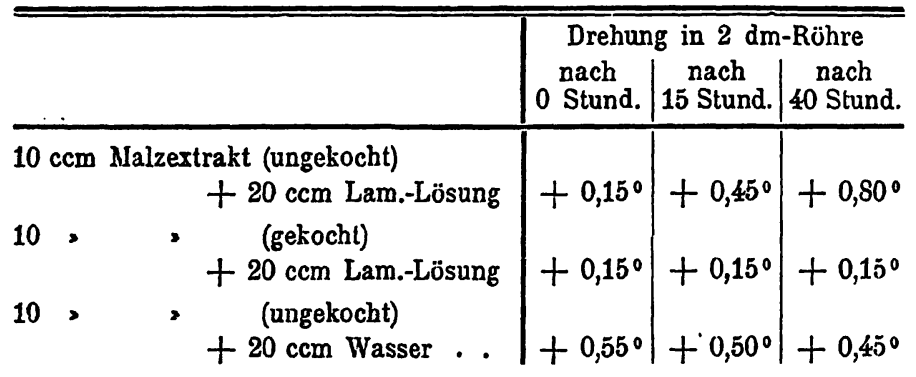

Aus den oben gegebenen Angaben ist ohne weitere Erörterungen die Tatsache zu entnehmen, daß das Laminarin von Diastase aus Malz verzuckert wird.

Nehrere Versuche habe ich gemacht, teils aus getrockneten, zerkleinerten, teils aus frischen, zerschnittenen Thallusteilen von Ascophyllum nodosum, Fucus serratus und Laminaria digitata ein Enzym zu extrahieren, welches das Laminarin verzuckern könnte, aber immer mit negativem Erfolg, und doch scheint es mir vollkommen sicher, daß ein solches Enzym wirklich in den untersuchten Fucoideen vorhanden ist. Die ungeheueren Mengen schleimiger Membranbestandteile machen aber die einschlägigen Untersuchungen sehr schwierig, und sind Schuld daran, daß ich keinen Er- 
folg erzielt habe. Wahrscheinlich ist in den Fucoideen ein besonderes Enzym ausgebildet worden, welches die Aufgabe hat, das für einige Fucoideen eigentümliche Kohlenhydrat Laminarin $\mathrm{zu}$ spalten.

Torup (siehe Krefting und Torup, 1909, S. 155) ist es aber gelungen, aus frischer Laminaria ein Enzym zu extrahieren, welches das Laminarin in Dextrose verwandelt. Nach diesem Forscher soll das Laminarin von Ptyalin oder von Diastase aus Pankreas oder Malz nicht angegriffen werden.

\section{E. Quantitative Bestimmung des Laminarins.}

Die Laminarinmengen der untersuchten Fucoideen habe ich in folgender Weise zu bestimmen versucht.

$10 \mathrm{~g}$ an der Luft getrocknetes, zerkleinertes Material wurden mit $500 \mathrm{ccm}$ Wasser versetzt, eine Stunde in siedendem Wasserbade gekocht und dann bis zum nächsten Tag stehen gelassen. Nach dem Abdekantieren des Extraktes wurde das Material noch einmal auf dieselbe Weise mit $500 \mathrm{ccm}$ Wasser extrahiert, dann abfiltriert und gut ausgewaschen. Die vereinigten Extrakte wurden konzentriert, mit Bleiessig gefällt und auf $100 \mathrm{ccm}$ ergänzt. Nach dem Abfiltrieren wurde die optische Drehung des Filtrates bestimmt. Von dem Filtrate wurden $40 \mathrm{ccm}$ abgemessen, mit Schwefelsäure bis etwa $5 \%$ versetzt (mit Rücksicht darauf, daß die Flüssigkeit eine nicht unbedeutende Menge Bleiacetat enthielt) und vier Stunden in siedendem Wasserbade gekocht. Nach der Hydrolyse wurde Wasser bis genau $40 \mathrm{ccm}$ zugesetzt und das Bleisulfat abfiltriert. Das Filtrat wurde dann in bezug auf sein Drehungsvermögen und seine Reduktionsfähigkeit (nach Fehling) untersucht. Die Reduktionsfähigkeit gibt an, wieviel Zucker (Dextrose) nach der Hydrolyse vorhanden ist, und da das Laminarin während der Hydrolyse quantitativ in Dextrose umgewandelt worden ist, ist die Reduktionsfähigkeit auch ein Maßstab für die Laminarinmenge, die vor der Hydrolyse vorkam, und mit Rücksicht auf die extrahierte Materialmenge und das Volumen des mit Bleiessig gefällten Extraktes läßt sich die Laminarinmenge in Prozent des Trockengewichts berechnen. 
$\mathrm{Zu}$ dieser Bestimmung ist $\mathrm{zu}$ bemerken, daß die geringe Menge Dextrose, die vor der Hydrolyse vorhanden ist, als Laminarin berechnet wird. Die Bestimmung gilt eigentlich für die Summe der von Bleiessig nicht fällbaren Kohlenhydrate; da aber die Dextrosemenge sehr gering ist, ist diese Summe als der des Laminarins gleich $\mathrm{zu}$ betrachten. Noch $\mathrm{zu}$ bemerken ist, daß beim Zusatz des Bleiessigs eine große Menge Niederschlag gebildet wird, was es schwierig macht, die Extraktmenge bis $100 \mathrm{ccm}$ genau nachzufüllen. Es wäre vielleicht besser, die Extraktmenge bis 150 oder $200 \mathrm{ccm}$ zu ergänzen.

Die Angaben der quantitativen Laminarinbestimmung sind in der Tabelle 4 zusammengestellt. Die Laminarinmengen sind auf Grund der Angaben der Reduktionsfähigkeit nach der $\mathrm{Hy}-$ drolyse berechnet.

\section{Tabelle 4.}

Quantitative Bestimmung des Laminarins.

\begin{tabular}{|c|c|c|c|c|c|c|c|}
\hline & $\begin{array}{c}\text { Trocken- } \\
\text { gewicht } \\
\text { des } \\
\text { Materials } \\
\text { g }\end{array}$ & $\begin{array}{c}\text { Ex- } \\
\text { trakt- } \\
\text { menge } \\
\mathrm{ccm}\end{array}$ & $\begin{array}{c}\text { Optische } \\
\text { in } 2 \mathrm{dn} \\
\text { vor der } \\
\text { Hydrolyse }\end{array}$ & $\begin{array}{l}\text { Drehung } \\
\text { m-Röhre } \\
\text { nach der } \\
\text { Hydrolyse }\end{array}$ & \begin{tabular}{|l} 
Zucke \\
in \% \% \\
net na \\
opti- \\
schen \\
Dre- \\
hung
\end{tabular} & $\begin{array}{l}\text { rmenge- } \\
\text { berech- } \\
\text { ch der } \\
\begin{array}{|c|}\text { Reduk- } \\
\text { tions- } \\
\text { fähig- } \\
\text { keit }\end{array}\end{array}$ & $\begin{array}{l}\text { Lami- } \\
\text { narin- } \\
\text { menge in } \\
\% \text { des } \\
\text { Trocken- } \\
\text { gewichtes }\end{array}$ \\
\hline Ascophyllum nodosum & 8,74 & 100 & $-0,25^{\circ}$ & $+0,64^{\circ}$ & 0,61 & 0,62 & 7,1 \\
\hline Fucus serratus ... & 8,82 & 100 & $-0,68^{\circ}$ & $+1,80^{\circ}$ & 1,71 & 1,70 & 19,3 \\
\hline , vesiculosus .. & 8,92 & 100 & $-0,27^{\circ}$ & $+0,68^{\circ}$ & 0,65 & 0,67 & 7,5 \\
\hline Laminaria digitata . . & 8,84 & 100 & $-0,41^{\circ}$ & $+2,03^{\circ}$ & 1,93 & 1,88 & 21,4 \\
\hline saccharina & 8,99 & 100 & $-1,05^{\circ}$ & $+3,35^{\circ}$ & 3,18 & 3,14 & 35,0 \\
\hline , & 8,98 & 200 & $-0,52^{\circ}$ & $+1,58^{\circ}$ & 1,50 & 1,50 & 33,4 \\
\hline
\end{tabular}

Die Angaben der Laminarinmengen gelten für im August eingesammeltes Material.

Aus den Angaben geht hervor, daß die Laminarinmenge am reichlichsten bei Laminaria saccharina ist, welche Alge etwa 34\% Laminarin enthält. L. digitata und Fucus serratus enthalten auch bedeutende Laminarinmengen, bezichungs- . weise etwa 21 und 19\%, während die beiden Arten Fucus vesiculosus und Ascophyllum nodosum nur verhältnismäßig geringe Mengen, etwa $7 \%$, enthalten. 
Die Tabelle 4 bietet aber auch in einer anderen $\mathrm{Be}$ ziehung als für die quantitative Laminarinbestimmung ein besonderes Interesse dar. Man beobachte, daß die nach der Hydrolyse auftretenden Zuckermengen, als Dextrose berechnet, innerhalb der Fehlergrenzen dieselben Werte haben, ob sie nun nach der optischen Drehung oder nach der Peduktionsfähigkeit berechnet werden. Aus dieser Tatsache muB man den Schluß ziehen, daß nur Dextrose vorhanden ist, und daß Lävulose nicht beigemischt sein kann. Die Angaben in der Tabelle 4 bestätigen also die früher gemachte Behauptung, daß Lävulose und Rohrzucker, welche Zuckerart bei der Hydrolyse Dextrose und Lävulose gibt, bei den untersuchten Fucoideen nicht vorhanden sind; vgl. S. 367.

F. Die physiologische Bedeutung des Laminarins.

In meinem früheren Aufsatz "Zur Biochemie der Meeresalgen» habe ich die Meinung ausgesprochen, daß das Laminarin einen Reservestoff darstellt, welcher physiologisch der Stärke der höheren Pflanzen entspricht, und ich möchte in diesem Zusammenhang diese Behauptung etwas näher erörtern. Am besten scheint es mir, zuerst mit einigen Worten die Lebensverhältnisse der Laminaria-Arten zu besprechen, und zwar mit besonderer Rücksicht auf die beiden Arten Laminaria digitata und Laminaria saccharina und auf ihr Auftreten an der schwedischen Westküste.

Die Laminaria-Arten sind mehrjährige Algen, aber nur das Heftorgan und der Stamm sind perennierend, das Blatt wird dagegen einmal des Jahres gewechselt. Der Blattwechsel findet während des Winters statt. Im November findet man schon Individuen, bei denen das junge Blatt, welches sich zwischen das alte Blatt und den Stamm einschaltet, etwa dezimeterlang ist. Während der Wintermonate wächst das junge Blatt mehr und mehr, das alte Blatt wird dagegen nach und nach aufgelöst. Ende März oder spätestens im April hat das junge Blatt beinahe seine definitive Größe erreicht und von dem alten Blatte sind nur geringe Reste übrig. 
Der Winter ist auch die Zeit der Fortpflanzung unserer Laminaria-Arten. Schon Mitte Oktober habe ich Sporangiensori mit entwickelten Schwärmzellen gesehen. Die Sporangienentwicklung setzt dann während des ganzen Winters fort und noch im April findet man an den vorhandenen Resten des alten Blattes Sporangiensori.

Während des Winters geht demnach der Zuwachs und die Fortpflanzung von statten. Also finden zwei Lebenstätigkeiten, die eine reichliche Zufuhr organischer Nahrung fordern, während einer Zeit statt, wo die Neubildung solcher Nahrung sehr gering ist und zu Zeiten sicher vollkommen stillsteht. Die Laminaria-Arten müssen demnach während einer anderen Jahreszeit diejenigen Mengen organischer Nahrung bereiten, die sie im Winter für den Zuwachs und die Fortpflanzung nötig haben. Im Frühling ist das junge Blatt ausgebildet, der Sommer ist die Zeit der Assimilation, die Zeit der Bildung organischer Nahrung, und im Herbst ist das Blatt mit reichlichen Mengen Reservestoffe versehen, die während des Winters verbraucht werden. Der wichtigste dieser Reservestoffe ist das Laminarin und ich habe schon erwiesen, daß die LaminariaArten im August große Mengen Laminarin enthalten. Es erübrigt aber noch $\mathrm{zu}$ beweisen, daß das Laminarin während des Winters verbraucht wird und daß das junge Blatt keine erwähnenswerten Mengen davon enthält.

Ende März eingesammelte Laminaria wurde in bezug auf ihren Gehalt von Laminarin analysiert und zwar sowohl das alte wie das junge Blatt. Von den alten Blättern wurden die mehr oder weniger-aufgelösten Randpartien weggeschnitten und von den jungen Blättern nur das mittlere Drittel verwendet. Das Material wurde dann auf die schon oben beschriebene Weise analysiert.

Durch die Angaben in Tabelle 5 ist demnach erwiesen, daß das Laminarin im Laufe des Winters verbraucht wird und daß das junge Blatt nur sehr geringe Laminarinmengen enthält. Das Laminarin ist also ein Reservestoff, der während des Sommers gebildet, während des Winters dagegen zum $Z$ wecke des Zuwachses und der Fortpflanzung verbraucht wird. 
Tabelle 5.

Quantitative Bestimmung des Laminarins. Material Ende März eingesammelt.

\begin{tabular}{|c|c|c|c|c|c|c|}
\hline & $\begin{array}{c}\text { Trocken- } \\
\text { gewicht } \\
\text { des } \\
\text { Materials } \\
\text { g }\end{array}$ & $\begin{array}{c}\text { Ex- } \\
\text { trakt- } \\
\text { menge } \\
\text { ccm }\end{array}$ & $\begin{array}{c}\text { Optische } \\
\text { in } 2 \mathrm{dn} \\
\text { vor der } \\
\text { Hydrolyse }\end{array}$ & $\begin{array}{l}\text { Drehung } \\
\text { n-Röhre } \\
\text { nach der } \\
\text { Hydrolyse }\end{array}$ & $\begin{array}{c}\text { Zuckermenge } \\
\text { in } \% \text { berech- } \\
\text { net nach der } \\
\text { optischen } \\
\text { Drehung }\end{array}$ & $\begin{array}{l}\text { Lami- } \\
\text { narin- } \\
\text { menge in } \\
0 / 0 \text { des } \\
\text { Trocken- } \\
\text { gewichtes }\end{array}$ \\
\hline $\begin{array}{l}\text { Laminaria digitata } \\
\text { altes Blatt } . .\end{array}$ & 9,06 & 200 & $-0,04^{\circ}$ & $+0,10^{\circ}$ & 0,10 & 2,0 \\
\hline $\begin{array}{l}\text { Laminaria digitata } \\
\text { junges Blatt . . }\end{array}$ & 9,24 & 200 & $-0,06^{\circ}$ & $+0,06^{\circ}$ & 0,06 & 1,3 \\
\hline $\begin{array}{c}\text { Laminaria saccharina } \\
\text { altes Blatt - }\end{array}$ & 9,06 & 200 & $-0,05^{\circ}$ & $+0,04^{\circ}$ & 0,04 & 0,9 \\
\hline $\begin{array}{c}\text { Laminaria saccharina } \\
\text { junges Blatt . }\end{array}$ & 9,16 & 200 & $-0,01^{\circ}$ & $+0,02^{\circ}$ & 0,02 & 0,4 \\
\hline
\end{tabular}

Bei den Laminaria-Arten kommt aber auch Mannit (etwa $7 \%$ ) vor und dieser Stoff ist ebenfalls als ein Reservestoff $\mathrm{zu}$ betrachten.

Ascophyllum nodosum, Fucus serratus und F. vesiculosus enthalten außer Laminarin und Mannit auch Fett (vgl. Kylin, 1912, S. 22). Die Fettmengen sind besonders bei Ascophyllum reichlich und ersetzen wesentlich das Laminarin, von welchem Stoff im August nur etwa 7\% vorhanden ist. Fucus vesiculosus entbielt auch nur etwa $7 \%$ Laminarin, aber geringere Mengen Fett als Ascophyllum, was damit in Zusammenhang steht, daß die Fortpflanzung bei der letzteren Art im Winter und Frühling vonstatten geht, bei Fucus vesiculosus dagegen wesentlich in die Sommermonate verlegt ist. Die Fettmengen bei Fucus serratus und Fucus vesiculosus sind einander etwa gleich, die erstere Art ist aber viel reicher an Laminarin als die letztere, was wohl darauf beruht, daß die Fortpflanzung bei Fucus serratus im Winter stattfindet.

Es erübrigt jetzt, mit einigen Worten den Assimilationsprozeß der Fucoideen zu besprechen.

In bezug auf die Florideen wurde schon früher (S. 362) darauf hingewiesen, daß diese Algen bei ihrer Assimilation einfache Zuckerarten bilden, daß der Zucker sich aber schnell 
zu Stärke kondensiert. Die Florideen stimmen demnach wesentlich mit denjenigen höheren Pflanzen überein, die sogenannte sStärkeblätter > besitzen.

Die Fucoideen bilden aber nie Stärke, und sie können also hinsichtlich ihres Assimilationsprozesses nicht unter die sStärkeblätter» eingereiht werden. Es gelingt aber auch nicht, diese Algen unter die :Zuckerblätter» einzureihen, da Zucker nie angehäuft wird, sondern nur in sehr geringen Mengen vorkommt. Die Fucoideen müssen deshalb als ein neuer Typus aufgestellt werden. Die Assimilationsprodukte sind bei den Fucoideen in ähnlicher Weise wie bei den höheren Pflanzen und den Florideen einfache Zuckerarten, diese werden aber niemals angehäuft, sondern schnell kondensiert, abernicht zu Stärke wie in den «Stärkeblättern,, sondern zu einem Gemenge mit einander nahe verwandter Kohlenhydrate, welches Gemenge Laminarin genannt worden ist. Das Laminarin vertritt bei den Fucoideen die Stärke der «Stärkeblätter».

Die Frage, welche Stoffe die Pflanzen bei ihrer Assimilation bilden, wurde von Schimper (1885, S. 787) hinsichtlich der höheren Pflanzen folgendermaßen beantwortet: «Überall im Assimilationsprozeß wird Glykose gebildet». In der vorliegenden Untersuchung habe ich nachweisen können, daß diese Behauptung von Schimper auch in bezug auf die Florideen und die Fucoideen richtig ist, und ich möchte jetzt einen Schritt weiter gehen, indem ich behaupte, daß einfache Zuckerarten im Assimilationsproze $B$ aller Pflanzen gebildet werden, und daß die einfachen Zuckerarten die einzigen Stoffe sind, die im richtigen Sinne des Wortes als Assimilationsprodukte $z u$ bezeichnen sind.

Ich will auch darauf hinweisen, daß die in den letzten zehn Jahren besonders von Willstätter betriebenen Untersuchungen über die Chromatophorenfarbstoffe der Planzen das interessante Ergebnis gebracht haben, daß Chlorophyll in allen assimilierenden Pflanzen vorhanden ist, soweit sie bisher untersucht worden sind, und ich glaube jetzt behaupten zu können, dab alle chlorophyllführenden Pflanzen bei ihrer 
Photosynthese als Assimilationsprodukte einfache Zuckerarten bilden.

Die Assimilationsprodukte, d. h. die einfachen Zuckerarten, werden dann bei den verschiedenen Pflanzen in verschiedenen Weisen weiter zu Reservest offen verarbeitet. Eine große Anzahl höherer Pflanzen bilden Stärke (die «Stärkeblätter`), andere bilden dagegen gar nicht oder nur geringe Mengen Stärke (die «Zuckerblätter») aber wahrscheinlich andere amorphe, wasserlösliche Kohlenhydrate. Die Untersuchungen sind aber auf diesem Gebiete viel $\mathrm{zu}$ lückenhaft, um etwas sicheres sagen zu können. Neue Untersuchungen wären sehr erwünscht. Ich will nur daran erinnern, daß die Liliaceen, die im allgemeinen Stärke nicht bilden, Reservestoffe inulinartiger Natur besitzen, daß aber meines Wissens die Frage noch lange nicht erledigt ist, inwiefern diese Stoffe schon in den Blättern auftreten.

Bei den Chlorophyceen treten teils Stärke, teils Fett als Reservestoffe auf, bei den Florideen Stärke (Florideenstärke), bei den Fucoideen, soweit sie bisher untersucht worden sind, Laminarin $^{1}$ ) und bei einigen auch Fett. Den Literaturangaben nach zu urteilen tritt Fett als Reservestoff bei Diatomeen auf; bei Cyanophyceen ist Glykogen nachgewiesen worden.

Ich kann nicht umhin, in diesem Zusammenhang auch mit einigen Worten die so genannten Fukosanblasen zu besprechen. - Hinsichtlich der Literaturangaben verweise ich auf meinen Aufsatz "Über die Inhaltskörper der Fucoideen».

Die Fukosanblasen, von Hansteen (1892) Fukosankörner, von Crato (1892) Physoden genannt, werden besonders durch folgende mikrochemische Reaktionen gekenntzeichnet.

1. Sie werden von Vanillinsalzsäure rot gefärbt.

1) Es ist zu bemerken, daß nur mehrjährige Fucoideen untersucht worden sind. Bei den Untersuchungen über das Vorkommen von Mannit habe ich einige Beobachtungen gemacht, die mir dafür zu sprechen scheinen, daß Laminarin nicht bei allen Fucoideen vorhanden ist, z. B. nicht bei Halidrys siliquosa, Chorda filum, Spermatochnus paradoxus (die beiden letzteren sind einjährige Algen). Sicheres kann ich aber in dieser Beziehung nicht sagen. Neue Untersuchungen sind dringend nötig, es fehlt mir aber gegenwärtig an Material. 
2. Sie werden von Osmiumsäure geschwärzt, oder wenn sie bei Zusatz dieses Reagens zerplatzen, wird der ganze Zellinhalt geschwärzt.

3. Sie speichern lebhaft Methylenblau und Methylviolett an.

Die Fukosanblasen enthalten wahrscheinlich mehrere in Wasser gelöste Stoffe, es ist aber ein bestimmter Stoff, der die oben erwähnten mikrochemischen Reaktionen veranlabt. Diesen Stoff habe ich Fukosan genannt, und habe auch nachweisen können, daß er mit den Gerbstoffen verwandt ist, und daß es eben dieser Stoff ist, der bei seiner Oxydation zur Entstehung der braungefärbten Produkte führt, die Phykophäin genannt worden sind.

Nach Hansteen (1900, S. 611) entstehen die Fukosanblasen dadurch, daß unter der Einwirkung des Lichtes an der Oberfläche der Chromatophoren kleine lichtbrechende Körnchen sich bilden, die dann abgeschnürt und in das Protoplasma hinausgeführt werden. Betreffs der Entstehung der Fukosanblasen bei Dictyota schreibt Hunger (1902, S. 72): «Auch hier beobachtet man mit ein wenig Geduld sehr deutlich, daß die Neubildung der «Inhaltskörper» an der Oberfläche des Phaeoplasten durch vorherige Anschwellung und darauffolgende $A b-$ schnürung eines kleinen, lichtbrechenden Gebildes vor sich geht *. Die direkte Beobachtung, daß eine Fukosanblase von einem Chromatophoren sich abgeschnürt hätte, habe ich nicht gemacht, wohl aber andere Beobachtungen, die für die Richtigkeit der Ansicht von Hansteen und Hunger zu sprechen scheinen. Die jungen Fukonsanblasen vergrößern sich wahrscheinlich dadurch, daß mehrere mit einander zusammenschmelzen. Die größeren Fukosanblasen befinden sich $z$. B. bei A sperococcus bullosus und Pylaiella litoralis in einer traubenförmigen Ansammlung in der Mitte der Zelle, in den Assimilationszellen der Fucus-Arten dagegen im äußeren Teile derselben; die Chromatophoren sind zu dem hinteren Teile der Zelle verdrängt.

Hansteen bebauptet, die Fukosankörner beständen aus einem Kohlenhydrat, das er Fukosan nennt, und stellten das Assimilationsprodukt dar. Insofern will ich Hansteen recht geben, als die Bildung der Fukosanblasen (Fukosankörner) in

\footnotetext{
Hoppo-Segler' Zeitechrift 1. phseiol. Chemie. XCIV.
} 
irgend einer Beziehung $\mathrm{zu}$ dem Assimilationsprozeß steht, der charakteristische Inhalt der Blasen, das Fukosan, ist aber kein Kohlenhydrat und stellt nicht das Assimilationsprodukt dar.

Wahrscheinlich nehmen die Fukosanblasen während ihrer Entstehung das Laminarin auf, welches sich in den Chromatophoren gebildet hat, und führen es aus diesen in die Zelle hinaus. Das Laminarin bleibt aber nicht in den Fukosanblasen eingeschlossen, sondern tritt heraus und wandert von den Assimilationszellen zu dem Speicherungsgewebe. Die Fukosanblasen wandern nicht von Zelle zu Zelle. Um sicher entscheiden zu können, ob das Laminarin sich dabei zuerst zu Dextrose spaltet oder als Laminarin wandert, fehlt es mir an Beobachtungen. Im Speicherungsgewebe wird das Laminarin magaziniert. Es ist nicht notwendig, daß es dabei wieder von Fukosanblasen aufgenommen wird. In den besonders laminarinreichen Laminaria-Arten sind die Fukosanblasen nur spärlich vorhanden und fehlen beinahe vollkommen im Speicherungsgewebe. Ascophyllum nodosum und Fucus vesiculosus besitzen eine reiche Menge Fukosanblasen, haben aber nur verhältnismäßig geringe Mengen Laminarin.

VII. Die Membranbestandteile der Fucoideen.

1. Fukoidin.

Mit dem Namen Fukoidin habe ich (1913, S. 193) einen bei den Fucoideen vorkommenden Membranschleim bezeichnet, welcher aus einer wässerigen Lösung nicht von Bleizucker, wohl aber von Bleiessig gefällt wird.

Diese Substanz kommt besonders reichlich bei den Laminaria-Arten vor, und stellt eben denjenigen sehr schleimigen Stoff dar, der in den Schleimkanälen dieser Algen vorhanden ist. Es ist auch allen Algologen wohl bekannt, daß aus den frisch zerschnittenen Blättern der Laminaria-Arten ein fadenziehender, schleimiger Stoff hervorquillt. Dieser Stoff ist eben Fukoidin.

- Außer bei den Laminaria-Arten ist das Fukoidin in reichlichen Mengen bei Fucus serratus vorhanden, etwas 
weniger reichlich bei Fucus vesiculosus. Bei Ascophyllum nodosum kommt es dagegen nur in geringen Mengen vor.

Zum Zwecke des besseren Verständnisses der folgenden Darstellung ist schon hier zu bemerken, daß das Fukoidin das Calciumsalz einer Säure ist, die ich Fukoidinsäure nenne. Als Material für die Herstellung des Fukoidins habe ich Laminaria digitata gebraucht.

Wird getrocknetes, zerkleinertes Material mit Wasser übergossen, quillt es sehr stark auf, und man bekommt eine äußerst schleimige, wässerige Lösung, die sich garnicht filtrieren läßt. Das Fukoidin ist für die Schleimigkeit in ersterer Linie verantwortlich. Wird dagegen das Material in siedendem Wasserbade extrahiert, erhält man ein Extrakt, das freilich ziemlich schleimig ist, aber bedeutend weniger als beim Extrahieren bei Zimmertemperatur und das sich filtrieren läßt, wenn auch ziemlich langsam. Diese Erscheinung erkläre ich auf folgende Weise. Beim Erhitzen im siedenden Wasserbade wird das Fukoidin, d. h. das Calciumsalz der Fukoidinsäure, nach und nach in ein Alkalisalz umgesetzt, und die Schleimigkeit des Alkalisalzes ist bedeutend geringer als die des Calciumsalzes.

Das Fukoidin ist in Alkohol von 20-30\% ziemlich löslich, und man erhält deshalb, wenn man getrocknetes Material mit Alkohol von dieser Stärke versetzt, nach und nach ein äußerst schleimiges Extrakt. In diesem Falle werden die Membranbestandteile Algin und Fucin, die ich unten besprechen werde, nicht gelöst. Versetzt man die alkoholische Lösung mit Baryumacetat, erhält man einen voluminösen Niederschlag, der aus dem Baryumsalz der Fukoidinsäure besteht (vgl. die Methode 2 für die Laminarindarstellung S. 373). Das Fukoidin ist in Alkohol von 50\% Stärke noch nicht vollkommen unlöslich.

Wird getrocknetes, zerkleinertes Material mit Lösungen von Baryum- oder Kupfersalzen oder mit neutralem Bleiacetat behandelt, quillt es ebenfalls bedeutend auf, nicht aber in so hohem Grade wie bei der Behandlung mit Wasser. Das Fukoidin wird auch in diesen Fällen extrahiert, da die Fukoidinsäure 
bei Behandlung mit den erwähnten Salzen keine wasserunlöslichen Verbindungen gibt. Wird anstatt neutralen Bleiacetats basisches verwendet, quillt das Material nicht auf, und das Fukoidin geht nicht in Lösung. Diese Beobachtungen bestätigen die oben angeführte Angabe, daß eine wässerige Fukoidinlösung nicht von Bleizucker, wohl aber von Bleiessig gefällt wird. $\mathrm{Zu}$ bemerken ist aber, daß das Fukoidin aus einem bei Zimmertemperatur dargestellten Extrakte bei Zusatz von Bleizucker zum großen Teile niedergeschlagen wird. Dies steht wahrscheinlich damit im Zusammenhang, daß es von anderen von Bleizucker erzeugten Niederschlägen mitgerissen wird.

Säuert man eine bei Zimmertemperatur dargestellte Fukoidinlösung mit Salzsäure an, so geht die Schleimigkeit in hohem Grade verloren. Diese Erscheinung erklärt sich dadurch, daß die Salzsäure die Fukoidinsäure frei macht, und daß die Schleimigkeit der freien Säure bedeutend geringer ist als die des Calciumsalzes (d. h. des Fukoidins).

Die Fukoidinlösung wird von $\mathrm{FeCl}_{3}$ gefällt. Der Niederschlag ist in Essigsäure schwer löslich; löst sich aber leicht in Salzsäure.

Die Fukoidinlösung wird von Leimlösung nach Zusatz von Essigsäure gefällt; der Niederschlag löst sich bei Zusatz

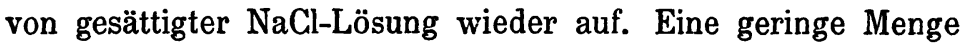
Kochsalz ist für die Entstehung des Niederschlages unbedingt notwendig.

Das Fukoidin möglichst frei von anderen organischen Verbindungen herzustellen, habe ich in folgender Weise versucht. Getrocknetes, zerkleinertes, schon vorher in 50\% igem Alkohol extrahiertes Material wurde mit einer größeren Menge Alkohol von $20 \%$ Stärke versetzt, während einiger Tage mehrmals durchgeschüttelt, und dann eine längere Zeit (3 Monate) stehen gelassen. Das vollkommen klare, etwas braungelblich gefärbte Extrakt wurde abgegossen (an ein Filtrieren war nicht zu denken) und mit dreiviertel Volumen Alkohol versetzt, wodurch das Fukoidin niedergeschlagen wurde. Der Niederschlag wurde durch ein Seidentuch abfiltriert, in Wasser wieder gelöst und durch Zusatz von einem Volumen Alkohol ausgefällt. 
Dies Verfahren wurde, um das Laminarin so gut wie möglich $z u$ entfernen, noch ein paarmal wiederholt. Etwas Kochsalz mußte dabei auch zugesetzt werden, um einen Niederschlag zu erzeugen. Der Niederschlag wurde schließlich ausgepreßt und getrocknet. 0,5 g Substanz; 28,9\% Asche; 0,0969 g gaben $0,0280 \mathrm{~g}$ Asche. Die Asche bestand hauptsächlich aus Sulfaten; etwas Calciumcarbonat war auch vorhanden.

$0,092 \mathrm{~g}$, Asche abgerechnet, im Exsikkator getrocknet, wurden in Wasser gelöst; Lösung $50 \mathrm{ccm}$; Drehung in $2 \mathrm{dm}-$ Röhre $-0,81$; die spezifische Drehung ist demnach $-220^{\circ}$.

$$
\alpha_{\mathrm{D}}=-\frac{0,81 \cdot 50}{0,092 \cdot 2}=-220^{\circ} \text {. }
$$

$0,097 \mathrm{~g}$, Asche abgerechnet, bei $110^{\circ}$ getrocknet, wurden in Wasser gelöst; Lösung $50 \mathrm{ccm}$; Drehung in $2 \mathrm{dm}$-Röhre $-0,83^{\circ}$; die spezifische Drehung ist demnach $-219^{\circ}$.

$$
\alpha_{\mathrm{D}}=-\frac{0,83 \cdot 50}{0,097 \cdot 2}=-219^{\circ} \text {. }
$$

Die spezifische Drehung des Fukoidin oder richtiger die der Fukoidinsäure beträgt demnach etwa $-220^{\circ}$. Die Substanz kann ohne Veränderung der optischen Drehung bei $+110^{\circ}$ getrocknet werden. Dies ist besonders hervorzuheben, weil die Schleimigkeit der Lösung derjenigen Substanz, die bei $+110^{\circ}$ getrocknet worden war, bedeutend geringer war als die der Lösung der im Exsikkator getrockneten Substanz. Die letztere Lösung wurde mit drei Tropfen Salzsäure angesäuert und mit dem Glasstab umgerührt. Die große Schleimigkeit ging dabei schnell verloren. Die optische Drehung veränderte sich aber nicht, und war nach einem Tage noch nicht verändert. Dies steht in Übereinstimmung mit der oben gemachten Behauptung, daß bei Zusatz von Salzsäure die Fukoidinsäure frei gemacht wird, und daß die Schleimigkeit der freien Säure bedeutend geringer ist als die des Fukoidins.

In folgender Weise habe ich versucht, die Fukoidinsäure rein darzustellen. An der Luft getrocknetes, zerkleinertes Material wurde mit Wasser übergossen und dann einige, Stunden im siedenden Wasserbade gekocht. Das Extrakt wurde mit 
Baryumacetat versetzt, wobei das Algin (siehe unten) niedergeschlagen wurde. Der Niederschlag wurde abfiltriert, es gelang aber nicht (oder nur mit großen Schwierigkeiten) ein klares Filtrat zu bekommen, da das fein verteilte Baryumsulfat durch das Filtrum passierte. Das Filtrat wurde dann mit einem halben Volumen Alkohol versetzt, wobei die Fukoidinsäure in Form ihrer Baryumverbindung niedergeschlagen wurde. Der Niederschlag wurde in salzsäuresaurem Wasser gelöst und die Lösung mit einem Volumen Alkohol gefällt. Dies Verfahren wurde noch einigemal wiederholt, um das Laminarin gut zu entfernen (eine hinreichende Menge $\mathrm{NaCl}$ muß vorhanden sein, um einen Niederschlag zu erhalten). Es ist mir aber trotz großer Mühe nicht gelungen, auf diese Weise eine vollkommen klare Lösung von der Fukoidinsäure zu bekommen, sondern sie war immer wegen der Gegenwart anorganischer Verbindungen, hauptsächlich Sulfate von Baryum und Calcium, mehr oder weniger opalisierend. Die Fukoidinsäure bedingt keine Opalescenz. Der Niederschlag von Fukoidinsäure wird schließlich abfiltriert, mit Alkohol gewaschen und im Exsikkator getrocknet. Die so erhaltene Substanz stellt ein weißes oder wegen Verunreinigungen schwach gelbliches Pulver dar.

Die Fukoidinsäure (oder das Fukoidin) wird von Jod nicht gefärbt. Sie gibt die Phloroglucinsalzsäure und Orcinsalzsäurereaktion auf Pentosen. Außer Pentosen enthält sie auch Methylpentosen. Die Prüfung auf Methylpentosen wurde nach einer Methode von Rosenthaler. (1909, S. 167) gemacht. Nach dieser Methode erwärmt man die Substanz mit konzentrierter Salzsäure (etwa $10 \mathrm{ccm}$ ) und Aceton (etwa 1-2 ccm) zehn Minuten in siedendem Wasserbade. Die Flüssigkeit färbt sich dann rot (etwa himbeerrot) und zeigt, spektralanalytisch untersucht, ein scharfes Absorptionsband im Gelb, das die D-Linie bedeckt und sich noch etwas rechts und links davon erstreckt. Pentosen (bei denen unter diesen Umständen anfänglich eine rötliche Färbung eintreten kann). geben nach 10 Minuten langem Erhitzen braune Flüssigkeiten ohne charakteristisches Spektrum.

Die Fukoidinsäure gibt bei der Oxydation mit Salpetersäure keine Schleimsäure. Sie enthält demnach keine Galaktose. 
Aus den oben gemachten Angaben geht also hervor, daß die Fukoidinsäure Galaktose nicht enthält, wohl aber Pentosen und Methylpentosen. Um aber die Zuckerarten, welche die Fukoidinsäure zusammensetzen, näher kennen zu lernen, wurde eine Lösung dieser Säure mit Schwefelsäure bis $5 \%$ versetzt und dann fünf Stunden im siedenden Wasserbade gekocht. Nach der Hydrolyse wurde die Schwefelsäure mit Calciumcarbonat neutralisiert, das Filtrat auf dem Wasserbade konzentriert und mit Alkohol gefällt. Nach dem Abfiltrieren des Niederschlages wurde das Filtrat noch einmal stark konzentriert und mit zehn Volumen Alkohol gefällt. Aus dem Filtrate wurde der Alkohol durch Erhitzen auf dem Wasserbade unter Zusatz von Wasser vertrieben.

Die auf diese Weise erhaltene Zuckerlösung war linksdrehend. Eine Portion wurde mit essigsaurem Phenylhydrazin versezt und schon nach einigen Minuten begann ein Hydrazonniederschlag sich zu bilden. Nach einem Tage (bei Zimmertemperatur) wurde der Krystallbrei abgesaugt und mit etwas Wasser nachgewaschen. Der Niederschlag wurde dann mehrmals aus warmem Alkohol umkrystallisiert. Schmelzpunkt des reinen Hydrazons $+172^{\circ}$ bis $173^{\circ}$. Dieser Hydrazon stellt also den Phenylhydrazon der Fukose dar. Diese Methylpentose bildet schon in der Kälte ein in Wasser unlösliches Phenylhydrazon, das bei $+173^{\circ}$ schmilzt.

Das nach dem Absaugen des Hydrazonniederschlages erhaltene Filtrat wurde fünf Viertelstunden am siedendem Wasserbade gekocht. Es bildete sich dabei eine geringe Menge eines in warmem Wasser unlöslichen Osazonniederschlages, der wahrscheinlich das Osazon der Fukose darstellte. Wegen der geringen Menge konnte ich dieses Osazon nicht rein herstellen.

\section{Algin.}

Stanford (1883, S. 254) hat aus verschiedenen Fucoideen durch verdünnte Natriumcarbonatlösung einen sehr schleimigen Stoff extrahiert, den er Algin nennt, und über dessen Fällbarkeit mittels Säuren und Salzen er. Bescheid gibt. Über diesen Stoff babe ich schon in meinem früheren Aufsatz :Zur Bio- 
chemie der Meeresalgen einige Mitteilungen gemacht, habe aber später Gelegenheit gehabt, ihn etwas näher zu untersuchen, und kann jetzt einige neue Ergebnisse hinzufügen.

Die von Stanford benutzte Extraktionsmethode mittels verdünnter Natriumcarbonatlösung ist nicht verwendbar, weil dabei auch ein anderer Membranstoff, das unten zu besprechende Fucin, extrahiert wird. Am besten verfährt man so, daß man an der Luft getrocknetes, zerkleinertes Material mit Wasser übergießt, dann etwa eine Stunde im siedenden Wasserbade kocht und bis zum nächsten Tage stehen läßt. Ein längeres Kochen ist $\mathbf{z u}$ vermeiden, da dann auch etwas Fucin herausgelöst wird.

Das Algin stellt das Calciumsalz einer Säure dar, die ich Alginsäure nenne. Es ist in Wasser unlöslich oder wenigstens sehr schwer löslich, und die Möglichkeit, es in warmem Wiasser zu extrahieren, beruht wahrscheinlich darauf, daß das Calciumsalz sich in ein Alkalisalz umsetzt. Bei Zimmertemperatur lassen sich nur geringe Mengen Algin extrahieren.

Nach dem Abfiltrieren des auf die oben erwähnte Weise erhaltenen Alginextraktes wird das Filtrat mit Salzsäure angesäuert (bis zu etwa $0,1 \%$ ), wobei die Alginsäure als ein grobflockiger Niederschlag herausgefällt wird, der am besten durch ein Seidentuch abzufiltrieren ist. Die Alginsäure wird dann in verdünnter Natronlauge gelöst und aus der Lösung durch Ansäuern mit Salzsäure wieder herausgefällt. Dies Verfahren wird noch einigemal wiederholt, bis die Alginsäure farblos ausfällt. Die Alginsäure wird dann abfiltriert (durch Seidentuch) und in Wasser wieder aufgeschlemmt. Nach mehrmaligem Wiederholen dieses Verfahrens, um die Salzsäure gut zu entfernen, wird der Niederschlag von Alginsäure in Alkohol aufgeschlemmt und bis zum nächsten Tag stehen gelassen, dann wieder abfiltriert, mit Alkohol gewaschen und getrocknet.

Die Alginsäure ist in Wasser sehr schwer löslich, beinahe unlöslich. Die getrocknete Säure quillt aber in Wasser sehr stark auf. In Ammoniak, Kali- oder Natronlauge ist sie leicht löslich und gibt dabei sehr schleimige Lösungen. Sie wird 
ebenfalls von den Lösungen der Carbonate und sogar von denen der Acetate der Alkalimetalle gelöst. Die Alginsäure wird von Essigsäure aus ihren Alkaliverbindungen nicht gefällt, wenn nicht größere Neutralsalzmengen vorhanden sind.

Eine schwach essigsaure (nicht salzfreie) Alginlösung zeigt folgende Fällbarkeitsverhältnisse:

1. Wird von Mineralsäuren und stärkeren organischen Säuren gefällt, von schwächeren organischen Säuren (auch Essigsäure) erst nach Zusatz einer hinreichenden Menge Neutralsalze;

2. wird von Alkohol und Eisessig (in hinreichender Menge zugesetzt) gefällt;

3. wird von $\mathrm{CaCl}_{2}, \mathrm{BaCl}_{2}, \mathrm{ZnSO}_{4}, \mathrm{CuSO}_{4}, \mathrm{AgNO}_{3}$ (Niederschlag löslich in $\left.\mathrm{NH}_{3}\right) \mathrm{FeCl}_{3}$ und $\mathrm{PbA}_{2}$ gefällt;

4. wird von $\mathrm{MgSO}_{4}$ und $\mathrm{HgCl}_{2}$ nicht gefällt;

5. wird von Leimlösung gefällt; der Niederschlag löst sich bei Zusatz von gesättigter $\mathrm{NaCl}$-Lösung wieder auf.

Alkalische oder essigsaure Lösungen der Alginsäure sind stark linksdrehend.

$0,450 \mathrm{~g}$ aus Ascophyllum nodosum hergestellte Alginsäure, aschenfrei berechnet, wurden in verdünnter Natronlauge gelöst; Lösung $100 \mathrm{ccm}$; Drehung in $4 \mathrm{dm}$-Röhre $-2,45^{\circ}$; die spezifische Drehung ist demnach $-136^{\circ}$.

$$
\alpha_{\mathrm{v}}=-\frac{2,45 \cdot 100}{0,450 \cdot 4}=-136^{\circ} \text {. }
$$

$0,536 \mathrm{~g}$ aus Ascophyllum nodosum hergestellte Alginsäure, aschenfrei berechnet, wurden in verdünnter Natronlauge gelöst, dann mit Essigsäure angesäuert; Lösung $100 \mathrm{ccm}$; Drehung in $4 \mathrm{dm}$-Röhre $-2,80^{\circ}$; die spezifische Drehung ist demnach $-135^{\circ}$.

$$
\alpha_{\mathrm{D}}=-\frac{2,80 \cdot 100}{0,536 \cdot 4}=-135^{\circ} \text {. }
$$

$0,477 \mathrm{~g}$ aus Laminaria digitata hergestellte Alginsäure, aschenfrei berechnet, wurden in verdünnter Natronlauge gelöst; Lösung $50 \mathrm{ccm}$; Drehung in $4 \mathrm{dm}$-Röhre $-5,22^{\circ}$; die spezifische Drehung ist demnach $-137^{\circ}$.

$$
\alpha_{\mathrm{D}}=-\frac{5,22 \cdot 50}{0,477 \cdot 4} \doteq-1370 \text {. }
$$


Die Alginsäure wird von Jod nicht gefärbt, auch nicht, wenn es sich in einer Lösung befindet, die $1 \%$ Schwefelsäure enthält (vgl. das Fucin). Sie gibt die Phloroglucinsalzsäure und die Orcinsalzsäurereaktion auf Pentosen, aber nicht die Reaktion von Rosenthaler auf Methylpentosen (vgl. das Fukoidin); wird von Salpetersäure nicht (oder nur mit großen Schwierigkeiten) oxydiert; Schleimsäure habe ich aus Algin nicht herstellen können.

Durch Kochen in verdünnten Mineralsäuren läßt sich die Alginsäure nur sehr langsam hydrolysieren. Die bei der Hydrolyse entstehenden Zuckerarten habe ich nicht untersucht, da mir nur eine verhältnismäßig geringe Menge Alginsäure zur Verfügung gestanden hat (vgl. näher das Fucin).

Es sei bemerkt, daß die oben erwähnte, aus Ascophyllum hergestellte Alginsäure auch etwas Fucinsäure enthielt. Sie wurde von Jod $+1 \%$ Schwefelsäure schwach blau gefärbt.

\section{Fucin.}

Das Fucin ist von van Wis selingh (1898, S. 635) entdeckt und kurz beschrieben worden, und da seine Angaben die einzigen sind, die wir in der Literatur finden, werde ich sie hier in extenso anführen. Er schreibt: «Das Gewebe von Fucus vesiculosus besteht aus ziemlich dickwandigen Zellen mit cellulosehaltigen Wänden, welche durch sogenannte Interzellularsubstanz verbunden sind. Diese ist in bedeutender Quantität anwesend. Unter den Zellwandbestandteilen finden wir zwei Stoffe, welche durch Jod und Schwefelsäure blau gefärbt werden, Cellulose und einen noch unbekannten Stoff, den ich Fucin nennen werde. Besagter Stoff wird durch Jodjodkaliumlösung und verdünnte Schwefelsäure blau gefärbt. Ein Teil Schwefelsäure auf 100 Teile Lösung genügt schon. Durch stärkere, z. B. $76 \%$ ige Schwefelsäure, geeignet, um in Vereinigung mit Jod die Cellulosereaktion herbeizuführen, geht die blaue Farbe wieder verloren. Das Fucin ist ein Bestandteil der sogenannten Interzellularsubstanz. Wenn wir dasselbe mit Jodjodkaliumlösung und sehr verdünnter Schwefelsäure blau 
gefärbt haben und dann Schwefelsäure von $76 \%$ hinzufügen, dann sehen wir bei der Interzellularsubstanz die blaue Farbe rerschwinden und beim Rest, dem cellulosehaltigen inneren Teil der Zellwand, eine blaue Farbe hervortreten. Durch Rutheniumrot wird die ganze Zellwand gefärbt. Durch Kupferoxydammoniak wird die Cellulose der Wand entzogen. Nach Erwärmung in Glycerin bis auf $300^{\circ} \mathrm{C}$. ist jener Teil der Wand, der die Cellulose enthält, wenigstens größtenteils befreit von anderen Stoffen und leicht löslich in Kupferoxydammoniak: Die Interzellularsubstanz hat einen gelblichen Rest zurückgelassen und wird durch Jod und sehr verdünnte Schwefelsäure nicht mehr blaugefärbt..

Durch das von van Wisselingh beschriebene Reagens habe ich eine Reihe Fucoideen auf das Vorkommen von Fucin untersucht und diesen Membranstoff bei folgenden gefunden: Ascophyllum nodosum, Chorda filum, Fucus serratus, F. vesiculosus, Halidrys siliquosa, Laminaria digitata und L. saccharina. Bei folgenden fehlt das Fucin dagegen: Asperococcus bullosus, Ectocarpus siliculosus, Elachista fucicola, Spermatochnus paradoxus und Sphacelaria cirrhosa. Das Fucin kommt demnach bei den gröberen Fucoideen vor, fehlt dagegen bei den zarteren.

In bezug auf das Reagens möge erwähnt werden, daß man eine kräftigere Blaufärbung erhält, wenn Jod in ziemlich reichlichen Mengen vorhanden ist. Die Menge der freien Schwefelsäure beeinflußt auch die Farbe, und zwar so, daß $1 \%$ ige eine blaue Farbe hervorruft, $10 \%$ ige eine blauviolette, $25 \%$ ige eine violette und $50 \%$ ige eine rote Farbe. Bei $\mathrm{Zu}-$ satz von Wasser wird die rote Farbe wieder ins Blaue verändert. Anstatt Schwefelsäure kann auch Salzsäure gebraucht werden: 1\% ige ruft eine blaue Farbe hervor, 10\% ige eine violette und $25 \%$ ige eine rotviolette. Essigsäure kann nicht verwendet werden, weder in verdünntem noch in konzentriertem Zustande.

Behandelt man die Schnitte mit Jodjodkaliumlösung und $1 \%$ iger Schwefelsäure, werden die Mittellamellen, die aus Fucin bestehen, schön blau gefärbt, diejenigen Teile der Zell- 
wände aber, die das Zellumen am nächsten begrenzen und die hauptsächlich aus Ciellulose bestehen, werden nicht gefärbt oder nehmen höchstens eine sehr schwach blaue Nuance an. Saugt man vorsichtig das Wasser ab und behandelt dann die Schnitte mit konzentrierter Schwefelsäure $\left(2 \mathrm{Vol} \mathrm{H}_{2} \mathrm{SO}_{4}+\right.$ $1 \mathrm{Vol} . \mathrm{H}_{2} \mathrm{O}$ ), so werden die vorher blau gefärbten Teile rot bis blaßrot, die ungefärbten, aus Cellulose bestehenden Teile dagegen blau. Man erhält so eine schöne Doppelfärbung. Die Cellulosepartien erscheinen als blaue Inseln, die in einer roten, aus Fucin bestehenden Grundmasse zerstreut liegen.

Schon oben (S. 346) wurde hervorgehoben, daß es sehr leicht ist, nachzuweisen, daß Calcium in der Interzellularsubstanz vorkommt. Es ist hier an Pektinsäuren gebunden, und unter diesen Pektinsäuren merken wir außer der früher erwähnten Alginsäure auch die Fucinsäure. Fucin ist das Calciumsalz der Fucinsäure.

Das Calcium läßt sich aus der Interzellularsubstanz entfernen, wenn man Schnitte einige Stunden mit verdünnter Salzsäure behandelt. Die Schnitte schrumpfen dabei ein wenig. Werden sie dann in destilliertem Wasser abgespühlt und in eine verdünnte Lösung von Natriumcarbonat gelegt, zerquellen sie vollkommen, was darauf beruht, daß die Fucinsäure sich mit dem Natrium verbindet und dann ein in Wasser lösliches Natriumsalz gibt. Die Pektinstoffe Algin und Fucin sind Substanzen, welche die verschiedenen Zellen mit einander verbinden; werden sie auf die oben erwähnte Weise herausgelöst, ist der Zusammenhang zwischen den einzelnen Zellen zerbrochen, und die Schnitte zerfließen deshalb vollkommen. Anstatt Natriumcarbonatlösung kann man selbstverständlich Natronlauge verwenden. Natriumacetatlösung läßt sich auch brauchen, die Schnitte zerquellen aber dabei langsamer.

Für die Herstellung der Fucinsäure habe ich Ascophyllum nodosum gebraucht, da diese Alge besonders reichliche Mengen davon enthält. Getrocknetes, zerkleinertes Material wurde mehrmals mit W.asser ausgekocht, dann durch ein Seidentuch abfiltriert und ausgepreßt. Nachdem auf diese Weise eine Menge Stoffe organischer und anorganischer Natur weg- 
geschafft worden waren, wurde das Material mit 1\%iger Salz.säure übergossen, bis zum nächsten Tag stehen gelassen, dann abfiltriert und gut ausgewaschen. Durch die Behandlung mit Salzsäure ist das Calcium aus dem Fucin herausgelöst. Versetzt man jetzt das Material mit verdünnter Natronlauge, so verbindet sich die Fucinsäure mit dem Natrium und wird als Natriumsalz herausgelöst. Man muß größere Mengen stark verdünnter Natronlauge zusetzen, da das Material sehr stark aufquillt. Das Extrakt ist sehr schleimig, läßt sich aber in hinreichend verdünnter Form filtrieren, wenn auch ziemlich langsam. Aus dem Filtrat wird die Fucinsäure durch Ansäuern mit Salzsäure herausgefällt. Die weitere Reinigung geschieht auf dieselbe Weise wie die der Alginsäure, und verweise ich deshalb auf die Herstellung dieser Substanz. - Zu bemerken ist jedoch, daß die Fucinsäure immer mit Alginsäure vermengt ist. Die Alginsäure zu entfernen, ist nicht möglich.

In bezug auf ihre Fällbarkeitsverhältnisse stimmt die Fucinsäure vollkommen mit der Alginsäure überein. Die getrocknete Fucinsäure quillt in Wasser sehr stark auf.

Alkalische oder essigsaure Lösungen der Fucinsäure sind stark linksdrehend.

0,552 g aus Ascophyllum nodos um hergestellte Fucinsäure, aschenfrei berechnet, wurden in verdünnter Natronlauge gelöst; Lösung $50 \mathrm{ccm}$; Drehung in $4 \mathrm{dm}$-Röhre - 5,25 ${ }^{\circ}$; die spezifische Drehung ist demnach $-120^{\circ}$.

$$
\alpha_{D}=-\frac{5,25 \cdot 50}{0,552 \cdot 4}=-120^{\circ} .
$$

$0,574 \mathrm{~g}$ aus Ascophyllum nodosum hergestellte Fucinsäure, aschenfrei berechnet, wurden in verdünnter Natronlauge gelöst, dann mit Essigsäure angesäuert; Lösung $50 \mathrm{ccm}$; Drehung in $4 \mathrm{dm}-\mathrm{Röhre}-5,75^{\circ}$; die spezifische Drehung ist demnach $-121^{\circ}$.

$$
\alpha_{\mathrm{n}}=-\frac{5,75 \cdot 50}{0,574 \cdot 4}=-121^{\circ} .
$$

Die Fucinsäure wird von Jodjodkaliumlösung, die $1 \%$ Schwefelsäure enthält, blau gefärbt. Sie gibt die Phloroglucinsalzsäure- und die Orcinsalzsüurereaktion auf Pentosen, nicht 
aber die Reaktion von Rosenthaler auf Methylpentosen (vgl. das Fukoidin und das Algin); wird von Salpetersäure nicht (oder nur mit großen Schwierigkeiten) oxydiert; Schleimsäure habe ich aus Fucin nicht herstellen können.

Durch Kochen in verdünnten Mineralsäuren läßt sich die Fucinsäure nur sehr langsam hydrolysieren. $35 \mathrm{~g}$ Fucinsäure (mit Alginsäure bemengt) wurden in verdünnter Natronlauge gelöst. Die Lösung wurde dann mit Schwefelsäure versetzt, bis sie 5\% freie Säure enthielt, und 10 Stunden in siedendem Wasserbade gekocht. Der Niederschlag war aber noch nicht vollständig gelöst, er wurde aber nicht mehr von Jod und 1\% \%iger Schwefelsäure blau gefärbt. Die Schwefelsäure wurde mit Calciumcarbonat neutralisiert, das Filtrat konzentriert und durch zweimaliges Ümfällen mit Alkohol gereinigt. Bei diesen Umfällungen wurden große Mengen gummiähnliche Stoffe niedergeschlagen; dies deutet darauf hin, daß die Hydrolyse trotz einem Kochen von so langer Dauer sehr unvollständig war.

Eine Portion der schließlich erhaltenen Zuckermischung wurde mit essigsaurem Phenylhydrazin versetzt und bei Zimmertemperatur bis zum nächsten Tag stehen gelassen. Es bildete sich aber kein Niederschlag von Hydrazonen, und man kann daraus den Schluß ziehen, daß die Zuckerarten Fukose und Mannose fehlen. Die Lösung wurde dann im siedenden Wasserbade fünf Viertelstunden gekocht, es bildete sich aber kein in warmem Wasser unlöslicher Osazonniederschlag. Erst nach dem Erkalten wurden Osazonkrystalle erhalten, aber nur eine geringe Menge, und ich mußte deshalb auf eine nähere Untersuchung dieses Niederschlages verzichten.

Algin und Fucin sind zwei wahrscheinlich miteinander sehr nahe verwandte Stoffe. Nur einen sicheren Unterschied habe ich finden können, nämlich denjenigen, daß das Fucin von Jodjodkaliumlösung und 1\% iger Schwefelsäure blau gefärbt wird, das Algin dagegen nicht. Außerdem scheint das Algin beim Kochen in Wasser etwas leichter extrahiert zu werden, als das Fucin.

Die physiologische Bedeutung dieser beiden Stoffe ist, die einzelnen Zellen miteinander zu verbinden. Beide Stoffe 
gehören den Pektinstoffen an, und stellen Calciumsalze besonderer Pektinsäuren, der Alginsäure und der Fucinsäure, dar. Sie bilden die Mittellamellen der Zellwände der gröberen Fucoideen.

\section{Cellulose.}

Diejenige Schicht der Zellwände der Fucoideen, die das Zellumen am nächsten begrenzt, besteht, wie schon von mehreren Forschern nachgewiesen worden ist, hauptsächlich aus Cellulose. Mit Chlorzinkjodlösung gelingt aber der Nachweis nur sehr schwer, und im allgemeinen garnicht, mit Jod und konzentrierter Schwefelsäure (2 Vol. $\mathrm{H}_{2} \mathrm{SO}_{4}+1$ Vol. $\left.\mathrm{H}_{2} \mathrm{O}\right)$ dagegen sehr leicht.

Bei einigen Fucoideen habe ich versucht, die Cellulose quantitativ zu bestimmen. Die Methode von Henneberg wurde dabei verwendet. Das Material wurde zuerst in 1,25\% iger Schwefelsäure, dann in 1,25\% iger Natronlauge und schlieblich mehrmals in Wasser ausgekocht, mit Alkohol und mit Äther gut ausgewaschen. Die Resultate sind in der Tabelle 6 zusammengestellt.

Tabelle 6 .

Quantitative Bestimmung der Cellulose.

\begin{tabular}{|c|c|c|c|c|c|c|}
\hline & $\begin{array}{c}\text { Trocken- } \\
\text { gewicht } \\
\text { des } \\
\text { Materials } \\
\text { g }\end{array}$ & $\begin{array}{c}\text { Cella- } \\
\text { lose } \\
\text { und } \\
\text { Asche } \\
\mathrm{g}\end{array}$ & $\begin{array}{c}\text { Asche } \\
\text { g } \\
\end{array}$ & $\begin{array}{c}\text { Cellu- } \\
\text { lose } \\
\mathbf{g}\end{array}$ & $\begin{array}{c}\text { Mittel- } \\
\text { wert d. } \\
\text { Cellu- } \\
\text { lose } \\
\text { g }\end{array}$ & $\begin{array}{l}\text { Cellulose } \\
\text { in } \% \text { des } \\
\text { Trocken- } \\
\text { gewichtes }\end{array}$ \\
\hline Ascophyllum nodosum & 2,62 & $\begin{array}{l}0,050 \\
0,044\end{array}$ & $\begin{array}{l}0,002 \\
0,001\end{array}$ & $\begin{array}{l}0,048 \\
0,043\end{array}$ & 0,046 & 1,7 \\
\hline Fucus vesiculosus . . & 2,68 & $\begin{array}{l}0,045 \\
0,043\end{array}$ & $\begin{array}{l}0,001 \\
0,001\end{array}$ & $\begin{array}{l}0,044 \\
0,042\end{array}$ & 0,043 & 1,6 \\
\hline Laminaria digitata . & 2,65 & $\begin{array}{l}0,145 \\
0,139\end{array}$ & $\begin{array}{l}0,002 \\
0,001\end{array}$ & $\begin{array}{l}0,143 \\
0,138\end{array}$ & 0,111 & 5,3 \\
\hline Laminaria saccharina & 2,70 & $\begin{array}{l}0,124 \\
0,123\end{array}$ & $\begin{array}{l}0,005 \\
0,005\end{array}$ & $\begin{array}{l}0,119 \\
0,118\end{array}$ & 0,119 & 4,4 \\
\hline
\end{tabular}

Nach Angaben in Czapek :Biochemie der Pflanzen, 1. Aufl., Bd. 1, S. 520 enthält Fucus vesiculosus $4,40 \%$, 
Laminaria saccharina $9,33 \%$ Cellulose; diese Werte sind demnach bedeutend höher als die von mir gefundenen.

5. Geschichtliches über den Bau der Zellwände der Fucoideen.

Aus dem oben Angeführten geht hervor, daß die Zellwände der gröberen Fucoideen aus zwei Schichten bestehen, einer inneren, die das Zellumen direkt umgibt, und einer mittleren, der Mittellamelle. Die erstere wird von Jod und konzentrierter Schwefelsäure blau gefärbt und besteht wesentlich aus Cellulose, die letztere wird von diesem Reagens nicht gefärbt, wird aber von Jod und 1\% iger Schwefelsäure blau gefärbt. Sie besteht aus Pektinstoffen, und denen ich zwei, das Algin und das Fucin, etwas näher zu charakterisieren versucht habe. Für die Blaufärbung ist das Fucin verantwortlich.

Die untersuchten Fucoideen enthalten noch einen vierten Membranstoff, das Fukoidin. Dies ist ein Membramschleim, der besonders reichlich bei den Laminaria-Arten vorkommt. Seine Aufgabe liegt wahrscheinlich darin, daß es die Algen biegsamer macht, und es ist demnach von besonderer Bedeutung bei denjenigen Fucoideen, die auf solchen Lokalitäten vorkommen, wo die Brandungen sich mehr bemerkbar machen.

Von Wille (1897, S. 41) ist schon früher nachgewiesen worden, daß die Zellwände der Laminariaceen aus zwei wesentlich verschiedenen Substanzen bestehen. Im innersten hat man nämlich die Cielluloselamelle der Zellen, welche das Protoplasma direkt umgibt, und diese.Celluloselamellen sind mit einer Interzellularsubstanz verbunden, welche eine ganz andere chemische Zusammensetzung hat. Wille versucht auch nachzuweisen, daß die Interzellularsubstanz der Laminariaceen jedenfalls zum wesèntlichen Teil aus Calciumpektinat besteht. Diese Annahme wird nach Wille auch ganz wesentlich dadurch gestützt, daß es Krefting (1897) gelungen ist, aus der Interzellularsubstanz der Laminaria-Arten eine Säure rein darzustellen, die Tangsäure genannt wurde. Den Angaben von Wille stimme ich vollkommen bei, und ich will außerdem hinzufügen, daß die 
von Krefting dargestellte Tangsäure ein Gemenge von Alginsäure und Fucinsäure ist.

Die von Schmiedeberg (1885, S. 427) erwähnte Laminarsäure, die kolloid sein und ein enormes Quellungsvermögen besitzen soll, stellt wahrscheinlich auch ein Gemenge von Alginsäure und Fucinsäure dar, vielleicht mit Fukoidin bemengt. Dasselbe gilt von dem von Stanford (1883, S. 254) dargestellten Algin.

Die Zuckerarten, die bei der Hydrolyse der Fucoideenzellwände entstehen, sind besonders von Tollens und seinen Mitarbeitern Bieler, Günther, Widtsoe, Oshima, Müther und Mayer untersucht worden. Als ein interessantes Ergebnis der Untersuchungen dieser Forscher möge in diesem Zusammenhang die Tatsache hervorgehoben werden, daß eine Methylpentose, die Fukose, sich bei der Hydrolyse des Seetanges bildet. Die Muttersubstanz der Fukose wird von Widtsoe (1900, S. 142) Fukosan genannt, und später wird derselbe Name von Mayer $(1907$, S. 2) vorgeschlagen. Es scheint, als ob man sich vorstellte, daß das Fukosan von Fukose in etwa ähnlicher Weise aufgebaut wäre wie Cellulose von Dextrose.

Nun ist aber zu bemerken, daß der Name Fukosan auch in einer anderen Bedeutung gebraucht wird, und zwar, um denjenigen gerbstoffähnlichen Stoff $z u$ bezeichnen, der in den Fukosanbläschen vorkommt; ich habe deshalb. bei einer früheren Gelegenheit vorgeschlagen (Kylin, 1912, S. 18, Fußnote), die Muttersubstanz der Fukose Fukan zu nennen.

In der vorliegenden Arbeit ist es mir aber gelungen, nachzuweisen, daB die Fukose in dem Membramschleim Fukoidin gebunden ist. Außer der Methylpentose Fukose enthält das Fukoidin auch eine Pentose. Die Behauptung von Bauer (1889, S. 618), daß der Laminariaschleim Dextrose enthält, kann kaum richtig sein. Die von diesem Forscher gefundene Dextrose stammt sicher von dem Laminarin her, welches vor der Hydrolyse nicht entfernt worden war.

Pentosen scheinen bei der Hydrolyse der Fucoideenzellwände immer gebildet $z \mathrm{u}$ werden. $\mathrm{Ob}$ auch Hexosen gebildet werden, scheint mir nicht sicher bewiesen zu sein. Am 
ehesten ist in diesem Zusammenhang an Mannose und Galaktose zu denken. Diese beiden Hexosen habe ich aber in den Membranbestandteilen der untersuchten Fucoideen nicht nachweisen können. Sie spielen, wie bekannt, im allgemeinen eine hervorragende Rolle beim Aufbau der Zellwandbestandteile der Pflanzen.

VIII. Die Membranbestandteile der Florideen.

Über die Membranbestandteile der Florideen habe ich nur nebenbei einige Beobachtungen.gemacht; es hat mir für eine systematische Untersuchung an Zeit gefehlt, doch möchte ich in diesem Zusammenhang auf einige Literaturangaben kurz hinweisen.

Es ist schon von Greenish (1882) nachgewiesen worden, daß die Zellwände der Floridee Sphaerococcus (Gracilaria) lichenoides aus zwei Schichten bestehen, einer inneren, die von Cellulosereagenzien blau gefärbt wird, und einer mittleren, die von diesen Reagenzien nicht gefärbt wird, und aus einer Art Interzellularsubstanz besteht.

Die Cellulose läßt sich bei den Florideen sehr leicht sowohl durch Chlorzinkjod wie durch Jod und konzentrierte Schwefelsäure nachweisen, und die Cellulosemengen dürften bei diesen Algen größer sein als bei den Fucoideen. Bei zwei Florideen ist es mir indessen nicht gelungen, Cellulose nachzuweisen; diese sind Bangia fuscopurpurea und Porphyra laciniata. Sie gehören unter den Florideen den Bangiaceen an. Bei einer anderen Bangiacee, Erythrotrichia ceramicola, -kommt Cellulose dagegen vor.

Die Cellulose bildet in ähnlicher Weise wie bei den Fucoideen die innere Schicht der Zellwände, die das Protoplasma am nächsten umgibt. Die Mittellamelle besteht aus Interzellularsubstanz, und diese Substanz besteht ihrerseits in ähnlicher Weise wie bei den Fucoideen aus verschiedenen Pektinstoffen, d. h. aus an Calcium gebundenen Pektinsäuren. In bezug auf den Nachweis des Calciums in den Zellwänden verweise ich auf S. 346. 
Unsere bisherigen Kenntnisse von den Pektinstoffen der Florideen stützen sich fast ausschließlich auf einige, an Handelsprodukten angestellte Untersuchungen. Diese Handelsprodukte sind das japanische Nori aus Porphyra, der Carrageenschleim aus Chondrus crispus und Gigartina mammillosa und das Agar-Agar hauptsächlich aus Gracilaria- und Gelidium-Arten. In bezug auf die gegenwärtige Kenntnis dieser Produkte verweise ich auf die Darstellung in Abderhalden \&Biochemisches Handlexikon», Bd. 2, S. 73.

IX. Einige quantitative Bestimmungen.

Tabelle 7.

Bestimmung des Trockengewichtes.

\begin{tabular}{l|c|c|c}
\hline \hline & $\begin{array}{c}\text { Frisch- } \\
\text { gewicht } \\
\mathbf{g}\end{array}$ & $\begin{array}{c}\text { Trocken- } \\
\text { gewicht } \\
\text { g }\end{array}$ & $\begin{array}{c}\text { Trockengewicht } \\
\text { in \% des } \\
\text { Frischgewichtes }\end{array}$ \\
\hline Ascophyllum nodosum . . . & 2,439 & 0,7235 & 29,66 \\
Fucus resiculosus . . . . . & 2,335 & 0,6245 & 26,75 \\
Laminaria digitata . . . . . & 2,820 & 0,4940 & 17,52
\end{tabular}

Tabelle 8.

Bestimmung des Aschengehalts. ${ }^{1}$ )

\begin{tabular}{l|c|c|c}
\hline \hline & $\begin{array}{c}\text { Trockengewicht } \\
\mathrm{g}\end{array}$ & $\begin{array}{c}\text { Asche } \\
\mathrm{g}\end{array}$ & $\begin{array}{c}\text { Asche in \% des } \\
\text { Trockengewichtes }\end{array}$ \\
\hline Ascophyllum nodosum & 1,0035 & 0,1475 & 14,70 \\
Fucus vesiculosus . . & 1,2133 & 0,1944 & 16,03 \\
Laminaria digitata . . & 1,0669 & 0,1886 & 17,68
\end{tabular}

Das Material dieser Bestimmungen ist im August eingesammelt worden. Die Mengen der wasserlöslichen Stoffe sind auch bestimmt worden, und zwar sowohl diejenigen, die sich in siedendem Wasser, als auch die, welche sich in Wasser bei Zimmertemperatur lösen.

9) Bei der Bestimmung des Aschengehalts war auf den recht hohen Gehalt an Kochsalz Rücksicht zu nehmen, weshalb die Substanz zuerst nur verkohlt und mit Wasser ausgelaugt, und der Rückstand dann erst vollständig verascht wurde. 
Zum Zwecke der ersteren Bestimmung wurden $\mathbf{3} \mathbf{g}$ an der Luft getrocknetes Material abgewogen, mit $300 \mathrm{ccm}$ Wasser versetzt, eine Stunde im siedenden Wasserbade gekocht und dann bis zum nächsten Tag stehen gelassen. Das Extrakt wurde dann vorsichtig abdekantiert und das Material wieder eine Stunde in $300 \mathrm{ccm}$ Wasser ausgekocht und über Nacht stehen gelassen. Das Material wurde abfiltriert, gut ausgewaschen, getrocknet und gewogen, dann eingeäschert und wieder gewogen.

Die Bestimmung der in kaltem Wasser löslichen Stoffe wurde folgendermaßen bewerkstelligt. $3 \mathrm{~g}$ an der Luft getrocknetes Material wurden abgewogen, mit $300 \mathrm{ccm}$ Wasser (neben etwas Chloroform als Antiseptikum) versetzt und bis zum nächsten Tag stehen gelassen, dann vorsichtig abdekantiert und wieder mit $300 \mathrm{ccm}$ Wasser versetzt. Dies Verfahren wurde noch zweimal wiederholt. Das Material wurde abfiltriert, gut ausgewaschen, getrocknet und gewogen, dann eingeäschert und wieder gewogen. Die Resultate sind in den Tabellen 9 und 10 zusammengestellt.

\section{Tabelle 9 .}

Bestimmung der Mengen der in siedendem Wasser löslichen Stoffe.

\begin{tabular}{|c|c|c|c|c|c|c|c|c|c|c|}
\hline & $\begin{array}{c}\text { Trocken- } \\
\text { gewicht } \\
\text { g }\end{array}$ & $\begin{array}{c}\text { Wasser- } \\
\text { un- } \\
\text { lösliche } \\
\text { Be- } \\
\text { stand- } \\
\text { teile } \\
\text { g }\end{array}$ & $\begin{array}{c}\text { Wasser- } \\
\text { un- } \\
\text { lossliche } \\
\text { anorga- } \\
\text { nische } \\
\text { Be- } \\
\text { stand- } \\
\text { teile } \\
\text { :g }\end{array}$ & \begin{tabular}{|c|} 
Wasser- \\
un- \\
lösliche \\
orga- \\
nische \\
Be- \\
stand- \\
teile \\
$\mathrm{g}$
\end{tabular} & $\begin{array}{l}\text { Mittelw } \\
\text { wasse } \\
\text { lich } \\
\text { anorga- } \\
\text { nischen } \\
\text { Be- } \\
\text { stand- } \\
\text { teile } \\
\text { g }\end{array}$ & $\begin{array}{l}\text { yert der } \\
\text { unlös- } \\
\text { en } \\
\text { orga- } \\
\text { nischen } \\
\text { Be- } \\
\text { stand- } \\
\text { teile } \\
\text { g }\end{array}$ & $\begin{array}{c}\text { Was } \\
\text { unlös } \\
\text { anorg. } \\
\text { Best. } \\
\%\end{array}$ & $\begin{array}{l}\text { sser- } \\
\text { sliche } \\
\begin{array}{c}\text { org. } \\
\text { Best. } \\
\%\end{array}\end{array}$ & $\begin{array}{c}\text { Was } \\
\text { lösli } \\
\text { anorg. } \\
\text { Best. } \\
\%\end{array}$ & $\begin{array}{l}\text { Sser- } \\
\text { liche } \\
\begin{array}{|c|}\text { org. } \\
\text { Best. } \\
\%\end{array}\end{array}$ \\
\hline Ascophyll. nodosum & 2,62 & $\begin{array}{l}1,2762 \\
1,2537\end{array}$ & $\begin{array}{l}0,1538 \\
0,1479\end{array}$ & $\begin{array}{l}1,1224 \\
1,1058\end{array}$ & 0,1509 & 1,1141 & 5,76 & $42, \check{2}$ & 8,94 & 42.78 \\
\hline Fucus vesiculosus & 2,68 & $\begin{array}{l}1,2307 \\
1,2342\end{array}$ & $\begin{array}{l}0,1518 \\
0,1585\end{array}$ & \begin{tabular}{|l|}
1,0789 \\
1,0757
\end{tabular} & 0,1552 & 1,0773 & $\check{0,80}$ & 40,20 & 10,23 & 43,77 \\
\hline Laminaria digitata & 2,65 & $\begin{array}{l}1,0931 \\
1,0960\end{array}$ & $\begin{array}{l}0,1243 \\
0,1243\end{array} \mid$ & $\begin{array}{l}0,9688 \\
0,9717\end{array}$ & 0,1243 & 0,9703 & 4,69 & 36,60 & 12,99 & 45,72 \\
\hline
\end{tabular}

Beim Vergleich der Tabellen 9 und 10 geht hervor, daß siedendes Wasser eine nicht unbedeutend größere Menge Stoff herauslöst als kaltes. Besonders ist der Unterschied bei A s cophyllum groß, und er ist in erster Linie davon bedingt, daß 
Tabelle 10.

Bestimmung der Mengen der in kaltem Wasser löslichen Stoffe.

\begin{tabular}{|c|c|c|c|c|c|c|c|c|c|c|}
\hline & $\begin{array}{c}\text { Trockon- } \\
\text { gewicht } \\
\text { g }\end{array}$ & $\begin{array}{c}\text { Wasser- } \\
\text { un- } \\
\text { losliche } \\
\text { Be- } \\
\text { stand- } \\
\text { teile } \\
\text { g }\end{array}$ & $\begin{array}{c}\text { Wasser- } \\
\text { un- } \\
\text { Iosliche } \\
\text { anorga- } \\
\text { nische } \\
\text { Be- } \\
\text { stand- } \\
\text { teile } \\
\mathrm{g}\end{array}$ & \begin{tabular}{|c|} 
Wasser- \\
un- \\
lösliche \\
orga- \\
nische \\
Be- \\
stand- \\
teile \\
$\mathbf{g}$
\end{tabular} & $\begin{array}{l}\text { Mittel w } \\
\text { wasser } \\
\text { lic } \\
\text { anorga- } \\
\text { nischen } \\
\text { Be- } \\
\text { stand- } \\
\text { teilo } \\
\text { g }\end{array}$ & $\begin{array}{l}\text { ert der } \\
\text { unlös- } \\
\text { hen } \\
\text { orga- } \\
\text { nischen } \\
\text { Be-- } \\
\text { stand- } \\
\text { teile } \\
\text { g }\end{array}$ & $\begin{array}{c}\text { Was } \\
\text { unlös } \\
\text { anorg. } \\
\text { Best. } \\
\%\end{array}$ & $\begin{array}{c}\text { sser- } \\
\text { liche } \\
\text { org. } \\
\text { Best. } \\
\%\end{array}$ & $\begin{array}{c}\text { Was } \\
\text { lösli } \\
\text { anorg. } \\
\text { Best. } \\
\%\end{array}$ & $\begin{array}{l}\text { sser- } \\
\text { iche } \\
\text { org. } \\
\text { Best. } \\
\%\end{array}$ \\
\hline scophyll. nodosun & 2,62 & $\begin{array}{l}1,830 \\
1,822\end{array}$ & $\begin{array}{l}0,267 \\
0,266\end{array}$ & $\begin{array}{l}1,563 \\
1,556\end{array}$ & 0,267 & 1,560 & 10,2 & 59,5 & 4,5 & 25,8 \\
\hline aminaria & 2,65 & $\begin{array}{l}1,284 \\
1,288\end{array}$ & $\begin{array}{l}0,160 \\
0,159\end{array}$ & $\begin{array}{l}1,124 \\
1,129\end{array}$ & 0,160 & 1,127 & 6,0 & 42,5 & 11,7 & 39,8 \\
\hline
\end{tabular}

die Pektinstoffe Algin und Fucin in siedendem Wasser teilweise gelöst werden.

In bezug auf die quantitative Bestimmung von Mannit, Laminarin und Cellulose verweise ich auf die Seiten 354, 397 und 417.

\section{Literaturverzeichnis.}

Bauer, R. W., Über ein aus Laminariaschleim entstehende Zuckerart. Ber. d. deutsch. chem. Ges., Bd. 22 : 1, Berlin 1889.

Bettels, J., Die Kohlenhydrate der Meeresalgen und daraus hergestellter Brzeugnisse. Diss., Münster 1905.

Bieler, K. und Tollens, B., Über das \&Fucusols genannte Gemenge von Furfurol und Methylfurfurol. Annalen der Chemie, Bd. 258, Leipzig 1890. (Bieler, Diss., Göttingen.)

Boehm, J., Über den vegetabilischen Nährwert der Kalksalze. Sitzungsberichte der k. Akadem. der Wissensch., mathem.-naturw. Kl., Bd. 71, Abt. I, Wien 1875.

Ellet, W. B. und Tollens, B., Über die Bestimmung der Methylpentosane neben den Pentosanen. Ber. d. deutsch. chem. Ges., Bd. 38: 1, Berlin 1905. (Ellet, Diss., Göttingen 1904.)

Eschle, Über den Jodgehalt einiger Algenarten. Diese Zeitschr., Bd. 23, Straßburg 1897.

Gödechens, J., Analyse der Asche einiger Fucus-Arten. Annalen der Chemie und Pharmacie, Bd. 54, Heidelberg 1845.

Golenkin, M., Algologische Notizen. Bull. de la soc. imp. des naturalistes de Moscou, n. sér. 8, 1894.

Greenish, H. G., Die Kohlenhydrate des Fucus amylacens. Archiv der Pharmacie, 3. Reihe, Bd. 20, Halle 1882. 
Günther, A. und Tollens, B., Über die Fucose, einen der Rhamnose isomeren Zucker aus Seetang (Fucus-Arten). Ber. d. deutsch. chem. Ges., Bd. 23: 2, Berlin 1890. (Günther, Diss., Göttingen 1891).

Hansen, A., Über Stofmildung bei den Meeresalgen. Mitteilungen aus d. zool. Stat. zu Neapel, Bd. 11, Berlin 1893.

Hansteen, B., Studien zur Anatomie und Physiologie der Fucoideen, Jahrb. für wiss. Bot., Bd. 24, Berlin 1892.

- Über das Fucosan als erstes scheinbares Produkt der Kohlensäureassimilation bei den Fucoideen. Jahırb. für wiss. Bot., Bd. 35, Leipzig 1900.

- Über das Verhalten der Kulturpflanzen zu den Bodensalzen. Jahrb. für wiss. Bot., Bd. 47, Leipzig 1910.

Hundeshagen, Fr., Über jodhaltige Spongien und Jodospongin. Zeitschrift für angew. Chemie, Berlin 1895.

Hunger, F. W. T., Über das Assimilationsprodukt der Dictyotaceen. Jahrb. für wiss. Bot., Bd. 38, Leipzig 1902.

Itallie, L. van, Über das Vorkommen von Jodium in Fucus vesiculosus und Chondrus crispus. Archiv der Pharmacie, Reihe 3, Bd. 27, Halle 1889.

Kolkwitz, R., Beiträge zur Biologie der Florideen. Wissenschaftliche Meeresuntersuchungen, N. F. 4, Abt. Helgoland, 1900.

Kniep, H., Über die Assimilation und Atmung der Meeresalgen. Intern. Revue der gesamten Hydrobiologie und Hydrographie, Band 7, Leipzig 1914.

Krefting, A., Über wichtige organische Produkte aus Tang. Chem. Industrie, 1897. (Just, Jahresber., Bd. 2, 1897, S. 76.)

Krefting, A. und Torup, S., Et.nyt Kulhydrat i Laminariaarterne. Tidskrift for Kemi, Farmaci og Terapi, Aarg. 6, Kristiania 1909.

Kylin, H., Über Phykoerythin und Phykocyan bei Ceramium rubrum (Huds.) Ag. Diese Zeitschr., Bd. 69, Straßburg 1910.

- - Über die Inhaltskörper der. Fucoideen. Arkiv för Botanik, utg. af Sv. Vet. Akadem., Bd. 11, Stockholm 1912.

- Über die roten und blauen Farbstoffe der Algen. Diese Zeitschr., Bd. 76, Straßburg 1912.

- Zur Biochemie der Meeresalgen. Diese Zeitschrift, Bd. 83, Straßburg 1913.

- - Über die Blasenzellen einiger Florideen und ihre Beziehung zur Abspaltung von Jod. Arkiv för Botanik, utg. af Sv. Vet. Akadem., Bd. 14, Stockholm 1915.

Mayer, W. und Tollens B., Untersuchungen über die Fucose. Ber. d. deutsch. chem. Ges., Bd. 40: 2, Berlin 1907. (Mayer, Dissert., Göttingen 1907.)

Molisch, H., Die Ernährung der Algen (Süßwasseralgen, 1. Abhandl). Sitzungsber. der k. Akadem. der Wissensch., mathem.-naturw. Kl., Bd. 104, Abt. I, Wien 1895. 
Nolisch, H., Mikrochemie der Pfanzen, Jena 1913.

Nüther, A. and Tollens, B., Über die Produkte der Hydrolyse von Seetang (Fucus), Laminaria und Caragheenmoos. Ber. d. deutsch. chem. Ges., Bd. 37: 1, Berlin 1904. (Müthor, Diss., Göttingen 1903.)

Nathansohn, A., Über Regulationserscheinungen im Stoffaustausch. Jahrb. für wiss. Bot., Bd. 38, Leipzig 1902.

Robertson, D., Bonnemaisonia asparagoides C. Ag., that gave a blue stain to paver. Transactions of the nat. hist. soc. of Glasgow, 4,1894 .

Rosenthaler, L., Zum Nachweis von Methylpentosen und Pentosen. Zeitschr. für analytische Chemie, Jahrg. 48, Wiesbaden 1909.

Saurageau, C., Sur la membrane de l'Ectocarpus fulvescens. Comptes rendus de l'acad. des sciences, Tome 122, Paris 1896. (Auch in Journal de Bolanique, Tome 10, Paris 1896.)

Schimper, A.F. W., Über Bildung und Wanderung der Kohlenlyydrate in den Laubblättern. Bot. Zeitung, Jahrg. 43, Leipzig 1885.

Schmiedeberg, Über die Bestandteile der Laminaria. Tageblatt der 58. Vers. deutscher Naturf. und Ärzte, Straßburg 1885.

Stanford, E., On Algin, a new substance obtained from some of the commoner species of marine algae. The chemical News, Vol. 47, London 1883. (Auch in The pharm. Journal, Vol.13, London 1882-83.)

- The economic applications of seaweed. The pharm. Journal, Vol.14, London 1883-84.

Stenhouse, J., Über das Vorkommen von Mannit in Laminaria saccharina und einigen andern Seegräsern. Annalen der Chemie und Pharmacie, Bd. 40, Heidelberg 1844.

Tihomirow, W. A., Sur la valeur de la réaction micro-chimique de la phénylhydrazine pour la constatation du sucre dans les tissus des plantes. Annales du jardin bot. de Buitenzorg, Suppl. 3: 2, Leide 1910.

Tunmann, 0., Zur Kenntnis der Laminaria. Pharm. Zenlralhalle, N. F. Jalurg. 28, Dresden 1907.

- Pflanzenmikrochemie, Berlin 1913.

Widtsoe, J.A. und Tollens, B., Über Arabinose, Xylose und Fucose aus Traganth. Ber. d. deutsch. chem. Ges., Bd. 33: 1, Berlin 1900. (Wid tsoe, Diss., Göttingen 1899.)

Wille, N., Beiträge zur physiologischen Anatomio der Laminariaceen. Festskrift till Hans Majestät Oscar II, Bd. 2, Christiania 1897.

- - Über die Wanderung der anorganischen Nïhrstoffe bei den Laminariaceen. Botanische Untersuchungen S. Schwendener dargebracht, Berlin 1899.

Wisselingb, C. van, Mikrochemische Untersuchungen über die Zellwände der Fungi. Jahrb. Sür wiss. Bot., Bd. 31, Berlin 1898. 